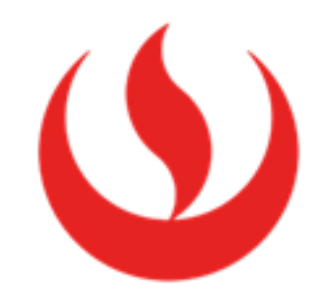

UNIVERSIDAD PERUANA DE CIENCIAS APLICADAS

FACULTAD DE NEGOCIOS

PROGRAMA ACADÉMICO DE NEGOCIOS INTERNACIONALES

\title{
Estudio de la aplicación del Sistema de Garantías Previas antes de numerar la declaración aduanera en las importaciones del rubro textil durante el periodo 2014-2016 en Lima Metropolitana y Callao.
}

Tesis para optar el título profesional de Licenciado en Negocios Internacionales presentado

Guillén Heredia, Felix Martin (0000-0003-2690-6129)

Yupan Chumpitaz, Maribel Isabel (0000-0002-7431-3785)

Asesor:

Prof. Esparta Sanchez, Miguel Angel (0000-0001-8345-5024)

Lima, agosto del 2018 
A nuestros padres, familiares y amigos, porque siempre están allí brindándonos el apoyo y ánimo que nos hace concretar todo tipo de metas. 


\section{AGRADECIMIENTOS}

A los especialistas de cada segmento,

Por compartir sus experiencias y opiniones, por la amabilidad en atendernos y por ayudarnos a tener una idea más allá de nuestro tema de investigación.

A nuestros centros de trabajo,

Por darnos facilidad para poder elaborar esta investigación, por darnos permisos durante las horas laborales y por contribuir con los contactos necesarios para las entrevistas.

A nuestros padres, hermanos y amigos

Por entender que el esfuerzo requería de sacrificios y que gracias a ello se logran nuestras metas como profesionales, por darnos el aliento para seguir continuando y acompañarnos en cada parte de este proceso. 


\section{RESUMEN}

La presente investigación tiene como propósito analizar los factores del porqué los importadores de las empresas pequeñas y medianas del rubro textil no se acogen al sistema de garantías previas durante el periodo 2014 -2016. Para ello planteamos tres factores los cuales son el desconocimiento, el costo de la carta fianza o póliza de caución y la cultura empresarial.

En el primer capítulo, desarrollamos el marco teórico comprendido por la importación para el consumo, el Sistema de garantías previas a la numeración de la declaración, el Acuerdo de Promoción Comercial Perú- Estados Unidos, factores que limitan el uso del sistema de las garantías previas a la numeración de la declaración, empresas peruanas pequeñas y medianas, antecedentes del rubro textil peruano y el comportamiento e importaciones del rubro textil durante el 2014 2016.

El segundo capítulo explica la metodología de investigación, especificando el problema, objetivo e hipótesis para luego definir el planteamiento, propósito y tipo de investigación; ademas los temas involucrados con los actores entrevistados como las preguntas, el contexto, la muestra, el diseño y el procedimiento de investigación.

El tercer capítulo comprende del análisis de datos y resultados, en el cual se describe la información recopilada de cada segmento para luego proceder a desarrollar el cuarto capítulo que concierne a la discusión de resultados, en la que 
analizamos la información recopilada de los segmentos con las categorías para poder obtener los hallazgos, barreras y brechas de investigación.

Finalmente, presentamos las conclusiones y recomendaciones basadas del análisis de los capítulos anteriores.

Palabras clave: garantías previas, sector textil, despacho anticipado, carta fianza, poliza de caucion, cultura empresarial. 


\begin{abstract}
The purpose of this research is to analyze the factors why importers of small and medium enterprises in the textile sector do not use the system of previous guarantees during the 2014-2016 period. We raise three factors, which are ignorance, the cost of bond letter or caution policy and the corporate culture.

In the first chapter, we developed the theoretical framework comprised by the import for consumption, the System of guarantees prior to the numbering of the declaration, The Peru-United States Trade Promotion Agreement, factors that limit the use of the system of the previous guarantees to the numeration of the declaration, Peruvian small and medium companies, antecedents of the peruvian textile items, the behavior and imports of the textile item during 2014 - 2016.
\end{abstract}

The second chapter explains the research methodology, specifying the problem, objective and hypothesis in order to define the approach, purpose and type of research; in addition, the issues involved with the actors interviewed, such as the questions, the context, the sample, the design and the research procedure.

The third chapter includes the analysis of data and results, in which the information collected from each segment is described and then proceed to develop the fourth chapter that concerns the discussion of results, in which we analyze the information gathered from the segments with the categories to obtain the findings, barriers and research gaps. 
Finally, we present the conclusions and recommendations based on the analysis of the previous chapters.

Key words: previous guarantee, textile sector, advance clearance, bond letter, caution policy, corporate culture. 


\section{$\underline{\text { INDICE }}$}

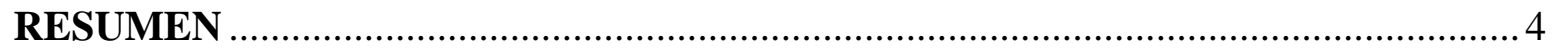

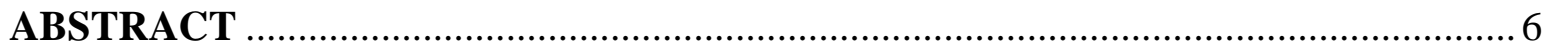

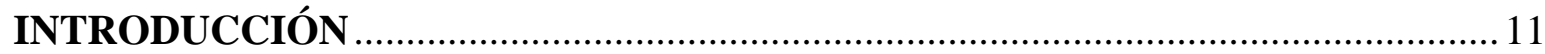

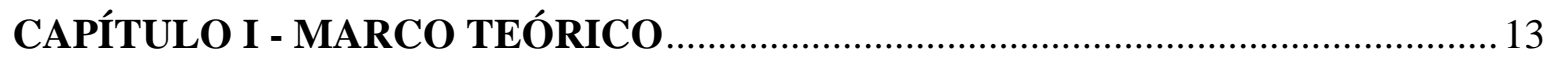

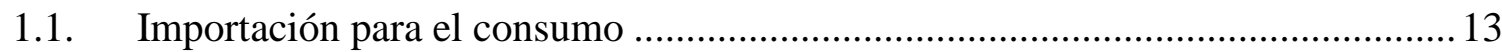

1.2. Sistema de garantías previas a la numeración de la Declaración ............................13

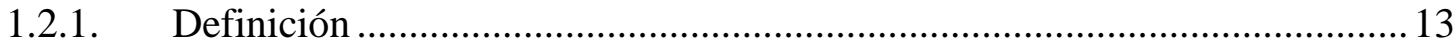

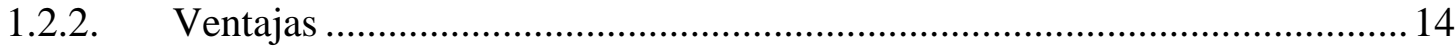

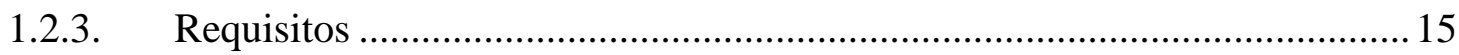

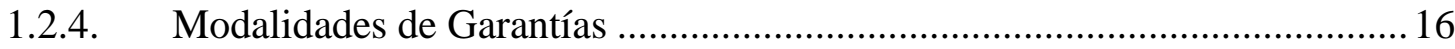

1.2.5. Garantías mediante Carta Fianza y Pólizas de Caución ..................................21

1.3. El Acuerdo de Promoción Comercial Perú- Estados Unidos .................................23

1.4. Factores que limitan el uso de las garantías previas antes de la numeración de la

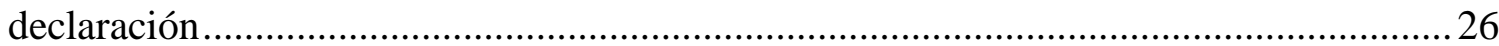

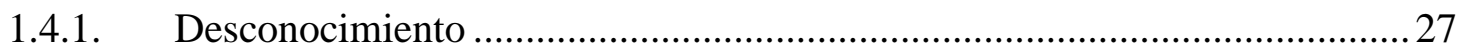

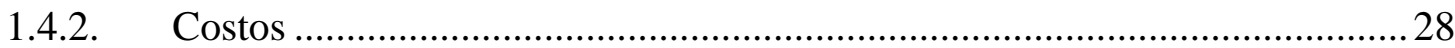

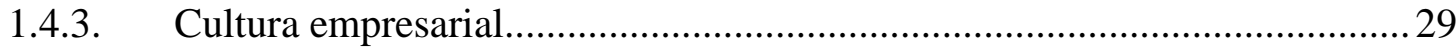

1.5. Empresas Peruanas pequeñas y medianas ...........................................................30

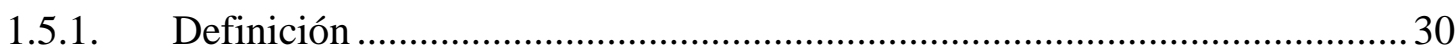

1.6. Rubro Textil en el Perú.................................................................................. 32

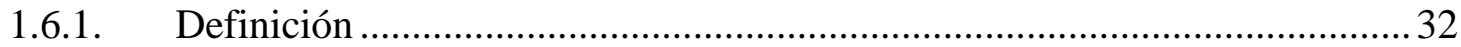

1.7. Comportamiento e importaciones del rubro textil durante el $2014-2016$............34

CAPITULO II - METODOLOGÍA DE INVESTIGACIÓN..........................................38

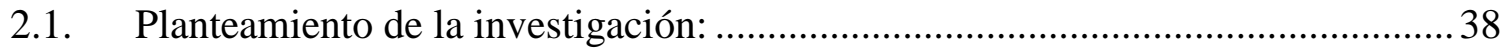

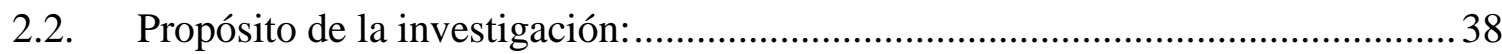

2.3. Tipo de investigación: ......................................................................................38

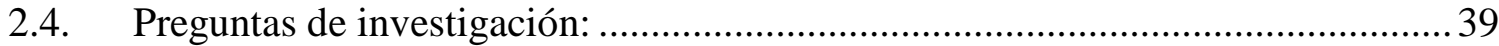

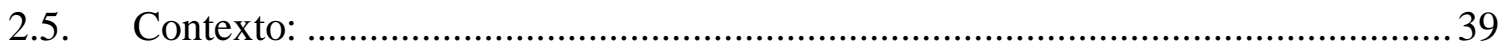




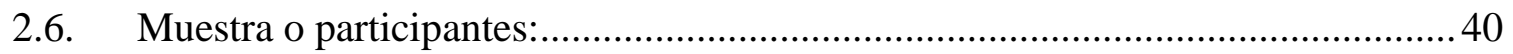

2.7. Diseño o abordaje principal .......................................................................... 41

2.7.1. Identificación de la estructura de la entrevista ..............................................41

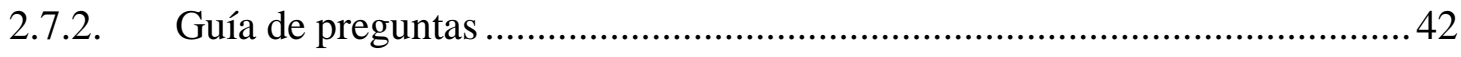

2.7.3. Segmentos ...................................................................................... 42

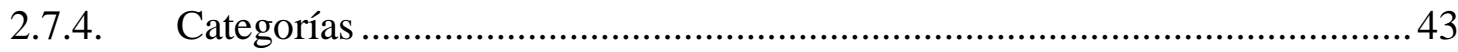

2.7.5. El instrumento de investigación ....................................................................4 43

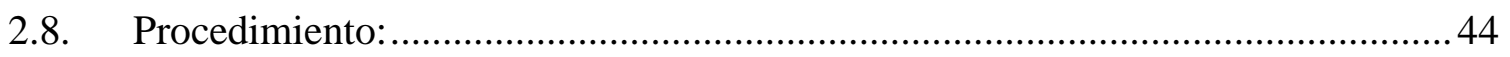

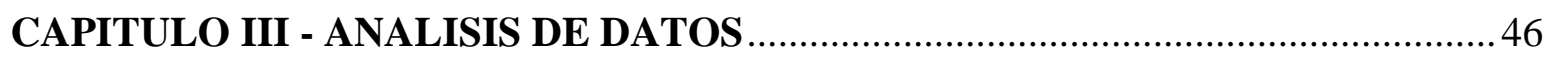

3.1. Segmento 1: Gerentes Generales y/o Encargado de Comercio exterior de Empresas importadoras del rubro textil...................................................................4

3.2. Segmento 2: Representantes de la Aduana Marítima ...........................................50

3.3. Segmento 3: Representantes Legales y/o sectorista de cuenta de Agentes de

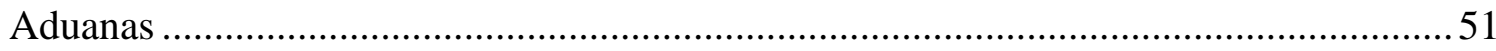

3.4. Segmento 4: Gerentes y/o ejecutivo de cuenta de Banca y seguros......................54

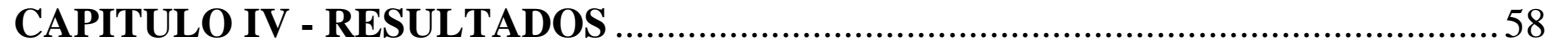

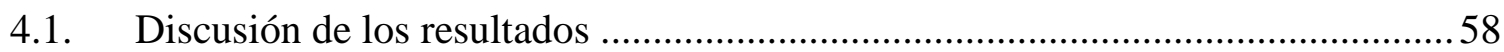

4.1.1. Categoría 1: Desconocimiento del Procedimiento a la Garantía Previa.......58

4.1.2. Categoría 2: Costo de la Carta fianza o Póliza de Caución. ..............................60

4.1.3. Categoría 3: Cultura y/o Tradición empresarial. ...........................................62

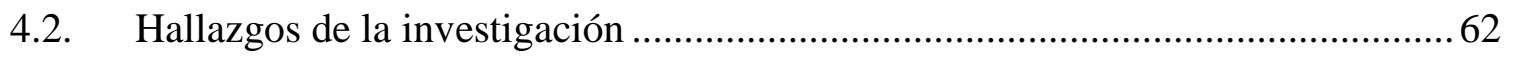

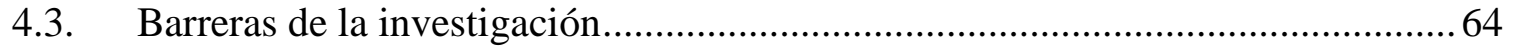

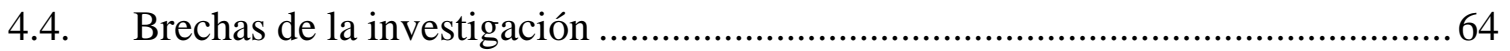

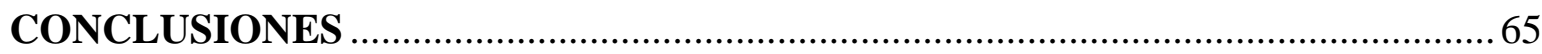

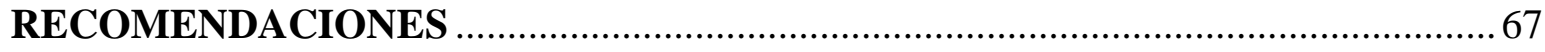

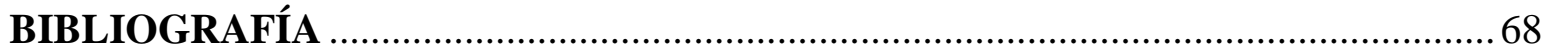

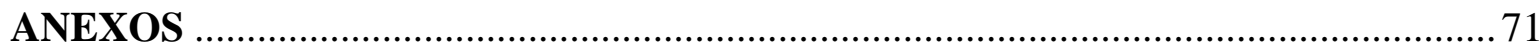

Anexo 1: Evolución del Sistema de Garantías Previas del año 2010 - 2014 ........................ 71

Anexo 2: Lista de empresas textiles que utilizan el sistema de garantías previas hasta el 2014 
Anexo 3: Costo y Requisitos para emitir una Carta Fianza - Banco Financiero 92

Anexo 4: Costo y Requisitos para emitir una Carta Fianza - Banco Interbank ..................93

Anexo 5: Subpartidas arancelarias más utilizadas en el periodo....................................95

Anexo 6: Análisis de las subpartidas arancelarias y empresas que las utilizan...................98

Anexo 7: Cuestionarios por segmento - Entrevistas de profundidad ............................. 106

Anexo 8: Cuadro de Segmentos y Categorías ............................................................. 109

\section{INDICE DE TABLAS}

Tabla 1: Empresas del Sistema Financiero autorizadas a emitir Cartas Fianzas. ........... 17

Tabla 2: Empresas del Sistema Financiero autorizadas a emitir Cartas Fianzas. ........... 18

Tabla 3: Empresas del Sistema de Seguros autorizadas a emitir Cartas Fianzas. ........... 18

Tabla 4: Empresas del Sistema de Seguros autorizadas a Pólizas de Cauciones. ..........20

Tabla 5: $\quad$ Evolución del Sistema de Garantías Previas del año 2010 - 2014.................26

Tabla 6: Relación de la situación económica con las importaciones totales y del sector. 35

Tabla 7: Representación del rubro, de la actividad textil y confecciones por año ..........36

Tabla 8: $\quad$ Subpartidas arancelarias más utilizadas en el periodo..................................95

Tabla 9: Empresas que utilizaron las subpartidas arancelarias en el periodo................98

Tabla 10: $\quad$ Empresas acorde a lo importado y al UIT/AÑO ........................................ 98

Tabla 11: Contraste de las Mype por Monto Importado vs Directorio de Produce...... 98

Tabla 12: $\quad$ Empresas Mype que importaron textiles en el 2014................................98

Tabla 13: $\quad$ Empresas Mype que importaron textiles en el 2015................................. 100

Tabla 14: $\quad$ Empresas Mype que importaron textiles en el 2016............................... 101

Tabla 15: $\quad$ Unificado de empresas que importaron textiles del 2014-2016 ................ 103

Tabla 16: Muestra de empresas medianas y pequeñas que utilizan el sistema de garantías previas durante el 2014-2016............................................................ 105

Tabla 17: Muestra de empresas medianas y pequeñas que no utilizan el sistema de garantías previas durante el 2014-2016. 105 


\section{INTRODUCCIÓN}

El Acuerdo de Promoción Comercial Perú- Estados Unidos, que se firmó el 12 de abril del 2006 y que entró en vigencia el 01 de febrero del 2009, generó cambios y/o modificaciones en cuanto a las leyes, decretos y procedimientos que ayudarían a tener un comercio bilateral ordenado, el cual salvaguarde los intereses de nuestro país y tener un mejor acceso de mercado facilitando el comercio entre ambos.

Uno de los cambios efectuados gracias al acuerdo bilateral fue la implementación del sistema de garantías previas a la numeración de la declaración, ya que el gobierno norteamericano requería mayor dinamismo con las mercaderías que ingresaran a nuestro país y así la aduana y los importadores peruanos puedan estar alineados con los estándares internacionales.

Por otro lado, el Perú ha mantenido un crecimiento constante del Producto Bruto Interno (PBI) desde el año 2014 al 2016 según cifras del Banco Central de Reserva del Perú (BCRP); sin embargo las importaciones durante dicho periodo han decaído y uno de los sectores denominados como la principal actividad no extractiva a nivel nacional (industria textil) ha mostrado el mismo comportamiento respecto al total de las importaciones; de esta manera surge la interrogante del porqué las importaciones 
del rubro textil han decaído a pesar de contar con mayor facilidad para retirar las mercaderías gracias a procedimientos que facilitan y benefician al importador como el sistema de garantías previas a la numeración de la declaración.

Frente a esta interrogante, ubicamos algunas fuentes que nos permitieran contar con mayor soporte para determinar la existencia de factores por los que los importadores textiles no se acogen al sistema de garantías previas a la numeración de la declaración, como por ejemplo el desconocimiento en el procedimiento, los costos de la carta fianza y/o póliza de caución y la cultura empresarial.

Después de mencionar los antecedentes nace el siguiente problema, ¿por qué el desconocimiento en el procedimiento, los costos y la cultura empresarial están limitando el uso de las garantías previas a la numeración de la declaración aduanera en las importaciones de textiles durante el periodo 2014-2016?. Durante la investigación se identificaron hallazgos, barreras y brechas en los segmentos analizados; sin embargo no se perdió el objetivo de la investigación que fue el de demostrar que existen factores que impiden a los importadores del sector textil a no acogerse al procedimiento y que además este sea un material de ayuda para saber que existe un procedimiento que brinda beneficios a los importadores como minimizar los tiempos de retiro y tener una herramienta financiera de bajo costo. 


\section{CAPÍTULO I - MARCO TEÓRICO}

\subsection{Importación para el consumo}

El régimen de importación para el consumo es aquel que permite el ingreso de mercancías al territorio aduanero para el consumo después del pago o garantía según corresponda, de los derechos arancelarios, impuestos aplicables, así como el pago de los recargos y multas que pudieran haberse generado además de otras obligaciones aduaneras. (Decreto Legislativo 1053, 2008)

\subsection{Sistema de garantías previas a la numeración de la Declaración}

\subsubsection{Definición}

El Sistema de Garantías Previas a la numeración de la Declaración consiste en otorgar a favor de la SUNAT, en forma anticipada a las operaciones de comercio exterior una garantía que puede ser global o específica, para que aseguren el pago del integro de la deuda tributaria aduanera y recargos vinculados a declaraciones o solicitudes que el usuario opte por garantizar durante su vigencia (Decreto Legislativo 1053, 2008, art.160). Teniendo la referencia anterior se deduce que una garantía previa antes de la numeración de la Declaración es un mecanismo que permite al importador reemplazar el pago de la deuda tributaria en el momento que sea exigible para aligerar la parte operativa y de seguridad del comercio. 


\subsubsection{Ventajas}

Las ventajas del uso de sistema de garantías Previas de acuerdo a (Sunat, 2018) son las siguientes:

\section{- Levante Aduanero en 48 horas}

Asegura el levante dentro de las 48 horas desde el término de la descarga de la mercadería declarada agilizando el despacho.

\section{- Levante antes de la determinación Final}

El Sistema de Garantía Previa en el Despacho Anticipado Garantizado permite el levante antes que la Autoridad Aduanera culmine el análisis de la información obtenida en la revisión documentaria (canal naranja) o física (canal rojo).

No obstante, deben cumplirse los requisitos específicos (sanitarios, de seguridad pública, etc.), a que están sujetas las mercancías restringidas y de ser el caso someterse a las acciones de control extraordinario que está facultada a ejercer la Autoridad aduanera.

\section{- Pago Diferido}

$\mathrm{Al}$ realizar un despacho anticipado garantizado el pago de los tributos puede realizarse hasta el día 20 del mes siguiente al término de la descarga; iniciando el cómputo de los intereses moratorios recién a partir del día veintiuno del mes siguiente de producida la descarga, con lo cual queda 
remota la posibilidad de su ejecución en caso de incumplimiento de pago de la deuda.

\section{- Control de pagos pendientes}

$\mathrm{Al}$ acogerse al uso del sistema de garantías previas a la numeración de la declaración, el usuario puede consultar dicha garantía mediante el Portal de la Administración Tributaria utilizando su clave sol; la misma que se actualiza al momento que una declaración aduanera ha sido numerada o al momento de generarse una liquidación de cobranza; de esta manera, el usuario puede controlar en todo momento la totalidad de documentos aduaneros que tiene pendientes de pago y programar su cancelación al inicio de cada mes hasta el día 20 del mismo.

\section{- Servicio Centralizado}

Los usuarios que se acojan al sistema de Garantías previas a la numeración, son atendidos en forma centralizada en la División de Recaudación de la sede central IGCA sin importar el lugar del país por donde esté ingresando la mercancía.

\subsubsection{Requisitos}

Para acogerse al uso del sistema de garantías previas se debe cumplir con los siguientes requisitos establecidos por (Sunat, 2018):

- $\quad$ Ser usuario de la SUNAT al obtener su clave SOL. 
- $\quad$ Poseer Buzón Electrónico: El cual se obtiene cuando se tramita el RUC

- $\quad$ Estar afiliado al Pago Electrónico de Aduanas. Previamente al inicio del proceso de aceptación de la garantía el usuario deberá afiliarse al Sistema de Pago Electrónico, para lo cual deberá revisar y seguir las instrucciones colgadas en el Portal Web de la SUNAT / Operatividad Aduanera / Pago Electrónico.

- $\quad$ Obtener el monto mínimo y número de trámite (SUNAT) para emitir la Carta Fianza.

- $\quad$ Registrar a los funcionarios que autoriza la empresa como responsables para tener a cargo el control de la cuenta corriente.

- $\quad$ Tramitar la DAM bajo el sistema anticipado de despacho.

- $\quad$ Presentar una garantía previa

\subsubsection{Modalidades de Garantías}

De acuerdo a lo estipulado en el artículo $212^{\circ}$ del reglamento de la Ley General de Aduanas, que amplía la aplicación del artículo $160^{\circ}$ de la Ley General de Aduanas se aceptarán las siguientes modalidades de garantías:

\section{a) Carta Fianza}

Para definir el concepto de carta fianza nos basaremos en la descripción de la Asociación de Bancos del Perú (ASBANC) y la empresa de Seguros La Positiva, ya que nos brindan a detalle las características, beneficios y/o ventajas. Debemos tener 
en cuenta que no todas las entidades financieras están autorizadas a emitir cartas fianzas; para ello la Superintendencia de Banca Seguros y AFP (SBS) nos brinda la relación de empresas del sistema financiero y del sistema de seguros que están autorizadas a emitir cartas fianzas.

Tabla 1: $\quad$ Empresas del Sistema Financiero autorizadas a emitir Cartas Fianzas.

\begin{tabular}{|c|c|c|c|}
\hline Bancos & Financieras & $\begin{array}{l}\text { Caja Municipal de } \\
\text { Ahorro y Crédito }\end{array}$ & $\begin{array}{c}\text { Caja Rural de Ahorro } \\
\text { y Crédito }\end{array}$ \\
\hline BANCO CONTINENTAL & ERIKA FINANCIERA & CMAC CUSCO S A & CRAC LOS ANDES \\
\hline AGROBANCO & COMPARTAMOS FINANCIE & CMAC AREQUIPA & CREDIRAIZ S.A.A \\
\hline BANCO AZTECA & CREDISCOTIA & CMAC SULLANA & CRAC SIPAN \\
\hline BANCO CENCOSUD & FINANCIERA CONFIANZA & CMAC DEL SANTA & CRAC INCASUR \\
\hline BANCO DE COMERCIO & FINANC. CREDINKA & CMAC HUANCAYO & CRAC PRYMERA \\
\hline BANCO DE CREDITO & FINANCIERA EFECTIVA & CMAC ICA & \\
\hline NACION & FINANCIERA OH S A & CMAC MAYNAS & \\
\hline BANCO FALABELLA & FINANC. PROEMPRESA & CMAC PAITA & \\
\hline BANCO FINANCIERO & FINANCIERA QAPAQ & CMAC PIURA & \\
\hline BANCO GNB & FINANCIERA TFC S A & CMAC TACNA & \\
\hline BANBIF & MITSUI AUTO FINANCE & CMAC TRUJILLO & \\
\hline INTERBANK & & CMCP LIMA & \\
\hline \multicolumn{4}{|l|}{ BANCO RIPLEY } \\
\hline \multicolumn{4}{|l|}{ SANTANDER PERU } \\
\hline \multicolumn{4}{|l|}{ CITIBANK DEL PERU } \\
\hline \multicolumn{4}{|l|}{ COFIDE * } \\
\hline \multicolumn{4}{|l|}{ ICBC BANK } \\
\hline \multicolumn{4}{|l|}{ MIBANCO } \\
\hline SCOTIABANK PERU & & & \\
\hline
\end{tabular}

Fuente: Superintendencia de Banca, Seguros y AFP Elaboración Propia 
Tabla 2: $\quad$ Empresas del Sistema Financiero autorizadas a emitir Cartas Fianzas.

\begin{tabular}{|c|c|c|}
\hline EDPYME & Afianzadora y de Garantías & $\begin{array}{c}\text { Cooperativa de Ahorro y } \\
\text { Crédito (supervisión } \\
\text { directa SBS) }\end{array}$ \\
\hline BBVA CONSUMER FINANC & FOGAPI & CREDICOOP LUZ Y FUER ** \\
\hline ACCESO CREDITICIO & & \\
\hline EDPYME ALTERNATIVA & & \\
\hline EDPYME CREDIVISION & & \\
\hline GMG SERVICIOS PERU & & \\
\hline INVERSIONES LA CRUZ & & \\
\hline EDPYME MARCIMEX S.A. & & \\
\hline EDPYME MICASITA & & \\
\hline
\end{tabular}

Fuente: Superintendencia de Banca, Seguros y AFP Elaboración Propia

Tabla 3: $\quad$ Empresas del Sistema de Seguros autorizadas a emitir Cartas Fianzas.

\begin{tabular}{|c|}
\hline SegurOS \\
\hline LA POSITIVA CIA DE SEGUROS Y REASEGUROS S.A. \\
\hline SECREX COMPAÑIA DE SEGUROS DE CREDITO Y GARANTIAS \\
\hline RIMAC SEGUROS Y REASEGUROS \\
\hline MAPFRE PERU COMPAÑIA DE SEGUROS Y REASEGUROS \\
\hline AVLA PERU COMPAÑIA DE SEGUROS S A (anteS AVAL PERU \\
COMPAÑIIA DE SEGUROS S.A) \\
\hline CHUBB PERÚ S.A. COMPAÑIA DE SEGUROS Y REASEGUROS \\
\hline INSUR S A COMPAÑIA DE SEGUROS
\end{tabular}

Fuente: Superintendencia de Banca, Seguros y AFP Elaboración Propia

En relación con lo mencionado anteriormente, ASBANC (2011) señala que:

Es una modalidad de crédito indirecto, que consiste en un contrato de garantía del cumplimiento del pago de una obligación ajena, suscrito entre un banco u otra entidad financiera (fiador) y un deudor (afianzado). Se materializa en un documento valorado, emitido por el fiador a favor de un 
tercero (acreedor) garantizando las obligaciones del deudor solicitante, con un monto y un plazo determinado (párr.2).

Por otro lado, tenemos una segunda definición según lo mencionado por La Positiva (2018):

Son garantías de cumplimiento, vinculada a prestaciones de hacer o no hacer. Pueden ser contratadas por aquellos que participan en licitaciones públicas o privadas, aquellas que realizan operaciones de comercio exterior o aquellos que son contratistas de obras; en el cual participan un garante, el contratante y el beneficiario (párr.4).

Teniendo en cuenta ambas definiciones, podemos concluir que una carta fianza es un instrumento financiero en el cual participan un garante, un contratante y un beneficiario; éstas entidades financieras otorgan éste servicio a sus clientes respaldándolos en el cumplimiento de sus obligaciones adquiridas por conceptos determinados a cambio de una comisión, que se da por parte del garante al contratante y por subsiguiente el contratante y/o beneficiario obtiene el respaldo de un garantía (Carta Fianza).

\section{b) Póliza de Caución}

La superintendencia de Banca, Seguros y AFP publica en su página a las empresas del sistema de seguros autorizadas a emitir pólizas de cauciones. 
Tabla 4: $\quad$ Empresas del Sistema de Seguros autorizadas a Pólizas de Cauciones.

\begin{tabular}{|l|}
\hline \multicolumn{1}{|c|}{ SegurOS } \\
\hline LA POSITIVA CIA DE SEGUROS Y REASEGUROS S.A. \\
\hline SECREX COMPAÑIA DE SEGUROS DE CREDITO Y GARANTIAS \\
\hline RIMAC SEGUROS Y REASEGUROS \\
\hline MAPFRE PERU COMPAÑIA DE SEGUROS Y REASEGUROS \\
\hline AVLA PERU COMPAÑIA DE SEGUROS S A (anteS AVAL PERU COMPAÑÍA DE SEGUROS S.A) \\
\hline HDI SEGUROS S A \\
\hline INTERSEGURO COMPAÑIA DE SEGUROS S A \\
\hline CHUBB PERÚ S.A. COMPAÑIA DE SEGUROS Y REASEGUROS \\
\hline BNP PARIBAS CARDIF S A COMPAÑIA DE SEGUROS Y REASEGUROS \\
\hline PROTECTA S A COMPAÑIA DE SEGUROS \\
\hline INSUR S A COMPAÑIA DE SEGUROS \\
\hline
\end{tabular}

Fuente: Superintendencia de Banca, Seguros y AFP Elaboración Propia

Hasta finales del 2013 se ofrecía la fianza, como la garantía de mayor frecuencia por las empresas, emitida por las entidades bancarias; sin embargo, a partir de ese periodo en adelante las empresas aseguradoras empezaron a tener mayor participación generando la siguiente pregunta a sus clientes ¿qué haces cuando una fianza copa tu línea de crédito? Lo trabajas a través de un seguro de caución pues cumple la misma función en una licitación o para asegurar la entrega de un proyecto o producto (Gestión, 2013).

De esta manera la definición para una empresa aseguradora nos dice que La póliza de caución es un contrato mediante el cual una aseguradora, a cambio de una prima, garantiza el cumplimiento por parte del tomador o afianzado, de una obligación contenida en un contrato o disposición legal, y se obliga a pagar al acreedor de la misma, el asegurado, hasta por una 
suma determinada (monto asegurado) los perjuicios que le haya ocasionado el incumplimiento de la obligación garantizada. (Gestión, 2013, párr.7)

\section{c) Garantía Nominal}

Es un documento emitido por un organismo del sector público nacional, universidad, organismo internacional, misiones diplomáticas o entidades religiosas y otras debidamente acreditadas oficialmente y que por su prestigio moral o solvencia son aceptados como garantes por la Superintendencia Nacional de Administración Tributaria (Sunat, 2018).

\subsubsection{Garantías mediante Carta Fianza y Pólizas de Caución}

De acuerdo a lo indicado por Sunat (2018), dentro del artículo 160 de la Ley general de aduanas, las modalidades de garantías pueden ser globales y específicas si es que son utilizadas como carta fianza o póliza de caución.

\section{a) Garantía Global:}

Asegura el cumplimiento de las deudas generadas por aquellas declaraciones numeradas durante su vigencia siempre que se acojan a su cobertura y tiene como plazo de vigencia no mayor a un año, pudiendo ser renovada de acuerdo a lo establecido por el reglamento. El importe de esta garantía debe ser no menor a un porcentaje del monto de las deudas tributarias aduaneras y/o recargos registrados durante los doce meses 
anteriores al inicio del trámite de presentación de la garantía más un porcentaje por riesgo.

\section{b) Garantía específica:}

Asegura el cumplimiento de obligaciones derivadas de una declaración o solicitud de régimen aduanero y tiene como plazo de vigencia no mayor a tres meses. El monto de esta garantía debe ser no menor a un porcentaje del valor de la mercancía fijado en función del riesgo del usuario, más el monto de la deuda tributaria aduanera y recargos.

Asimismo, el importador puede consultar dicha garantía mediante el Portal de la Administración Tributaria utilizando su clave sol, accediendo de este modo a una cuenta corriente que le permitirá verificar si las declaraciones aduaneras de importación para el consumo se encuentran cubiertas con la misma.

También debemos resaltar la presentación de la citada garantía constituye un requisito básico para acceder al beneficio del levante aduanero en sólo 48 horas, lo cual agiliza los despachos y se convierte en otro atractivo más para la elección por parte del importador. Adicionalmente, ofrece la ventaja de iniciar el cómputo de los intereses moratorios recién a partir del día veintiuno del mes siguiente de producida la descarga (despacho anticipado) o de numerada la declaración aduanera (despacho excepcional); con lo cual queda remota la posibilidad de su ejecución en caso de incumplimiento de pago de la deuda. 
En caso de incumplimiento en la obligación de renovación de la garantía, la Autoridad Aduanera deberá proceder a su requerimiento, debiendo mantener la misma en condición de requerida hasta la fecha de exigibilidad de las deudas que se encuentran bajo su cobertura, fecha a partir de la cual procede su ejecución conforme a lo dispuesto por el tercer párrafo del artículo $160^{\circ}$ de la Ley General de Aduanas.

\subsection{El Acuerdo de Promoción Comercial Perú- Estados Unidos}

"Un Acuerdo de Promoción Comercial es un acuerdo vinculante en el que se suscriben dos o más países para acordar la concesión de preferencias arancelarias mutuas y la reducción de barreras no arancelarias al comercio de bienes y servicios" (Acuerdos Comerciales, 2017, párr.1)

Con el fin de contar con mayor apertura comercial se dieron inicio a las negociaciones con uno de nuestros principales socios comerciales, Estados Unidos de Norteamérica, para establecer un acuerdo bilateral que culminaría con la firma del Tratado de Libre Comercio Perú - Estados Unidos el 12 de Abril del 2006 y que entro en vigencia el 01 de Febrero del 2009.

Este acuerdo de Promoción Comercial fue un evento importante para nuestra economía dado que Estados Unidos es uno de nuestros principales socios comerciales a nivel mundial, para que se dé la puesta en vigencia de este tratado fue necesario llevar a cabo un cambio que permitiera adecuar y alinear procesos 
operativos que aseguren el cumplimiento de los nuevos estándares regulatorios estipulados por el gobierno Norteamericano.

Estos lineamientos se enfocaron en temas aduaneros, comerciales y otros sectores que están involucrados dentro de la cadena del comercio exterior.

En lo que refiere a los temas aduaneros, mediante la legislación se creó la nueva Ley General de Aduanas aprobada por Decreto Legislativo $N^{\circ} 1053$ el día 27 de junio de 2008 y en consecuencia señala Araujo (2013), "El Decreto Legislativo 1053 aprueba la Ley General de Aduanas, que adecúa la normativa vigente en materia de comercio con los estándares del capítulo 5 del TLC con Estados Unidos sobre administración aduanera y facilitación del comercio exterior” (p.13).

Se debe considerar que la finalización de este acuerdo comercial se podía dar después de haber culminado con los requisitos por cada parte y que de acuerdo a lo mencionado por Aldea (2009).

En este capítulo se describe al despacho de mercancías en el cual podemos encontrar los siguientes puntos a tener en consideración:

1. Cada Parte adoptará o mantendrá procedimientos aduaneros simplificados para el despacho eficiente de las mercancías, con el fin de facilitar el comercio entre las Partes.

2. De conformidad con el párrafo 1 , cada Parte adoptará o mantendrá procedimientos que: 
a) Deberán prevenir que el despacho de mercancías se haga dentro de un período no mayor al requerido para asegurar el cumplimiento de su legislación aduanera y en la medida en que sea posible, que se despache las mercancías dentro de las 48 horas siguientes a su llegada.

b) Permitan que las mercancías sean despachadas en el punto de llegada, sin traslado temporal a depósitos u otros recintos.

c) Permitan que los importadores retiren las mercancías de sus aduanas antes de y sin perjuicio de la decisión final por parte de su autoridad aduanera acerca de los aranceles aduaneros, impuestos y cargos que sean aplicables (p.139).

De acuerdo a como se menciona en el párrafo 1 del Tratado de Libre Comercio entre Perú y Estados Unidos se implementa el procedimiento del Sistema Anticipado de Despacho Aduanero de Importación Definitiva en el que se realizan las medidas necesarias para que las mercancías puedan ser despachadas dentro de las 48 horas a partir de su ingreso al punto de llegada, sin el requisito de su ingreso previo a un terminal.

Asimismo dentro del marco de negociaciones se implementó el Sistema de garantías previas a la numeración de la declaración, la cual está vigente desde el año 2011 y se profundiza detalles en el punto 1.2. 


\subsection{Factores que limitan el uso de las garantías previas antes de la numeración de la declaración}

Una de las funciones de la Superintendencia Nacional de Administración Tributaria (SUNAT) es difundir la información a los usuarios para lograr el mejor entendimiento y uso de las prácticas correctas de los procedimientos aduaneros, es así que esta entidad preparó una presentación en la que nos indica cómo se ha ido desarrollando el Sistema de garantías previas a la numeración de la declaración desde que se inició en el año 2010 hasta el 2014; se inició con 49 usuarios y en los años siguientes ha tenido un incremento considerable llegando a 403 usuarios hasta Marzo del 2014 (Ver Anexo 1)

Tabla 5: $\quad$ Evolución del Sistema de Garantías Previas del año 2010 - 2014

\begin{tabular}{|c|c|c|c|}
\cline { 2 - 4 } & Usuarios & Garantías & Monto Garantizado \\
\cline { 3 - 4 } & & & Mill.USD \\
\hline $\mathbf{2 0 1 0}$ (A Dic. 2010) & 49 & 49 & 22,5 \\
\hline $\mathbf{2 0 1 1}$ (A Dic. 2011) & 181 & 290 & 150 \\
\hline $\mathbf{2 0 1 2}$ (A Dic. 2012) & 304 & 473 & 473 \\
\hline $\mathbf{2 0 1 3}$ (A Dic. 2013) & 423 & 515 & 404 \\
\hline $\mathbf{2 0 1 4}$ (A Mar. 2014) & 405 & 431 & 430 \\
\hline
\end{tabular}

\section{Fuente: SUNAT}

Caviedes, J. (2014). Garantías previas a la numeración de la declaración, Artículo $160^{\circ}$ D.Leg.1053, Procedimiento INPCFA-PE.03.06 [Tabla]. Recuperado de diapositivas por correo electrónico [Consulta: 23 de Setiembre del 2014]. 
De acuerdo a la tabla mostrada las empresas del rubro textil que se acogieron al sistema de garantías previas representan alrededor del $7 \%$ del total de usuarios registrados en el 2014 (Ver anexo 2).

La recolección de las importaciones totales, las importaciones del rubro textil, las partidas más representativas del sector y el análisis de las empresas que utilizan el sistema de garantías previas es parte del sustento inicial para el planteamiento a nuestro problema de investigación y en consecuencia generamos nuestra hipótesis en la que mencionamos que el desconocimiento, los costos y la cultura empresarial podrían ser los factores que influyen para que los importadores de textiles no se acojan a este sistema.

\subsubsection{Desconocimiento}

Los factores que limitan el uso del sistema de garantías previas a la numeración de la declaración pueden ser varios dependiendo de la perspectiva del autor. Al respecto, Oyarse (2018) señala que:

El desconocimiento del procedimiento por parte de los importadores es uno de ellos; este factor se dio debido a que la aduana se demoró en difundir el mecanismo que se había hecho para los importadores. Aduana opto por elegir a aquellos importadores que fueron considerados grandes contribuyentes nacionales por SUNAT que inicialmente fue buena idea pero no suficiente para poder difundir el procedimiento. 


\subsubsection{Costos}

Debemos tener en cuenta que el procedimiento de las garantías previas se dio para poder cubrir requisitos que exigía el Acuerdo de Promoción Comercial PerúEstados Unidos y por tal motivo la Aduana empezó a generar procedimientos con replicas a las del procedimiento Americano como por ejemplo la utilización de las cartas fianzas y pólizas de caución que podríamos comparar con los Custom Bond norteamericanos que se utilizan para poder garantizar la mercadería que estan ingresando a los Estados Unidos por un monto mayor a $\$ 2,500.00$ y que es tramitado únicamente con el agente de Aduana (Custom and Border Protection [CBP], 2017).

Para obtener una carta fianza las entidades financieras solicitan requisitos complejos como estados financieros de los 3 últimos años, manifestación de bienes patrimoniales, contar con una cuenta corriente, tener línea de crédito aprobada, facturar más de medio millón de soles al año, además de una previa evaluación por parte del área de riesgos de la entidad financiera; la comisión promedio para este producto financiero está entre $4 \%$ y $5 \%$ de acuerdo a la calificación que la entidad financiera le brinde al cliente (Espinoza, 2018; Lau. J, 2018) (Ver Anexo 3).

De acuerdo a lo mencionado en el diario GESTIÓN (2017), el entrevistado Daniel Chávez menciona que la mayoría de personas desconoce que las compañías aseguradoras están autorizadas para emitir cartas fianzas, las cuales brindan diversas 
opciones para su adquisición dependiendo la antigüedad la empresa y el importe a financiar.

Los clientes por un tema comercial asocian la carta fianza con los bancos y póliza de caución con las compañías aseguradoras. En el 2011 La Positiva emitía US\$ 3.6 millones en primas de estos instrumentos y en el 2016 se llegó a US\$ 37 millones, logrando un crecimiento de casi $1,000 \%$ en cinco años. Cabe mencionar, que el sector que más demanda realiza sobre cartas fianzas es el de construcción.

\subsubsection{Cultura empresarial}

Enfocándonos dentro de variables internas y externas tendremos dos casos que nos ayudarán a entender el concepto de la cultura empresarial, en el primer caso la cultura constituye una fuerza fundamental del entorno y en el segundo caso nos indican que la cultura empresarial es el resultado de la expresión de un grupo humano cohesionado; de esta manera es que Morcillo (2007) cita diferentes definiciones de autores basándose en cinco enfoques de estudio que son la Cultura y liderazgo; Cultura, valores, ética, sociabilidad y solidaridad; Cultura y Éxito; Cultura y ventajas competitivas; y Cultura e Innovación.

Dentro de estos cinco enfoques ubicamos dentro de cultura y liderazgo la perspectiva de Pettigrew (1979, como se cita en Morcillo 2007) que dice, "los fundadores son creadores de símbolos ideologías, lenguajes, ritos, creencias y mitos expresivos de la vida organizacional”. 
Otra definición similar a la expuesta por Morcillo es la de Chiavenato \& Mascaró (2007) quienes nos mencionan que:

La cultura organizacional es un conjunto de hábitos creencias establecidos por medio de normas, valores, actitudes y expectativas que comparten todos los miembros de la organización, el cual refleja la mentalidad que predomina en la organización y que de esta manera cada organización aprendió a manejar su ambiente. Es una mezcla compleja de prejuicios, creencias, comportamientos, historias, mitos, metáforas y otras ideas que, juntas, representan el modo particular en que trabaja y funciona una organización.

Teniendo ambos conceptos podemos indicar que los importadores peruanos son muy arraigados a sus costumbres y creaciones dentro de su organización y esto genera que las empresas no siempre logren ir a la vanguardia con los procedimientos y operaciones de la organización (Oyarse, 2018).

\subsection{Empresas Peruanas pequeñas y medianas}

\subsubsection{Definición}

Para obtener la definición del término empresa encontraremos variedad de conceptos y consideramos que el brindado por Victoriano (2012) es el que se adecua más a nuestra actualidad en la que hablamos de globalización:

La empresa es uno de los principales motores del cambio tecnológico, económico, social y político, pero al mismo tiempo, debe adaptarse a las condiciones impuestas por el entorno institucional del nuevo orden 
económico mundial, por lo que se encuentra en un permanente proceso de transformación.

Tenemos la definición general que nos ayudará a describir las características de una pequeña y mediana empresa en el Perú de acuerdo al (Decreto Supremo 013-2013produce, art.4), en la que se considera que:

La empresa es la unidad económica que es constituida por una persona natural o jurídica y bajo una forma de organización que se contempla en la legislación vigente; además que tiene como objeto desarrollar actividades de extracción, transformación, producción, comercialización de bienes o prestación de servicios.

Las características básicas para una pequeña empresa es que gestione ventas anuales por un valor mínimo de 150 UIT y hasta el monto máximo de 1700 UIT (Unidad Impositiva Tributaria), sin importar el número de trabajadores; por otro lado una empresa mediana tiene ventas anuales superiores a 1700 UIT hasta un monto máximo de 2300 UIT y se considera que existe un rango entre 50 hasta 250 trabajadores en su planilla (Decreto Supremo 013-2013-produce, art.5). 


\subsection{Rubro Textil en el Perú}

\subsubsection{Definición}

El sector textil y de confecciones agrupa a muchas actividades, las cuales son el tratamiento de las fibras sean naturales o artificiales para elaborar los hilos, luego tenemos la fabricación y acabado de telas y finalmente la confección de prendas de vestir y otro tipo de artículos.

La mejor manera de poder explicar el que es, como es, como se originó y cómo será el sector textil en el Perú, definitivamente debe darse a partir de conocer y analizar ciertos temas dentro del sector, como su historia, estadísticas en el comercio internacional, inteligencia comercial de los países que más se compra y se vende y finalmente la competitividad de los principales productos del sector, Muñoz (2006) señala que:

El sustento del desarrollo en el sector textil se basa en el crecimiento y cuidado que se tuvo al algodón y pelo fino de camélidos en nuestro entorno como la lana de oveja, pelo fino de alpaca y vicuñas; la gran muestra de cómo se empezaron a utilizar dichos insumos se da desde la cultura Paracas, la cual produjo tejidos y prendas de gran calidad y belleza, puesto que plasmaban en sus creaciones la manera en como interpretaban al mundo; además de influir bastante en la vida cotidiana de sus pobladores debido a que los tejidos cumplían diferentes finalidades, como económicas, sociales, 
ceremoniales y funerarias; por ejemplo se utilizaba para hacer redes de pesca, bolsas, camisas, vinchas, hondas, calzado, mantos, tapices y muñecas.

La costumbre y técnicas textiles de los antiguos peruanos en brocado, tapicería, dobles telas y gasas fueron desarrollándose durante la colonia puesto que llego el telar a pedal y las nuevas versiones de telar vertical; los españoles trajeron un nuevo proceso de confección, que incluía el corte y la costura de telas para hacer trajes y objetos. En este periodo hubo mucha explotación a los indígenas en los obrajes debido a la voracidad española para obtener mayor producción y captar mayores tributos, cometiendo abusos y exceso en las jornadas laborales lo que finalmente se traducía en castigos.

Se inicia la época republicana siendo el cultivo principal la caña de azúcar en las grandes haciendas y con lo que progresivamente cobraría mayor importancia el algodón. Finaliza la guerra con Chile y esto debilita ciertas elites terratenientes y de esa manera surgen nuevos grupos de poder constituido principalmente por europeos.

La producción nacional fue orientada a la exportación con el fin de convertirse en la fuente principal de ingresos para el fisco; basado en lo anterior mencionado es que un científico puertorriqueño, Fermín Tanguis desarrolla en el valle de Pisco una variedad de algodón, de fibra larga, resistente, suave y apropiada para el teñido convirtiéndose así en uno de los principales productos de agro exportación en la costa central del Perú. 
Con todo lo expuesto podemos afirmar que el desarrollo del sector textil en el Perú ha evolucionado gracias al algodón y a los camélidos sudamericanos, los pisos ecológicos y la destreza y versatilidad de los artesanos; también debemos mencionar que los cambios constantes en las cadenas productivas han generado que haya mayor demanda de mano de obra, materia prima, procesos y capitales, teniendo como consecuencia la generación de bienes intermedios y finales para los mercados locales y extranjeros.

En la actualidad vivimos en un país con democracia y eso conlleva a que estemos abismados en procesos de apertura comercial e integración económica, hay más oportunidades para el sector y serán precisamente las cadenas productivas, las que generen una oferta exportable adecuada a la demanda internacional, con su capacidad de crecimiento y adaptación a este mundo globalizado (pp. 15-16-17).

\subsection{Comportamiento e importaciones del rubro textil durante el 2014 - 2016.}

Se considera al sector textil en el Perú como uno de los motores de desarrollo y uno de los mayores generadores de empleo. Todo esto es gracias a las múltiples características del rubro; por ejemplo estar involucrado para el proceso de otras industrias, uso de las materias primas nacionales, el gran uso de mano de obra y es fuente importante para las exportaciones lo que contribuye a la diversificación de la producción del país (Produce, 2015). 
El Producto Bruto Interno nacional (PBI) ha variado de $2.4 \%$ a $4.0 \%$ de manera general (Banco Central de Reserva del Perú [BCRP], 2018).

Tabla 6: Relación de la situación económica con las importaciones totales y del sector.

\begin{tabular}{|c|c|c|c|}
\hline $\begin{array}{c}\text { AÑo/SEGMENTO } \\
2014\end{array}$ & PBI (MIL. \$) & $\begin{array}{c}\text { TOTAL IMPORTACIONES } \\
\text { (MILL \$) }\end{array}$ & $\begin{array}{c}\text { IMPORT ACION SECTOR } \\
\text { TEXTIL (MIL. \$) }\end{array}$ \\
\hline 2015 & $\$ 137,480.24$ & $\$ 42,193.00$ & $\$ 1,941.00$ \\
2016 & $\$ 142,026.35$ & $\$ 38,104.00$ & $\$ 1,799.00$ \\
\hline
\end{tabular}

\section{Fuente: BCRP, Trademap} Elaboración Propia

Las importaciones del periodo fueron de \$ USD 42,193.00 millones de dólares en el 2014, teniendo una representación de casi $31 \%$ al producto bruto interno (PBI) del mismo año, por otro lado en el 2015 y 2016 se puede ver un incremento constante del mismo indicador; habría muchas maneras de cómo interpretar el aumento del producto bruto interno y una de ellas es la relación que hay con el descenso en las importaciones totales del país de la misma manera en cómo se comportaron las importaciones del sector textil.

Se puede analizar de diversas maneras el comportamiento de las importaciones de un sector y una de ellas es porque los usuarios no hacen el uso máximo a los procedimientos que nos brinda la Superintendencia Nacional de Administración Tributaria (SUNAT) y que ayudan a agilizar el despacho de mercancías para beneficio del importador (Oyarse, 2018). 
Las importaciones del sector fueron de \$ USD 1,941 mil millones de dólares en el 2014 y estas han disminuido los dos años siguientes; sin embargo la representación del sector con el total importado ha sido ascendente del 2014 al 2015 pues paso de ser $4.6 \%$ a $4.72 \%$; sin embargo fue descendente del 2015 al 2016 teniendo un representación de 4.63\% (Ver Tabla 8).

El sector de los textiles comprende desde el capítulo 50 al 63 en el arancel de aduanas y a su vez es subdividido desde el capítulo 50 al 60 denominado como actividad textil y del capítulo 61 al 63 como actividad confecciones (Ministerio de la Producción [Produce], 2015).

Tabla 7: Representación del rubro, de la actividad textil y confecciones por año

\begin{tabular}{|lcccc}
\hline Importaciones del rubro vs. Total importado & 2013 & 2014 & 2015 & 2016 \\
\hline & $4.27 \%$ & $4.60 \%$ & $4.72 \%$ & $4.63 \%$ \\
\hline Actividad Textil, capitul os (50-60) vs. Total importado & $58.64 \%$ & $58.93 \%$ & $57.87 \%$ & $57.30 \% 6$ \\
\hline Actividad Confecciones, capitulos (61-63) vs. Total importado & $41.36 \%$ & $41.07 \%$ & $42.13 \%$ & $42.70 \% 6$ \\
\hline
\end{tabular}

\section{Fuente: BCRP, Trademap Elaboración Propia}

La actividad textil en el periodo analizado es mayor a la de confecciones, existe un promedio en el periodo de casi $60 \%$ para la actividad textil contra $40 \%$ para la actividad de confecciones (Ver Tabla 7).

Con esta información hemos podido ubicar las subpartidas arancelarias con mayor representación en el periodo analizado, ya que representan casi el 50\% del total importado en cada año (Ver Anexo 5). 
Después de haber obtenido las subpartidas, procederemos a ubicar las empresas que importen por cada año dichas subpartidas (Ver Anexo 6); de esta manera tendremos una lista de importadores que podremos contrastar con el informe del Ministerio de Producción (Produce) acerca del directorio con las empresas medianas y pequeñas que están registradas por actividad (Ver Tabla 10).

Finalmente, tendremos una lista de empresas importadoras medianas y pequeñas del sector textil para poder generar un filtro con las que hayan declarado en la declaración aduanera de mercancías (DAM) que el despacho fue garantizado y con eso obtendremos una lista más segmentada que nos podrá ayudar con la investigación (Ver Tabla 16 y 17). 


\section{CAPITULO II - METODOLOGÍA DE INVESTIGACIÓN}

\subsection{Planteamiento de la investigación:}

Vamos a mostrar el planteamiento de la investigación para poder resolver nuestra hipótesis planteada y para lo cual tendremos que desarrollarlo explicando el propósito, el tipo y las preguntas de investigación, de una manera metodológica y ordenada.

\subsection{Propósito de la investigación:}

El propósito de nuestra investigación es determinar por qué el desconocimiento en el procedimiento, los costos y la cultura empresarial están limitando el uso de las garantías previas a la numeración de la declaración aduanera en las importaciones de textiles durante el periodo 2014-2016, para lo cual hemos utilizado cuestionarios y las entrevistas a profundidad que vienen a ser el instrumento y técnica de investigación respectivamente, con el fin de recolectar datos a diferentes segmentos como Importadores textiles, agencias de aduana, entidades financieras-aseguradoras y la aduana (Superintendencia de Administración Tributaria [SUNAT]).

\subsection{Tipo de investigación:}

Se ha trabajado una investigación cualitativa; ya que nos hemos enfocado en los factores por los que el importador de textiles no utiliza el procedimiento de las 
garantías, siendo explorado desde la perspectiva de cada segmento, en su ambiente natural y en relación con su contexto. De esta manera nos enfocaremos en

Utilizar la recolección y análisis de datos para afinar las preguntas de investigación o revelar nuevas interrogantes en el proceso de interpretación (Hernández, 2014, p.7).

\subsection{Preguntas de investigación:}

Luego de definir el marco teórico planteado hemos desarrollado entrevistas a profundidad utilizando los cuestionarios por cada segmento (Ver anexo 7) con el fin de considerar las opiniones de cada segmento para que nos ayuden a responder la siguiente pregunta de investigación; ¿Por qué el desconocimiento en el procedimiento, los costos y la cultura empresarial están limitando el uso de las garantías previas a la numeración de la declaración aduanera en las importaciones de textiles durante el periodo 2014-2016?.

\subsection{Contexto:}

Para iniciar nuestra investigación tuvimos que ubicar nuestro segmento mediante el desarrollo del marco teórico; después de ubicar a las empresas y entidades, buscamos a los contactos potenciales que nos podrían brindar la información necesaria, haciendo entrevistas a profundidad con la mayoría de entrevistados, de los cuatro segmentos (Importadores Textiles, Entidades Financieras y de seguros, La Aduana y Agentes de Aduana) el segmento de Importadores Textiles de 
empresas medianas y pequeñas fue el más difícil de lograr contacto puesto que estas empresas están ubicadas la mayoría en La Victoria, especialmente en Gamarra y persuadirlos a que nos brinden algunos minutos era sinónimo de que ellos dejen de trabajar por un momento; sin embargo, después de ir varias oportunidades a Gamarra se logró citar a tres empresas que nos ayudaron con la información, hubieron dos casos que no nos permitieron filmarlos pero si hacer una grabación de voz y un caso en el que no nos permitió filmar ni grabar por lo que tuvimos que escribir los comentarios, respuestas y aportes adicionales que finalmente corroboro con un correo de confirmación como sustento. En el caso de los otros segmentos logramos obtener entrevistas filmadas, salvo en uno del segmento de entidad aseguradora que no permitió grabar por lo que tuvimos que tomar apuntes y solicitar la confirmación por correo, los otros participantes se mostraron dispuestos a apoyar.

\subsection{Muestra o participantes:}

Debido al trabajo elaborado fue necesario tomar como muestra representativa a diferentes empresas y entidades de cada segmento para recolectar la información; fueron cuatro segmentos; Importadores Textiles, Entidades Financieras y de seguros, La Aduana y Agentes de Aduana; los cuales nos brindaron información y opinión de acuerdo a la experiencia en el rubro acerca de los diversos factores por los que los importadores del sector textil no se acogen al procedimiento de las garantías previas antes de numerar la DAM. 


\subsection{Diseño o abordaje principal}

La presente investigación se realizara basandose en la teoría fundamentada, ya que no hay estudios o investigaciones relativas al tema y las fuentes encontradas no son suficientemente adecuadas para el contexto, tiempo, muestra y circunstancias que hemos planteado; ademas el diseño utilizado es el sistemático debido a la inlcusión de las codificación abierta, axial y selectiva que se requiere en el proceso del diseño (Hernández, 2014).

\subsubsection{Identificación de la estructura de la entrevista}

Para el presente estudio se ha utilizado la entrevista semiestructurada ya que el cuestionario fue elaborado de acuerdo a los objetivos de nuestra investigación, realizándose preguntas semiestructuradas que nos permite hacer cambios imprevistos a lo que va respondiendo el entrevistado.

Para realizar las entrevistas se utilizó una guía de preguntas elaboradas por cada segmento, donde los entrevistados nos brindaron respuestas extensas, sólo en algunos casos se obtuvo respuestas concisas, que de igual forma respondían a nuestro objetivo. 


\subsubsection{Guía de preguntas}

La elaboración de la guía de preguntas se realizó tomando en cuenta el segmento a entrevistar y se consideró los cuatro cuestionarios por cada segmento que se seleccionó para este estudio; las clases de preguntas utilizadas fueron generales, para evaluar el nivel de conocimiento y cultura en el rubro; y preguntas de contraste, para que nos pueda dar una comparación con respecto al procedimiento en el periodo solicitado y en la actualidad. Se priorizo empezar de lo general a lo particular; sin embargo, cuando los entrevistados se adelantaban en alguna pregunta se manejaba la situación para seguir con la o las preguntas pendientes, de esa manera no dejábamos de tener toda la información necesaria por entrevistado.

\subsubsection{Segmentos}

La segmentación de nuestra investigación se realizó a empresas importadoras del sector textil, empresas de banca y seguros, Agentes de Aduanas y La Aduana; el cual podemos detallar a continuación:

Segmento 1: Gerentes Generales y/o Encargado de Comercio exterior de Empresas importadoras del rubro textil.

Segmento 2: Representantes de la Aduana Marítima

Segmento 3: Representantes Legales y/o sectorista de cuenta de Agentes de Aduanas.

Segmento 4: Gerentes y/o ejecutivo de cuenta de Banca y seguros. 


\subsubsection{Categorías}

Para la presente investigación se determinaron 03 categorías, considerando los factores que planteamos en la investigación:

- Categoría 1: Desconocimiento del Procedimiento a la Garantía Previa

- Categoría 2: Costo de la Carta Fianza o Póliza de Caución

- Categoría 3: Cultura y/o Tradición empresarial

\subsubsection{El instrumento de investigación}

De acuerdo a los objetivos de nuestra investigación, el instrumento que nos permitió registrar la información y cumplir con la recolección de datos fue el cuestionario; donde se realizaron entrevistas semiestructuradas con una guía de preguntas y en algunos casos por correo electrónico; con ello se podía conocer las opiniones y experiencias de los expertos elegidos para nuestra investigación. Las preguntas elaboradas correspondían a cada una de las categorías que se requería investigar; donde se realizaron entrevistas personales filmadas, audios grabados y por correo electrónico. Tuvimos algunos casos en donde no nos permitieron filmarlos, pero si realizar audios grabados y otros casos donde no nos permitieron realizar ninguno de los dos, por lo cual se tuvo que elaborar un correo electrónico con el resumen de la entrevista, donde el entrevistado nos brindó la conformidad por el mismo medio. 
El tiempo mínimo de las entrevista fue de 10 minutos y el máximo tiempo de entrevista duro un poca más de media hora.

\subsection{Procedimiento:}

Para obtener respuestas e información adicional, que nos ayude a sustentar nuestra investigación, tuvimos que ordenarnos mediante el siguiente procedimiento:

1) Se elaboró la matriz de consistencia que nos permitió tener nuestros objetivos planteados y con ello definir los segmentos, que necesitábamos para recopilar la información de los entrevistados, y las categorías, que nos sirvió para responder el objetivo definido y la elaboración del cuestionario.

2) Se realizaron las preguntas, que fueron elaboradas después de haber trabajado con la bitácora, en la cual se colocaron los segmentos y las categorías definidas para elaborar los cuestionarios de cada segmento basados en los objetivos específicos.

3) Después de tener el cuestionario terminado, se elaboró una agenda con los posibles entrevistados de acuerdo a cada segmento para determinar citas dependiendo a la disponibilidad de las personas que íbamos a entrevistar.

4) Una vez confirmadas las citas se fueron realizando las entrevistas tomando los apuntes necesarios para que finalmente sean analizados.

5) Después de culminar las entrevistas se procedió con la valoración de las respuestas considerando la experiencia en el rubro, el manejo de la entrevista y la forma de 
recolectar la información; de esta manera lograremos ser más objetivos con los resultados para elaborar nuestras conclusiones, recomendaciones y si es necesario elaborar una nueva hipótesis después de los resultados obtenidos. 


\section{CAPITULO III - ANALISIS DE DATOS}

\subsection{Segmento 1: Gerentes Generales y/o Encargado de Comercio exterior de Empresas importadoras del rubro textil}

Categoría 1: Desconocimiento del Procedimiento a la Garantía Previa

Las empresas entrevistadas Rocky Textil S.A.; Textiles El Paisa S.A.C. Y Textil

Díaz Ponce EIRL nos manifestaron que si habían escuchado del sistema de garantías previas antes de numeración de la DAM; sin embargo, cada uno de ellos tiene un concepto diferente de su aplicación y los beneficios que pueden obtener de éste sistema de acuerdo a su necesidad y modo de trabajo.

Para Rocky Textil S.A., nos indica que los temas de importación se asesora con los agentes de carga con los que trabaja y agentes de aduana; el entrevistado sabe de comercio exterior y lo ha aprendido de manera empírica ya que anteriormente trabajo en una agencia de aduana por un corto tiempo; en el asesoramiento que tuvo le indicaron que acogiéndose al SADA podría retirar la mercadería en máximo 48 horas; sin embargo nos indica que al ser telas se va a demorar más de 48 horas en retirar la mercadería por los boletines químicos que se debe analizar; la empresa trabaja con SADA $70 \%$ y el 30\% de manera excepcional; además, prefiere no utilizar garantías porque aprovecha los días de almacenaje que le brinda los 
almacenes extra portuarios, generando un ahorro en los costos para la empresa, el entrevistado se ha informado del procedimiento entre el 2011 y 2012 por su agente de aduana; por otro lado menciona que le puede traer complicaciones con la Aduana al momento de sustentar el valor de su producto, ya que con la experiencia que tiene en las importaciones textiles siempre se dan casos de ajuste de valor y el tiempo que se toma la aduana para resolver estos casos es demasiado, en algunos casos se tiene que ir hasta el tribunal fiscal para que sea resuelto; todo esto hace que le genere desconfianza para emitir una carta fianza a nombre de SUNAT, además no está de acuerdo en pagar los derechos los 21 de cada mes porque si obtiene levante el 15 no le encuentra beneficio pagar en tan solo 6 días.

Textiles El Paisa S.A.C.; nos indica que el tema de importaciones ha sido muy cambiante de manera general, el entrevistado comenta que la tecnología y la globalización ha ayudado a que tanto Aduana y el importador han tenido que acoplarse a esos cambios para mejorar procesos y agilizar la función de facilitar el comercio exterior, el $95 \%$ de las cargas que traen son FCL y el resto LCL, enfatiza que los costos son bastantes distintos entre FCL/ LCL y que ambos tienen la gestión similar para la empresa, los despachos de importación los hacen desde el 2014 bajo la modalidad SADA y EXCEPCIONAL, de acuerdo a la urgencia del momento; es decir alrededor de un 40 o $50 \%$ son SADA y sin garantía. El entrevistado indica que si ha escuchado de las garantías previas antes de numerar la DAM y que si conoce del procedimiento; sin embargo no es importador frecuente y eso impide que 
pueda acogerse; por otro lado, indica que el dueño no quiere usar las garantías porque demora la operación de su empresa haciendo procedimientos engorrosos y además representa un costo muy elevado por parte de los bancos (Los Bancos no dan facilidad para las cartas fianzas a empresas nuevas); además, menciona que la mayoría de sus importaciones sale con canal naranja o rojo por lo que no serviría de nada generar una garantía con la aduana si es que se va a demorar lo mismo en desaduanarlo.

Para Textil Díaz Ponce Eirl; el uso del Sistema de Garantía Previas a la numeración de la DAM es un sistema que les representa mucho beneficio, puesto que la mayoría de sus importaciones están programadas, es decir, ya cuenta con un cliente que ha dado un adelanto de dinero por el producto.

Categoría 2: Costo de la Carta fianza o Póliza de Caución

Para Rocky Textil S.A.; el importador indica que paga los tributos con capital propio, "felizmente hay liquidez en todo el año pero a pesar de ello debo ser rígido con mis proveedores de servicio para conseguir algo de crédito", son las palabras que nos mencionó para poder obtener crédito; con respecto a los inconvenientes nos menciona que al inicio algunos agentes de aduana y carga le cobraban diferente a como le cobraban otros y eso hizo que a partir de ese momento mantenga un 
seguimiento con ellos para que le homologuen los precios y que las cotizaciones sean de manera equitativa haciendo respetar su calidad de cliente.

Textiles El Paisa S.A.C.; Para pagar los derechos de aduana, el importador indica que después que el agente de Aduana declare la DAM y la Aduana le haya dado la liquidación, solicita al agente que pague los derechos y luego el importador financia los derechos con la agencia mediante descuento de letras; para lograr este procedimiento el importador trabaja con pocos agentes de aduana para poder lograr la confianza y tener la certeza de que el agente se especializara con la carga cada vez que le asignen despachos.

Para Textil Díaz Ponce Eirl; el administrador indica que el pago de tributos lo realiza al contado y cuenta con 02 agentes con quienes maneja crédito para que ellos paguen sus derechos; el entrevistado indica que es factible pagar los tributos al contado en ciertas ocasiones porque se acoge a las garantías previas antes de numerar la DAM y eso le brinda un respiro financiero entre 20 a 50 días en el mejor de los casos. 


\subsection{Segmento 2: Representantes de la Aduana Marítima}

Categoría 1: Desconocimiento del Procedimiento a la Garantía Previa

Con respecto a la modalidad más utilizada por los importadores textiles es el despacho excepcional o diferido (el objetivo de Aduana es convencerlos que utilicen más SADA) para lograr el standar internacional que es conceder el levante en 48 horas, no se ha logrado convencer a los textiles a utilizar SADA porque el sector textil no es muy dinámico es decir no son muy periódicas las importaciones a comparación de otros sectores. La Aduana va a empezar una difusión masiva para que los importadores sepan las ventajas y bondades del sistema SADA con garantía previa; además han sacado un producto que permitirá que los importadores frecuentes se conviertan en OEA, de esa manera podrán presentar solo garantías nominales en vez de las fianzas o pólizas de caución. La Aduana esta empecinada en esta idea puesto que quiere lograr la meta de lograr el levante en 48 horas; esto ayudaría a que la Aduana pueda focalizar las fiscalizaciones y controles después del levante ya que actualmente se hacen las fiscalizaciones y controles como condición para hacer el levante y eso hace que se retrase los tiempos de las salidas de la carga, además de castigar a buenos importadores que no tendrían que pasar por estos procedimientos rigurosos, otro punto que menciona el representante es que Aduana debe cambiar la forma de seleccionar canales y colocarlos por indicadores de riesgo para generar un mejor filtro. 


\subsection{Segmento 3: Representantes Legales y/o sectorista de cuenta de Agentes de $\underline{\text { Aduanas }}$}

Categoría 1: Desconocimiento del Procedimiento a la Garantía Previa

Para la Agencia AUSA; consideran que esto empezó más como despachos excepcionales y con el tiempo hasta el día de hoy se ha incrementado y el porcentaje es mayor de los que antes utilizaban SADA, el SADA en la actualidad es la modalidad más utilizada desde hace cinco años atrás aproximadamente.

Para la Agencia Capricornio; consideran que se utilizan más despachos excepcionales que los anticipados; el entrevistado menciona que utilizando el SADA los importadores ahorrarían dinero en el procedimiento; sin embargo para algunos importadores el SADA no es tan atractivo porque al hacerlo de esta manera tendrían que desaduanarlo rápido y llevarlo a su almacén cuando en realidad lo podrían dejar en el deposito temporal para almacenar las mercaderías sin problemas sin necesidad de alquilar almacenes y tener un gasto extra.

Para la Agencia Ransa; consideran que se utiliza más SADA en el presente, indicando que hay Garantía Global teniendo una fianza o póliza de caución; no dio opinión alguna con respecto a la modalidad más utilizada antes de que sea el SADA. 
Categoría 2: Costo de la Carta fianza o Póliza de Caución

Para la agencia AUSA; indican que sus clientes solicitan SADA en un 50\% y de los importadores textiles 7 de cada 10 importadores utilizan las garantías previas, ellos opinan que este procedimiento puede ayudar a las empresas a retirar la carga con mayor dinamismo evitando que el importador caiga en sobrecostos de almacenaje; por otro lado mencionó que el costo beneficio para la agencia de aduana es ahorro en procedimiento y por ende en personal que se ve reflejado finalmente en los costos; sin embargo indica que a partir de ser operadores OEA hacen doble proceso ya que se debe regularizar el proceso y además no les ayuda puesto que la norma indica que si hace más despachos con garantía previa le reducen el monto de su fianza como agente de aduana, puesto que ellos como operadores OEA ya tienen un monto determinado.

En el caso de la Agencia Capricornio; indican que sus clientes solicitan SADA en un $50 \%$ y de los importadores textiles 2 de sus 5 clientes utilizan garantías previas, el entrevistado indica que si los importadores se acogieran más a este procedimiento entonces podrían llevar la mercadería de manera directa al cliente final ya que muchos de ellos utilizan despachos directos sin llegar a sus almacenes ; además indica que al agente de aduana le beneficia mucho utilizar SADA con garantía previa ya que utiliza menos personal y por ende menos costo; además indica que hay más control por parte del importador en vez de otorgarle esa responsabilidad a 
la agencia de aduana por lo que minimiza tiempo de gestión y por ende se minimiza el costo que hay que invertir en ese personal de la agencia de aduana.

La agencia RANSA; indica que sus clientes se acogen al SADA y que desde la perspectiva como agente de Aduana considera que si su cliente tiene SADA, además del código de cuenta corriente automático, el cliente ya está automáticamente garantizado sea con la carta fianza o póliza de caución; el entrevistado considera que si el importador utiliza el SADA la mayoría de canales que ha visto caer son los verdes y al obtener automáticamente el levante se puede tomar decisión de sacar la mercadería ahorrando en sobrecostos de almacenajes; con respecto al uso de SADA con garantía previa el entrevistado indica que el $100 \%$ de sus clientes textiles lo utiliza para los despachos y que estos clientes textiles al utilizar SADA con garantía ahorran tiempo y dinero al no utilizar un deposito temporal sino enviar la mercadería de frente a sus almacenes.

\section{Categoría 3: Cultura y/o Tradición empresarial}

Para la agencia AUSA; indican que sus clientes normalmente son los gerentes del área responsable, gerentes regionales; por ende no hay autonomía directa para la toma de decisiones en las operaciones.

En el caso de la Agencia Capricornio; indican que sus clientes normalmente son los gerentes del área responsable, no hay contacto directo con los dueños de la empresa, 
además indica que no hay autonomía directa ya que deben reunirse con los demás gerentes y dueños para la toma de decisiones.

Para la agencia RANSA; el entrevistado menciona que la comunicación es directamente con el gerente de alto rango; sin embargo, considera que dependiendo la implicancia de la información que quieren brindarles es que podría necesitarse al dueño o gerente de alto rango a la vez.

\subsection{Segmento 4: Gerentes y/o ejecutivo de cuenta de Banca y seguros}

Categoría 2: Costo de la Carta fianza o Póliza de Caución.

En el caso de La Positiva Seguros; en la experiencia dentro del mercado de Seguros el producto más utilizado por las empresas importadoras es la carta fianza, para la Positiva emitir una carta fianza o una póliza de caución tiene la misma rentabilidad y representa el mismo costo, el producto más utilizado entre ambos es la carta fianza por un tema comercial (el cliente se siente más cómodo y más confiable con el nombre de carta fianza a comparación de una póliza de caución); las cartas fianzas y pólizas de caución no se cotizan, a comparación de otro producto financiero, este es requerido y no ofrecido; el cliente lo necesita y esto hace que la empresa aseguradora sea vista con características más agiles y blandas para poder obtener este producto a comparación de los bancos, con respecto a las ventajas de gestionar una carta fianza y/o una póliza de caución en el mercado asegurador son las siguientes; tasas competitivas, flexibilización de garantías, rapidez en la emisión, 
disminución de cumulo de deudas en el sistema. El entrevistado menciona que hay una gran diferencia en brindarle el producto a un cliente frecuente de la Positiva a brindárselo a una empresa nueva que inicia en el mercado; sin embargo igual le brindan opciones para obtener el producto.

Para Interbank; La entrevistada nos indica que el producto más recurrente para el banco es el capital de trabajo (pagare tasa vencida o taza descontada), este es denominado como un préstamo de corto plazo, esto sirve para las necesidades recurrentes del cliente. Con respecto a la carta fianza indica que el principal sector que solicita este producto son las constructoras, empresas que importan para presentar a SUNAT o para presentar a su proveedor; por otro lado el Banco tiene como condición para brindar este producto que el cliente tenga una línea de crédito, además de una evaluación de los estados financieros en el que se evalúan diferentes ratios para verificar que pueda cubrir los gastos financieros, parte de la deuda, giros, etc..; sin embargo en caso que el cliente lo necesite de manera urgente y sea un cliente nuevo entonces con una garantía liquida o un certificado bancario podrían brindarle la opción al cliente. Para el banco emitir una carta fianza representa una rentabilidad aproximada del $3 \%$ que viene a representar algo medianamente importante.

En el caso del Banbif; en la experiencia del entrevistado dentro del sector financiero los productos más comunes que ofrece el banco como Banca Empresa es el capital de trabajo (Prestamos), financiamiento de comercio exterior (importación exportación) y Carta Fianza. Siendo el capital de trabajo el producto más utilizado, 
para el Banbif la carta Fianza es un producto importante porque no hay un desembolso de dinero, si bien existe un riesgo como todo préstamo; la carta fianza es un riesgo indirecto salvo ésta se ejecute por algún siniestro. Para acceder a una carta fianza el cliente debe contar con los siguientes requisitos: La empresa debe estar constituida, contar como mínimo 03 años en el mercado, presentar los Estados Financieros de la empresa, declaración jurada de los accionistas, formatos del banco.

Categoría 3: Cultura y/o Tradición empresarial.

En el caso de La Positiva Seguros; los clientes con quienes mantienen reuniones para negociar tazas y condiciones principalmente son los dueños de la empresa (el $90 \%$ sucede de esa manera, mientras que el $10 \%$ es solo de gerentes de alto rango), al tener reuniones directas con los dueños de las empresas, esto hace que haya autonomía directa para tomar alguna decisión de índole financiera, la Positiva como empresa aseguradora brinda el producto y asesoría al cliente.

Para Interbank; el contacto más frecuente para el banco es el dueño en el caso de empresas pequeñas y medianas, esto permite que haya autonomía inmediata para las decisiones financieras que se dan en las reuniones. 
En el caso del Banbif; considerando una empresa mediana - Grande el contacto con quien se mantienen reuniones para negociar tazas y condiciones principalmente son los gerentes de altos rangos como Gerente Financiero o Gerente General que no necesariamente es el dueño de la empresa (el 70\% sucede de esa manera, mientras que el $30 \%$ es con los dueños de la empresa), si la empresa cumple con las condiciones para aplicar al producto solicitado, no siempre la toma de decisión es en automática, se considera que un $60 \%$ la decisión la toma el gerente financiero o alto rango, y el $40 \%$ es por el dueño de la empresa o el directorio si es una empresa corporativa. 


\section{CAPITULO IV - RESULTADOS}

\subsection{Discusión de los resultados}

Después de haber culminado con las entrevistas de cada segmento, enfocadas en las categorías planteadas, procederemos a discutir los resultados obtenidos en cada una de estas.

\subsubsection{Categoría 1: Desconocimiento del Procedimiento a la Garantía Previa.}

Para el Segmento 1 (Importadores de empresas textiles), las empresas entrevistadas cuentan con una experiencia en el rubro textil de 10 a 15 años, los embarques de importación son realizados en ambas modalidades y la media de los entrevistados indica que en FCL (Cargas con contenedores llenos) son de 70\% a más y en caso LCL (Cargas sueltas que no llenan el contenedor) es no mayor a 30\%, la modalidad más utilizada por los entrevistados en la actualidad es el SADA con un promedio del 60\%; además no dejan de utilizar los despachos excepcionales que en su mayoría no es más del 50\% y que fue la única modalidad que se utilizaba en promedio hasta el periodo 2015-2016 por diferentes motivos, 2 de los 3 entrevistados comentaron procedimientos incompletos y errados con respecto al tiempo máximo de levante en un despacho con garantía y con respecto al pago diferido. 
En el caso del Segmento 2 (Representante de la Aduana Marítima), en este segmento se indica que la modalidad más utilizada por los importadores textiles ha sido y es el despacho excepcional o diferido (el objetivo de Aduana es convencerlos que utilicen más SADA); para lograr el standar internacional se debe conseguir el levante en 48 horas y esa es una de las principales razones de la Aduana, no se ha logrado convencer a los textiles a utilizar SADA porque el sector textil no es muy dinámico es decir no son muy periódicas. La Aduana va a empezar una difusión masiva para que los importadores sepan las ventajas y bondades del sistema SADA con garantía previa; además han sacado un producto que permitirá que los importadores frecuentes se conviertan en OEA, de esa manera podrán presentar solo garantías nominales en vez de las fianzas o pólizas de caución. Aduana esta empecinado en esta idea puesto que quiere lograr la meta de lograr el levante en 48 horas; esto ayudaría a que la Aduana pueda focalizar las fiscalizaciones y controles después del levante ya que actualmente se hacen las fiscalizaciones y controles como condición para hacer el levante y eso hace que se retrase los tiempos de las salidas de la carga, además de castigar a buenos importadores que no tendrían que pasar por estos procedimientos rigurosos, otro punto que menciona es que Aduana debe cambiar la forma de seleccionar canales y colocarlos por indicadores de riesgo para generar un mejor filtro.

Con respecto al Segmento 3 (Representantes Legales y/o sectorista de cuenta de Agentes de Aduanas), el 50\% de los entrevistados consideran que el SADA es el despacho más utilizado actualmente, entre los comentarios resaltantes a mencionar, 
la modalidad más utilizada anteriormente fue el excepcional y actualmente es el SADA como fecha promedio desde el 2013, al utilizar el SADA los importadores ahorrarían dinero en el procedimiento; sin embargo para algunos importadores no es tan atractivo debido a que tendrían que desaduanarlo y llevarlo a su almacén cuando en realidad ellos no tienen almacén y eso obligaría a que tengan un costo fijo más.

\subsubsection{Categoría 2: Costo de la Carta fianza o Póliza de Caución.}

Para el Segmento 1 (Importadores de empresas textiles), las empresas importadoras utilizan crédito y capital propio para pagar sus derechos; en el caso del crédito, se financian con los agentes de aduana mediante letras y cuando mencionan del capital de trabajo quiere decir que pagan los derechos al Contado, entre los comentarios más resaltantes con respecto a inconvenientes con el pago de los derechos de aduana mencionaron que felizmente hay liquidez y que eso les permitía poder pagar al contado, en algunos casos podían tener la facilidad de negociar crédito con los agentes de Aduana y que eso les permitía optimizar la liquidez para otras operaciones.

Con respecto al Segmento 3 (Representantes Legales y/o sectorista de cuenta de Agentes de Aduanas), de acuerdo a las respuestas que los entrevistados indican por lo menos el 50\% de sus clientes textiles utilizan las garantías previas a la numeración de la DAM y si el importador se acoge puede optimizar sus costos ya que no incurrirían en sobrecostos de almacenajes; por otro lado hay una 
minimización de riesgo, gestión y el ahorro de personal para la agencia de aduana, debido que hay más control por parte del importador en vez de otorgarle esa responsabilidad a la agencia de aduana, por ende, se minimiza el costo que hay que invertir en ese personal de la agencia; sin embargo esto cambia drásticamente si el agente de aduana es OEA, ya que tendría que hacer doble proceso y además que la norma no les ayudaría puesto que no les podrían reducir el monto de su fianza al hacer más despachos con garantía.

En el caso del Segmento 4 (Gerentes y/o ejecutivo de cuenta de Banca y seguros), la empresa aseguradora utiliza cartas fianzas y pólizas de caución; sin embargo menciona que la carta fianza es las más utilizada debido a que los clientes prefieren utilizarlo por el nombre; la póliza de caución no les brinda confianza a diferencia de la carta fianza, para la empresa aseguradora este producto no es ofrecido sino requerido ya que es una necesidad para los clientes; por otro lado las entidades bancarias indican que el producto más utilizado por las empresas es el capital de trabajo y que los clientes deben pasar por cierta evaluación para poder requerir este producto en el que se les solicita los estados financieros de los 3 últimos periodos y algunos formatos del banco; además indicaron que la carta fianza es un producto importante porque no hay un desembolso de dinero, si bien existe un riesgo como todo préstamo; la carta fianza es un riesgo indirecto salvo ésta se ejecute por algún siniestro. 


\subsubsection{Categoría 3: Cultura y/o Tradición empresarial.}

Para el Segmento 3 (Representantes Legales y/o sectorista de cuenta de Agentes de Aduanas), Los entrevistados concuerdan que el contacto frecuente es el gerente de alto rango ya que es un proceso que implica más tema operativo; esto implica que la autonomía sea menor debido a que deben consultar para algún cambio o decisión con los dueños de la empresa.

En el caso del Segmento 4 (Gerentes y/o ejecutivo de cuenta de Banca y seguros), dos de los tres entrevistados concordaron que el contacto principal para la empresa de seguros y los bancos son los dueños de la empresa y esto hace que la autonomía del cliente sea de manera directa.

\subsection{Hallazgos de la investigación}

En la presente investigación se presentaron los siguientes hallazgos:

- $\quad$ Para algunos importadores textiles el Sustento de Valor de la mercadería declarada es uno de los motivos que les genera desconfianza para emitir una carta fianza a nombre de la ADUANA, ya que ellos alegan que la Aduana puede hacer efectiva su carta fianza en cualquier infracción que hayan incurrido.

- $\quad$ En el segmento de banca y seguros nos mencionaron que existen limitaciones para el importador cuando se utiliza la carta fianza de una entidad que 
no es reconocida por la aduana a pesar de estar registrada e inscrita por la Superintendencia de Banca y Seguros (SBS); ocasionando demoras y sobrecostos para los importadores.

- $\quad$ Debido a la poca acogida que ha venido presentado el sistema de garantías previas a la numeración de la declaración, la aduana está incentivando a los agentes de aduanas de manera que ellos motiven a los importadores a acogerse al sistema de garantías previas, de esta manera, ellos serían beneficiados en el importe de su fianza como agentes de aduanas; es decir, por cada importación que realicen acogiéndose con el sistema de garantías previas, dicho importe no será descontado de su carta fianza anual.

- Actualmente la Aduana ha implementado la certificación del Operador Único Autorizado (OEA), que estará vigente desde junio 2019, y está orientado a la reducción de tiempo y costo; esta certificación garantiza la seguridad en la cadena logística, teniendo los siguientes beneficios; la disminución del control aduanero, atención preferente en trámites (rectificación de DAM) y el uso de una garantía nominal para el sistema de garantías previas. 


\subsection{Barreras de la investigación}

Para la presente investigación mencionaremos algunas limitantes que se presentaron durante el estudio; sin embargo es importante mencionar que no impidieron a que se cumplan los objetivos planteados:

- Conseguir las entrevistas con los Gerentes y/o Encargados de Comercio Exterior fue un poco complicado, algunos se mostraban reacios y un poco desconfiados para brindar información de su empresa.

- $\quad$ La disponibilidad de tiempo de los entrevistados fue otra de las limitaciones ya que argumentaban que se encontraban muy atareados.

- Las fechas pactadas de las entrevistas fueron reprogramadas en más de una oportunidad, porque siempre se encontraban muy ocupados y no podían atendernos en la hora señalada. Asimismo, en una oportunidad, esperamos más de dos horas para que nos pueda atender.

\subsection{Brechas de la investigación}

Se presentaron brechas durante la investigación las mismas que no fueron impedimentos para alcanzar nuestros objetivos. Tuvimos algunos casos en donde no nos permitieron ni grabar ni filmar, sólo tomar apuntes de la entrevista. El cuál se elaboró un resumen de la entrevista para que sea validado por el entrevistado a través de un correo electrónico. 


\section{CONCLUSIONES}

Nuestra investigación tuvo el propósito de responder a la siguiente pregunta de investigación; ¿Por qué el desconocimiento en el procedimiento, los costos y la cultura empresarial están limitando el uso de las garantías previas a la numeración

de la declaración aduanera en las importaciones de textiles durante el periodo 20142016?; siendo nuestra hipótesis inicial, el desconocimiento en el procedimiento, los costos y la cultura empresarial limitan el uso de las garantías previas antes de numerar la declaración aduanera y son los principales motivos que conlleva a que los importadores peruanos de empresas medianas y pequeñas del rubro textil no hagan uso de la misma durante el periodo 2014-2016; después de realizada la investigación hemos obtenido resultados que nos permiten concluir lo siguiente:

- Después de analizar el marco teórico y entrevistas de cada segmento hemos podido responder cada objetivo específico y también definir que la hipótesis se valida parcialmente.

- $\quad$ Entre los motivos adicionales por los que no se acogen encontramos que el ajuste de valor declarado ante aduanas es un impedimento para que la empresa no emita una fianza a la Aduana (No hay un principio de buena $\mathrm{Fe}$ ).

- $\quad$ La función que ha ido desempeñando la Aduana es la de difundir los beneficios del sistema de garantías; sin embargo, no ha podido cumplir en totalidad esta función debido a inconvenientes externos y propios dentro del periodo analizado, esto se puede confirmar contrastando con el análisis del segmento 1 ya 
que se valida parcialmente que existe desconocimiento y con el segmento 3 ya que soporta el sustento de por qué se utilizaba con mayor frecuencia el despacho excepcional en el periodo analizado.

- $\quad$ De acuerdo a las entrevistas realizadas podemos manifestar que la carta fianza es la opción más viable por ser un producto confiable, comercial y adquisitivo que tanto empresas aseguradoras como las bancarias pueden emitirlo, sin embargo, dependerá de los requisitos que solicite cada entidad para que el importador pueda adquirirlo; para dar soporte a esta conclusión la analizamos y contrastamos con el segmento 1 ya que no mencionaron ningún inconveniente para el pago al contado o con financiamiento de los tributos y con el segmento 3 ya que los agentes indicaron que si los importadores se acogían al procedimiento de las garantías previas podrían optimizar sobrecostos de almacenaje y tiempos de entrega para sus clientes, de este modo se rechaza que el costo de la carta fianza o póliza de caución sea un factor que impida a que los importadores se acojan a este procedimiento.

- La estructura organizacional de las empresas textiles son de manera vertical y esto hace que las decisiones y cambios sean decididos por los dueños y en menor frecuencia por los gerentes en la empresa, esta conclusión se contrasta con las opiniones del segmento 3 y 4 , con la que validamos que el factor de la cultura empresarial es muy fuerte en este tipo de empresas. 


\section{RECOMENDACIONES}

- La aduana debe realizar actividades para generar confianza a los usuarios y de esa manera se pueda sustentar que el criterio utilizado está fundamentado de acuerdo a las normas y procedimientos aduaneros.

- La aduana debería utilizar más herramientas tecnológicas como las redes sociales para poder difundir con mayor amplitud los beneficios de este procedimiento.

- $\quad$ Las empresas aseguradoras y entidades bancarias deben difundir con mayor énfasis las características y beneficios de la carta fianza.

- La aduana debería brindar información de las empresas más frecuentes que emiten las cartas fianzas y que no son observadas por ellos, para que los usuarios puedan estar al tanto y de esa manera no perder tiempo y no asumir sobrecostos innecesarios.

- Las empresas importadoras de textiles deberían orientarse a trabajar bajo una estructura organizacional horizontal que les permitirá fortalecer los lazos y compromisos con los colaboradores y esto se verá reflejado en modernización y actualización en los procedimientos de manera constante para beneficio de la empresa; la cultura empresarial en una empresa es importante pero si se enfoca solo en ideas y opiniones de los líderes se estancará en el crecimiento empresarial. 


\section{BIBLIOGRAFÍA}

- Asociación de Bancos del Perú (ASBANC). (2018). Carta Fianza. http://www.asbanc.com.pe [Consulta 12 de Febrero del 2018]

- Banco Central de Reserva del Perú [BCRP] (2018). Indicadores Económicos I trimestre. Recuperado de http://www.bcrp.gob.pe/docs/Estadisticas/indicadorestrimestrales.pdf [Consulta: 24 de Abril de 2018].

- Caviedes, J. (2014). Garantías previas a la numeración de la declaración, artículo $160^{\circ}$ D.Leg.1053, Procedimiento INPCFA-PE.03.06 [Presentación para la difusión del procedimiento a los usuarios y agentes de aduana]. Lima: SUNAT.

- Customs and Border Protection (CBP). (2018). Custom Bonds. https://help.cbp.gov [Consulta 20 de Marzo del 2018]

- Chiavenato, \& Mascaró Sacristán. (2007). Administración de recursos humanos (1a ed.). México, D.F.: McGraw-Hill.

- Espinoza. A (15 de Marzo del 2018). Entrevista de M. Yupan [Comunicación de correo electrónico].

- Gestión. (17 de Setiembre del 2013). Compañías aseguradoras expanden su oferta con pólizas de nicho y para pymes. Gestión. Recuperado de https://gestion.pe/economia/empresas/companias-aseguradoras-expanden-ofertapolizas-nicho-pymes-48327 [Consulta 20 de Febrero del 2018]

- Gestión (2017). Entrevista a Daniel Chávez. Cartas fianza: ¿Por qué es importante que una empresa tenga este instrumento? Recuperado de: https://gestion.pe/economia/empresas/cartas-fianza-importante-empresa-tengainstrumento-142673 [Consulta 08 de Febrero del 2018]

- Hernández Sampieri, R., Fernández Collado, C., \& Baptista, P. (2014). Metodología de la investigación. $6^{\mathrm{a}}$ ed. México D.F.: Mc Graw Hill.

- Insur S.A Compañía de Seguros (INSUR). (2018). Póliza de Caución. https://www.insur.com.pe [Consulta 18 de Febrero del 2018]

- La Positiva Seguros (LA POSITIVA). (2018). Carta Fianza. https://www.lapositiva.com.pe [Consulta 15 de Febrero del 2018] 
- Lau. J (16 de Marzo del 2018). Entrevista de F. Guillén [Comunicación de correo electrónico].

- Ministerio de comercio exterior y turismo (2011). Acuerdos comerciales.

Recuperado de: http://www.acuerdoscomerciales.gob.pe [Consulta: 08 de Febrero de 2018].

- Ministerio de la Producción [Produce] (2015). Estudio de investigación del sector textil y confecciones. Recuperado de http://demi.produce.gob.pe/images/publicaciones/publie178337159547c39d_11.pdf [Consulta: 16 de enero de 2018].

- Ministerio de Trabajo y Promoción de Empleo (MINTRA). (28 de Diciembre del 2013). Artículo 4,- Definición de la Micro y Pequeña Empresa. [Decreto Supremo $\mathrm{N}^{\circ}$ 013-2013-PRODUCE.]. Recuperado de http://www2.produce.gob.pe/dispositivos/publicaciones/ds013-2013-produce.pdf [Consulta: 14 de Enero del 2018].

- Morcillo, P. (2007). Cultura e innovación empresarial: La conexión perfecta. Madrid: Thomson.

- Muñoz, W. (2006). Perú: Tradición textil y competitividad internacional. Recuperado de https://www.ucss.edu.pe/images/fondo-editorial/publicacionesdescargables/peru-tradicion-textil-y-competitividad-internacional.pdf [Consulta: 08 de diciembre del 2016]

- Oyarse, J. (20 de Marzo del 2018). Entrevista de F. Guillén y M. Yupan [Entrevista grabada no publicada] (https://youtu.be/-XSwh4CB7Jc)

- Superintendencia Nacional de administración tributaria (SUNAT). (2018). Legislación. http://www.sunat.gob.pe [Consulta 25 de Enero del 2018].

- Superintendencia Nacional de administración tributaria (SUNAT). (2018). Legislación. Sistema de Garantías previas. Recuperado de http://www.sunat.gob.pe [Consulta 25 de Enero del 2018].

- SUNAT (2014). Garantías previas a la numeración de la declaración, artículo $160^{\circ}$ D.Leg.1053, Procedimiento INPCFA-PE.03.06 [Presentación para la difusión del procedimiento a los usuarios y agentes de aduana]. Lima: SUNAT.

- Ver Araujo Mattos, Cintya. "SADA Sistema Anticipado de Despacho Aduanero" (2013), p.13 
- Ver Aldea, Vládik. "Manual Práctico de Importación y Exportación- TCL PerúEE.UU." (2009), p.139

- Victoriano, M. (2012) Historia de la empresa. 


\section{$\underline{\text { ANEXOS }}$}

Anexo 1: Evolución del Sistema de Garantías Previas del año 2010 - 2014

De: Felix Guillen <felix.guillen@colortexperu.com.pe>

Enviado: martes, 13 de marzo de 2018 21:36

Para: feguihe@hotmail.com

Asunto: CAPACITACION DE GARANTIAS PREVIAS

De: Jorge Jalck [mailto:Jorge.Jalck@colortexperu.com.pe]

Enviado el: martes, 13 de marzo de 2018 03:09 p.m.

Para: Felix Guillen

CC: Alfredo Pinto

Asunto: RV: CAPACITACION DE GARANTIAS PREVIAS

Felix tomar nota.

De: Edgar Campos Vilcas [mailto:edgar.campos@aduamerica.net]

Enviado el: martes, 23 de Setiembre de 2014 04:00 p.m.

Para: Alfredo Pinto; Jorge Jalck

Asunto: CAPACITACION DE GARANTIAS PREVIAS

Estimado Alfredo, adjunto lo solicitado.

De: DESPACHO ASISTIDO (División de Atención al Usuario Aduanero) <despachoasistido@sunat.gob.pe>;

Enviado el: lunes, 22 de Setiembre de 2014 05:00 p.m.

Para: Edgar Campos Vilcas; CONTACTENOS_CONSULTAS ADUANERAS_INTA <contactenos@sunat.gob.pe >

Asunto: CAPACITACION DE GARANTIAS PREVIAS

Estimado Agente de Aduana:

Buenas tardes,

Con referencia a la capacitación brindada el viernes 19 de setiembre, procedemos a adjuntar el material informativo para que pueda difundir la información con las características y beneficios del sistema.

Gracias por comunicarse con nosotros, le saluda atentamente;

\section{Edgardo Villayzán Tavera}

División de Atención al Usuario Aduanero y Liberaciones Intendencia Nacional de Control Aduanero- SNNA

Av, Gamarra $N^{\circ} 680$ - Chucuito - Cala

WwW.sunat.gob.pe

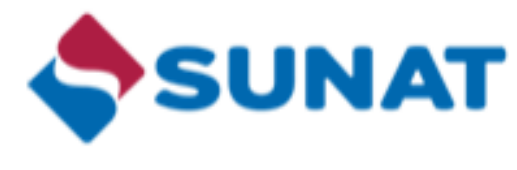



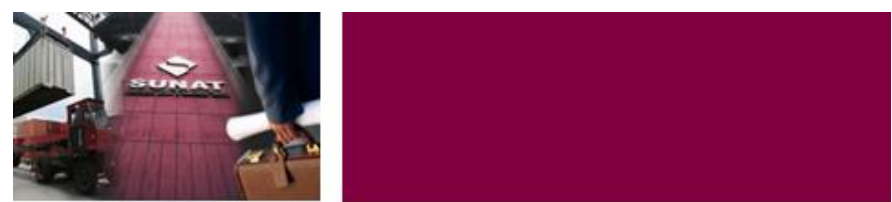

\section{GARANTIAS PREVIAS A LA NUMERACION DE LA DECLARACION \\ Articulo $160^{\circ}$ D.Leg. 1053 \\ Procedimiento INPCFA-PE.03.06}

\section{S SUNAT}

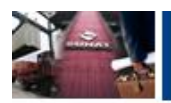

I. CARACTERISTICASY BENEFICIOS DEL MECANISMO

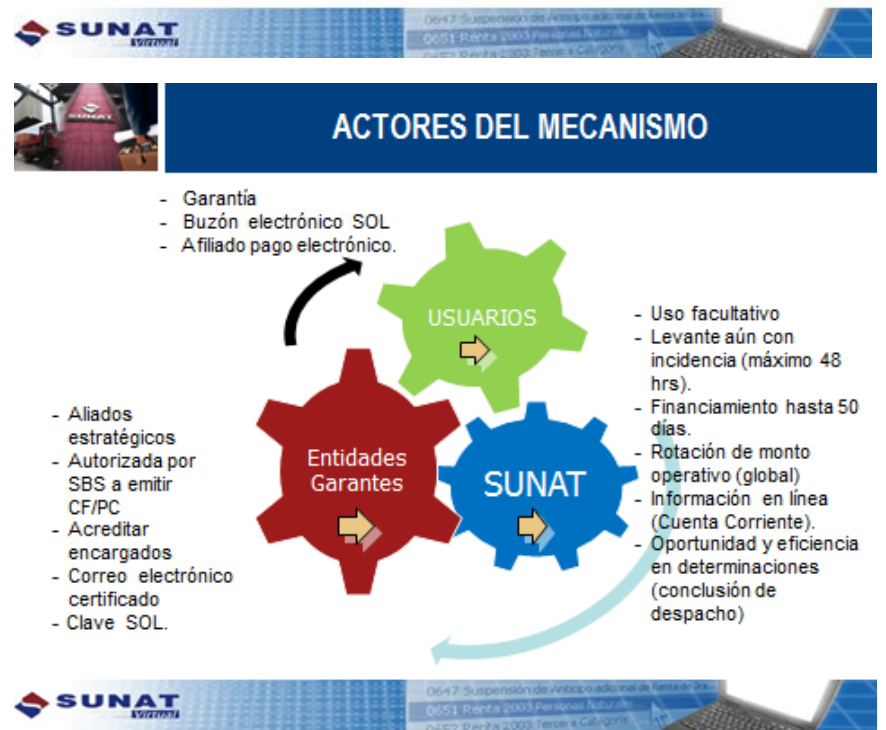




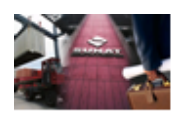

FINANCIAMIENTO

PAGO DE TRIBUTOS

DESPACHO ANTICIPADO
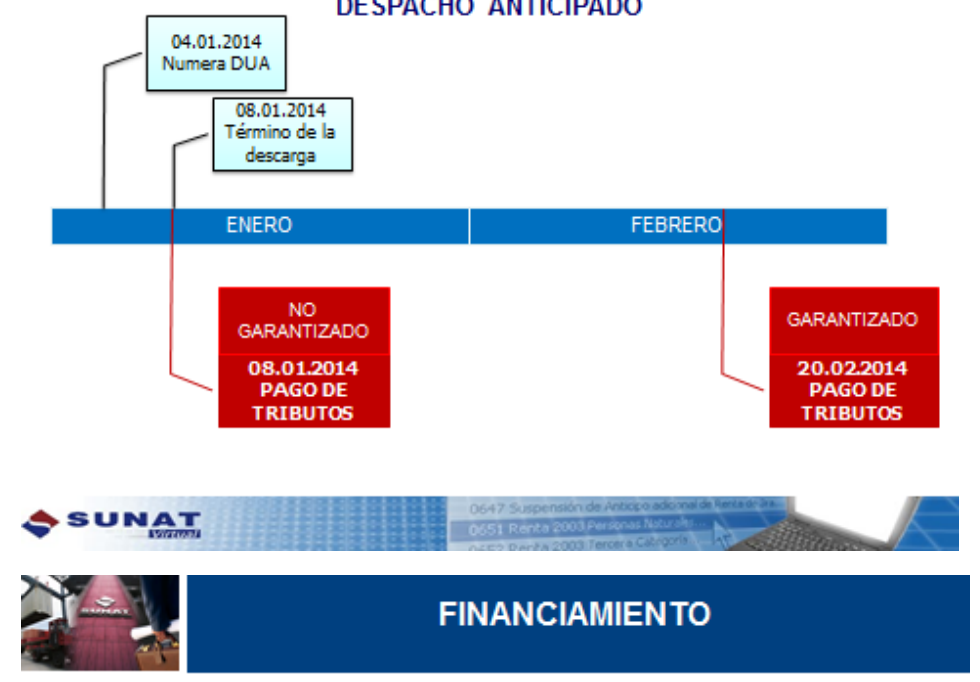

PAGO DE TRIBUTOS

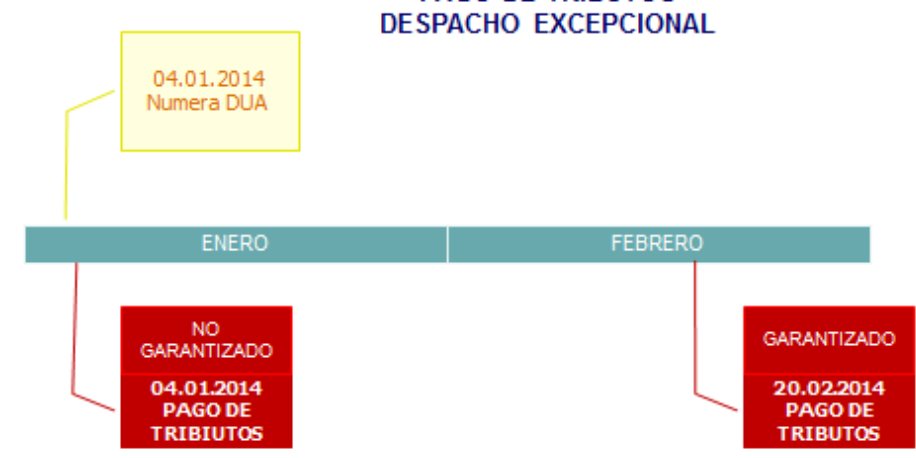

S SUNAT 


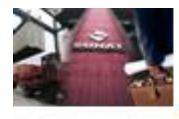

\section{USO FACULTATIVO}
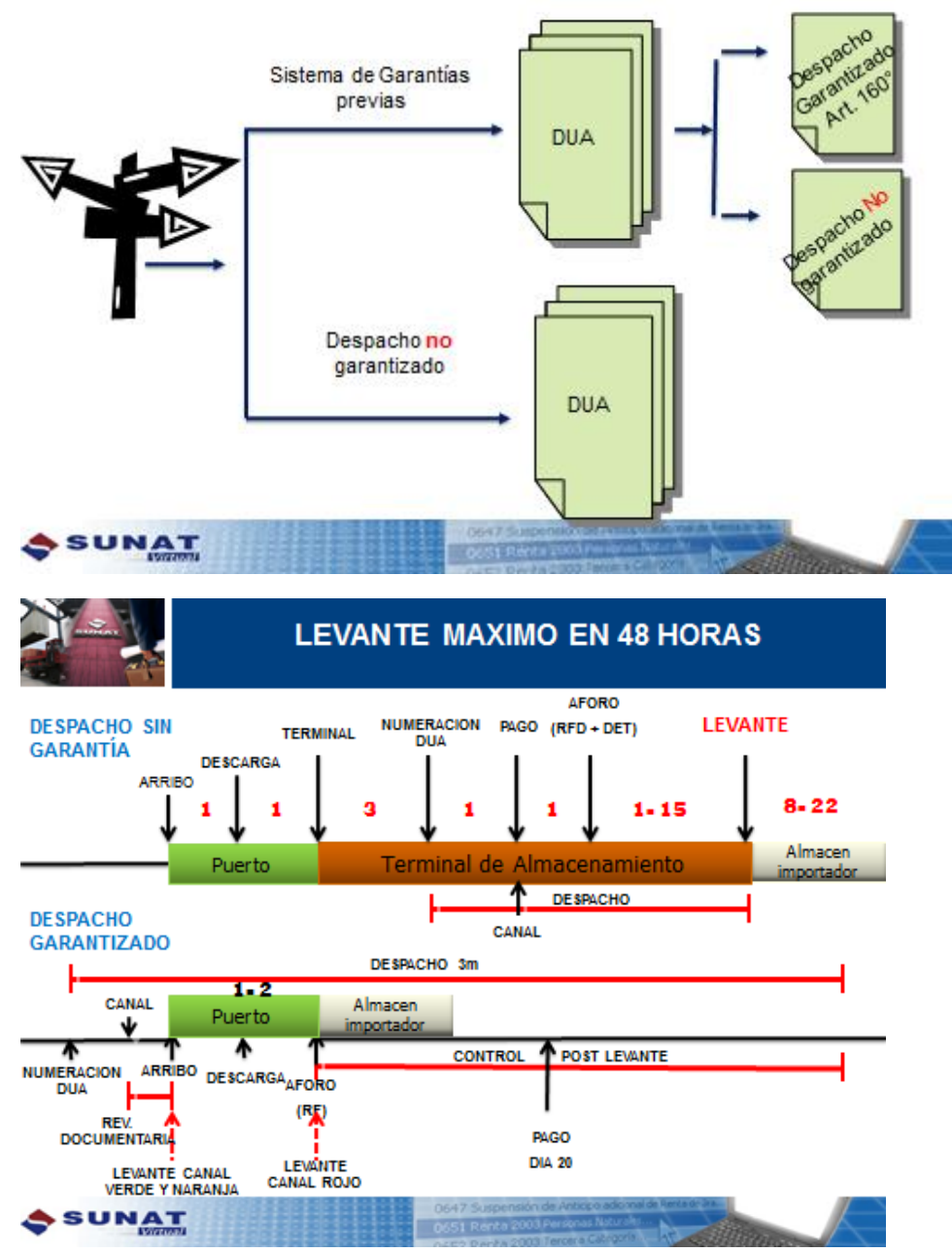

COMO ASEGURAR EL LEVANTE EN 48 HORAS

1. Contar con una garantía previa: Comisionar al Agente de Aduana para que consigne el número de la cuenta corriente en la transmisión de las DUAs que se desea garantizar.

2. Numerar declaración antes de la llegada del medio de transporte: Comisionar al agente de aduanas para que solicite que la carga salga directamente del puerto en caso de canal verde o naranja (debe dejar en blanco el campo de depósito temporal).

3.Contar con toda la documentación: Poseer las autorizaciones si se trata de mercancia restringida.

4.No se haya dispuesto sobre la mercancia medida preventiva : Inmovilización, incautación o medidas en frontera. 


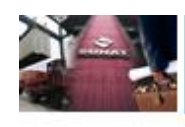

\section{OPERATIVIDAD DEL MECANISMO}

\section{S SUNAT}

AFILIARSE AL PAGO ELECTRONICO

Ssunat

SERVICIO DE PAGO ELECTRONICO

\begin{tabular}{|c|c|c|c|}
\hline \multicolumn{4}{|c|}{ 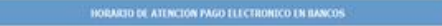 } \\
\hline$m$ & tenstume & nts & anderricosen \\
\hline $200 P$ & $\infty \times \infty, x=0$ & 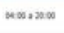 & $\infty$ \\
\hline 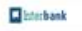 & max & wansess & แ⿻心㇒木 \\
\hline ayomones & และแ & mass & Hat:an \\
\hline Ssectiobank & mexsasp & nwoass & $\infty$ \\
\hline atibank & ะxass & $\infty$ & $\infty$ \\
\hline (7ifi & 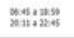 & 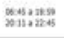 & 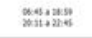 \\
\hline ๑) 19usos & axeases & แ⿻心a:s & axo, \\
\hline
\end{tabular}

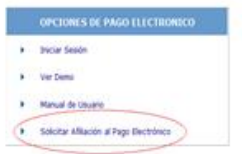

\& SUNAT

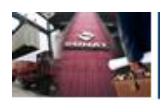

PASOS PARA INGRESAR AL SISTEMA

OBTENER EL MONTO MINIMO Y EL NUMERO DE TRÁMITE

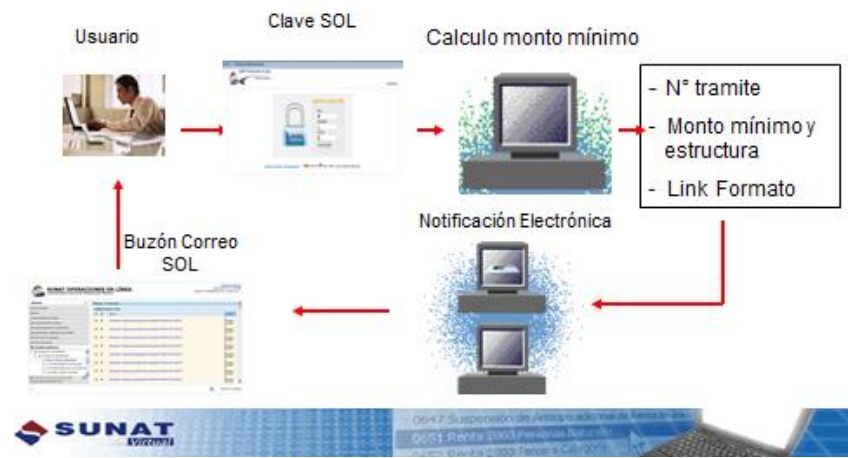



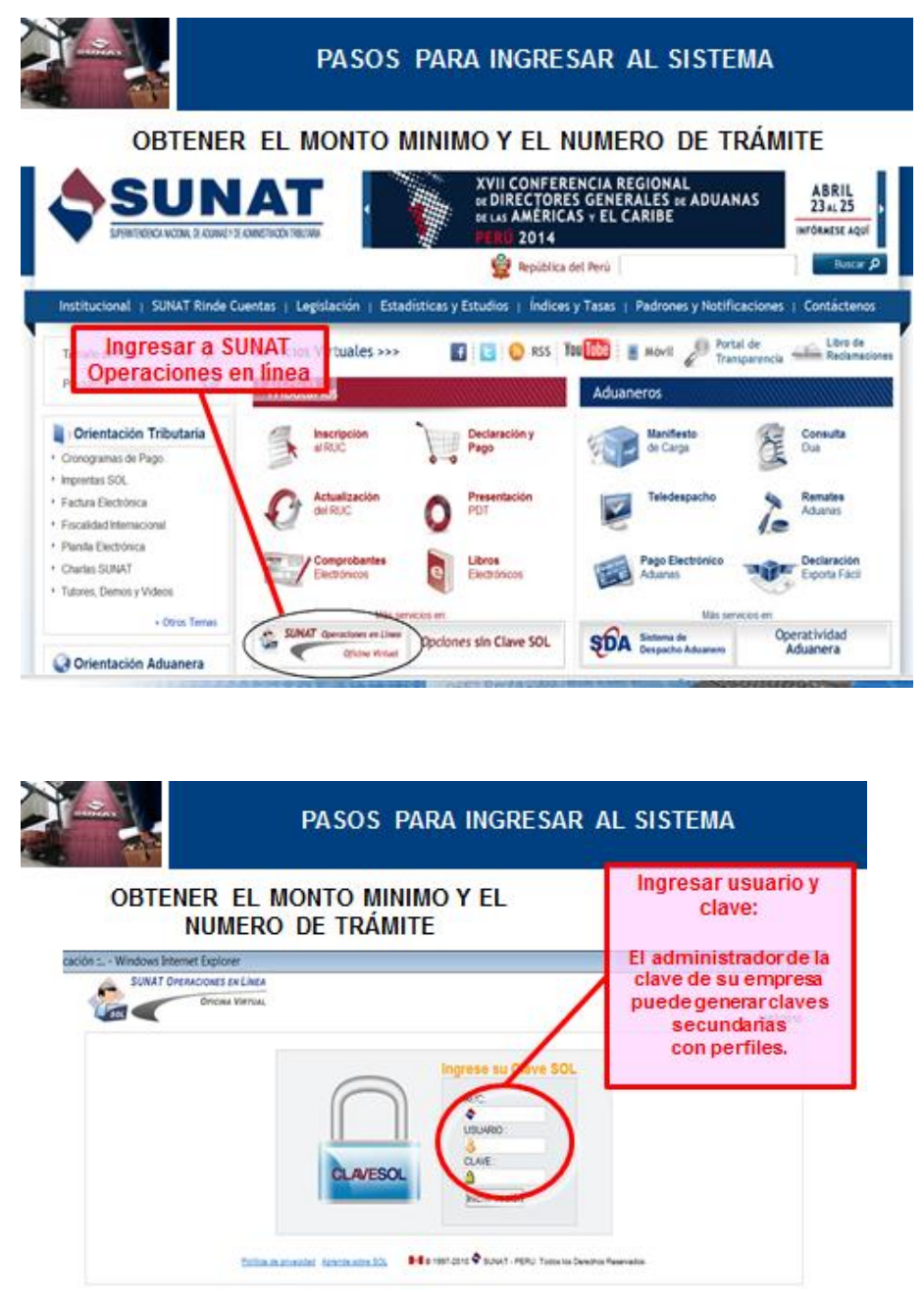
OBTENER EL MONTO MINIMO Y EL NUMERO DE TRÁMITE
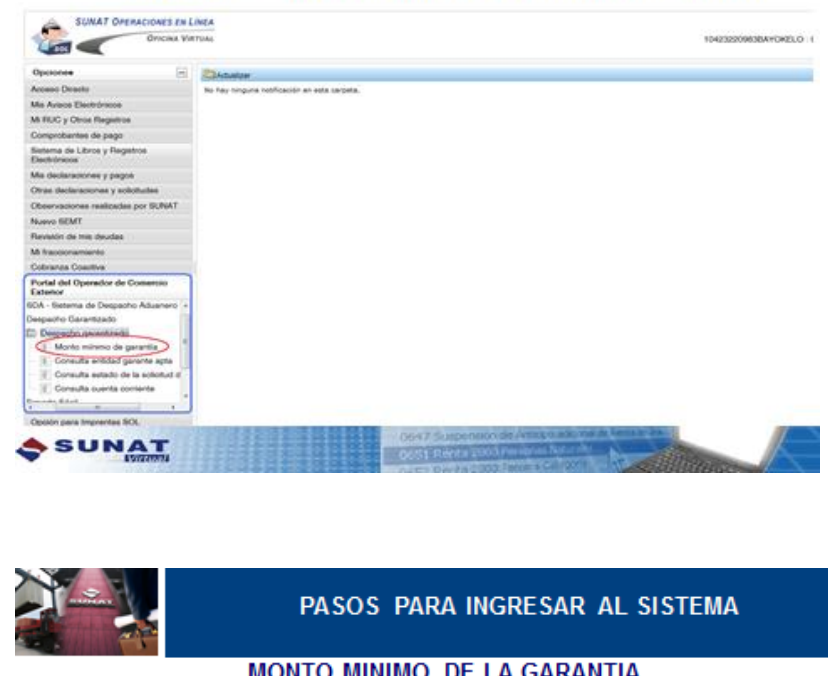

PASOS PARA INGRESAR AL SISTEMA

MONTO MINIMO DE LA GARANTIA

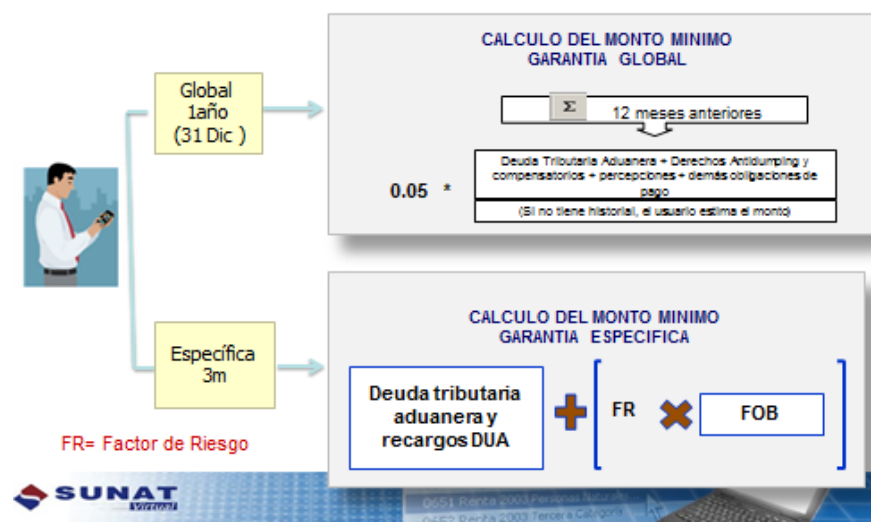

PASOS PARA INGRESAR AL SISTEMA

OBTENER EL MONTO MINIMO Y EL NUMERO DE TRÁMITE

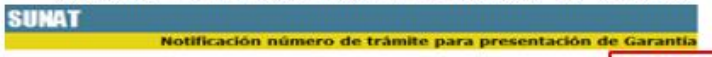

A Importadora D $\quad \begin{aligned} & 20 \text { dlas } \\ & \text { vigencla }\end{aligned}$

Focha : 22 Junio 2014

Uated ha obtenido el numero de trimite para presentación de garstio 2012 C.-FPC-00012.

El ultimo dia para la prestantación de la an

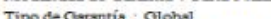

La estructura del Monto Minimo de la garantia es la siguiente.

\begin{tabular}{|l|c|c|}
\hline & (USDS) & 96 \\
\hline Monto Oporativo Minimo (MOM) & $\$ 57,735$ & 100 \\
\hline Monto de Seguridsd Mirimo (MSSM) & 0. & 0 \\
\hline Monto de Carmantia Minima (MCM) & $\$ 57,735$ & 100 \\
\hline
\end{tabular}

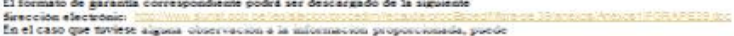

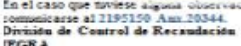

\& SUNAT 
CONTRATAR ENTIDAD GARANTE
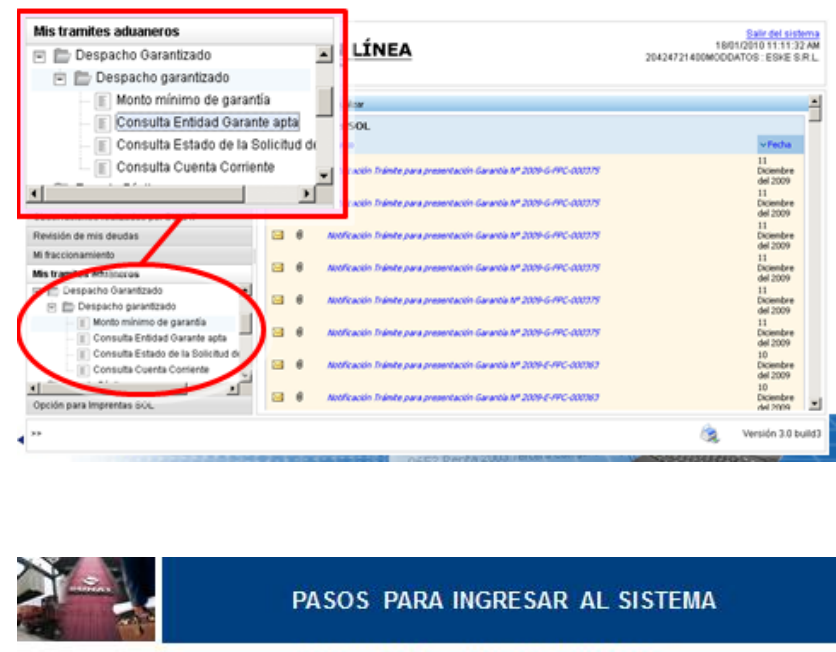

PASOS PARA INGRESAR AL SISTEMA

CONTRATAR ENTIDAD GARANTE

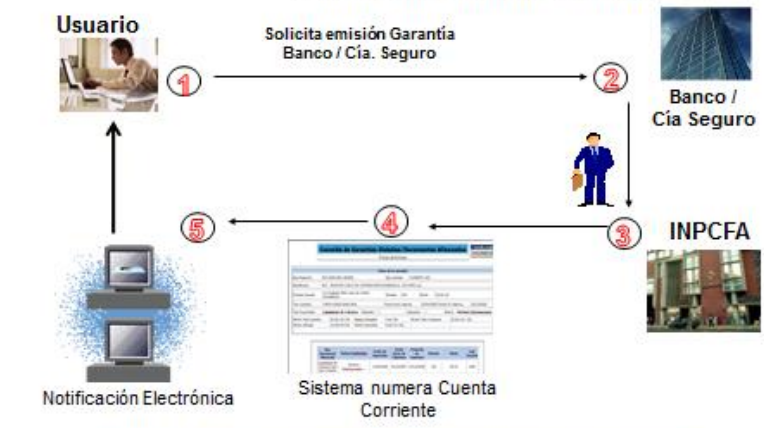

S SUNAT

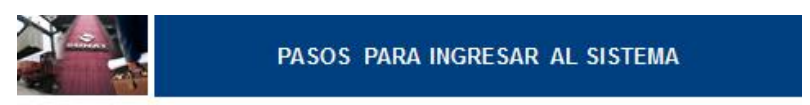

ANOTAR NUMERO DE CUENTA CORRIENTE

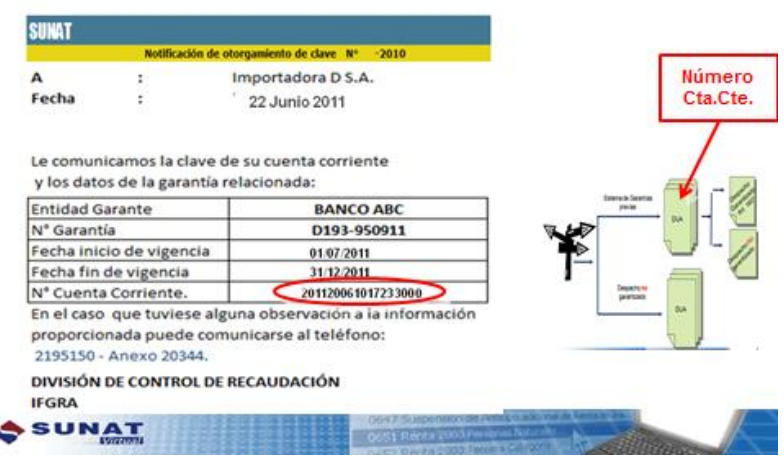


CONSULTAR LA CUENTA CORRIENTE
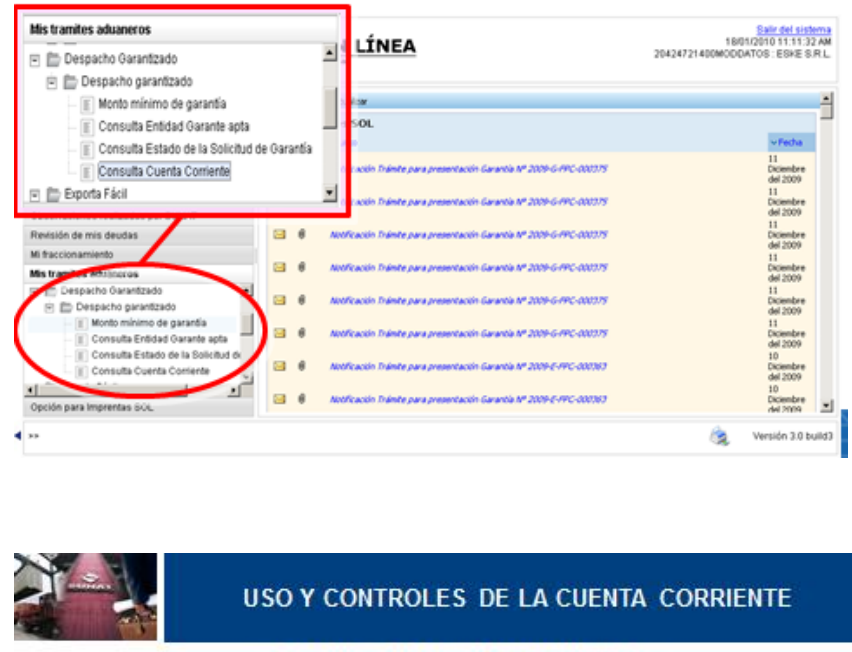

USO Y CONTROLES DE LA CUENTA CORRIENTE

\section{AFECTAR LA CUENTA CORRIENTE}

\begin{tabular}{|c|c|c|c|c|c|c|c|c|c|c|}
\hline \multicolumn{11}{|c|}{ Cuenta Comiente de la Garantia If 0193-9010040 } \\
\hline & Usuario Garantizado: & DSA & & & & eccha: & 10102: & & Hora: & 1548 \\
\hline & W' de Garantia Vig: & d3667809 & \multicolumn{6}{|c|}{ Monto Garantia: 750,000000 tiado Gara RECEPCONADA-ACEPTACON } & & \\
\hline & Fecha inicio vigencia: & 01012011 & \multicolumn{2}{|c|}{ Monto Operativo $\$ 780,000.00$} & Saldo MOP: S & $\$ 47,700.00$ & & & & \\
\hline & Fecha fin vigencia: & 31/122011 & \multicolumn{2}{|c|}{ Monto Seguridad 50.00} & Saldo MOS: S & 30.00 & & & & \\
\hline & Fecha fin renovación: & 311222011 & \multicolumn{2}{|c|}{ Selectfiscalizach 10} & & & & & & \\
\hline & \multicolumn{9}{|c|}{ Cargo } & \multirow[b]{2}{*}{$\begin{array}{l}\text { Uitimo dia } \\
\text { de pago }\end{array}$} \\
\hline 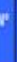 & Determinuciones & $\begin{array}{l}\text { Fecha de } \\
\text { afoctación }\end{array}$ & $\begin{array}{l}\text { Fecha de } \\
\text { conclusión }\end{array}$ & Monto S & $\begin{array}{c}\text { Intereses } \\
\text { \$ }\end{array}$ & Totals & $\begin{array}{l}\text { Monto } \\
\text { S. }\end{array}$ & $\begin{array}{l}\text { Intere } \\
\text { ses Si: }\end{array}$ & $\begin{array}{c}\text { Total } \\
5 .\end{array}$ & \\
\hline 1 & DUA 118-2011-10-002559 & $05 / 12011$ & 09022011 & $36,021.00$ & 0.00 & $36,021,00$ & & & & 200222011 \\
\hline & DUA $118.2011 \cdot 10.002570$ & $05: 0120011$ & 091022011 & 8.747 .00 & 0.00 & 8.74700 & & & & 20022011 \\
\hline 3 & DUA 118-2011-10-002657 & $05 / 01 / 2011$ & 09022011 & $6,344.00$ & 0.001 & 6,34400 & & & & 200022011 \\
\hline & OUA $118-2011-10-374655$ & $05 / 10 / 2011$ & $05001 / 2012$ & 31,25200 & 0.00 & आ,25200 & & & & $20011 / 2011$ \\
\hline 29 & DUA 118-2011-10-374730 & $05 / 102011$ & 0510120012 & $14,575.00$ & 0.000 & 14,575000 & & & & $20 / 112011$ \\
\hline 30 & OUA 118-2011-10.3777718 & $07 / 102011$ & $0901 / 2012$ & $40,955.00$ & 0.000 & $40,955,00$ & & & & $20 / 112011$ \\
\hline & DUA 118-2011-10-378231 & $07 / 102011$ & 09012012 & 51,68400 & 0.001 & $51,684,00$ & & & & $20 / 112011$ \\
\hline & DUA 118-2011-10-378237 & $07 / 102011$ & 090112012 & 3266200 & 0.001 & 37.96300 & & & & 201112011 \\
\hline & TOTALES & & & $131,108,00$ & & $7,131,10800$ & & & & \\
\hline
\end{tabular}

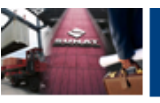

USO Y CONTROLES DE LA CUENTA CORRIENTE

DESAFCETAR LA CUENTA CORRIENTE

\begin{tabular}{|c|c|c|c|c|c|c|}
\hline \multicolumn{7}{|c|}{ Cuenta Corriente de la Garantia N" 0193-1010040 } \\
\hline \multicolumn{5}{|c|}{ Usuario Garantizac D S.A. } & \multicolumn{2}{|r|}{ 10/10/2011 } \\
\hline \multirow{2}{*}{\multicolumn{2}{|c|}{$\begin{array}{l}\text { Ne de Garantia Vig. d3667809 } \\
\text { Fecha inicio vigenc 01/01/2011 }\end{array}$}} & \multirow{2}{*}{\multicolumn{2}{|c|}{$\begin{array}{l}\text { Monto Garantia: } \$ 750,000.00 \\
\text { Monto Operativo } \$ 750,000.00\end{array}$}} & \multirow{2}{*}{\multicolumn{3}{|c|}{ Estado Garant RECEPCIONADA.ACEPTACIOI }} \\
\hline & & & & & & \\
\hline Fecha fin vigenci & 31/12/2011 & Monto Seguridac & 50.00 & Saldo MOS: & $\$ 0.00$ & \\
\hline \multicolumn{2}{|c|}{ Fecha fin renovaci $31 / 122011$} & \multicolumn{2}{|c|}{ Selecc.fiscalizaci NO } & & & \\
\hline \multirow[b]{2}{*}{$\begin{array}{l}\text { Uittimo dia de } \\
\text { pago }\end{array}$} & \multirow[b]{2}{*}{ LC reclamada } & \multicolumn{5}{|c|}{ Abono } \\
\hline & & Acción & Documento & Fecha & $\mathbf{s}$ & Sl. \\
\hline $20 / 0222011$ & & CANCELACION & & 0910222011 & $36,021.00$ & \\
\hline $20 / 0222011$ & & CANCELACION & & 0910222011 & $8,747.00$ & \\
\hline 2010222011 & & CANCEIACION & & 0910222011 & 6,34400 & \\
\hline \multicolumn{7}{|l|}{ 20/11/2011 } \\
\hline \multicolumn{7}{|l|}{$\begin{array}{l}20 / 11 / 2011 \\
20 / 112011\end{array}$} \\
\hline 20/11/2011 & & & & & & \\
\hline \multicolumn{7}{|l|}{$20 / 11 / 2011$} \\
\hline \multirow{2}{*}{\multicolumn{7}{|c|}{ 20/11/2011 }} \\
\hline & & & & & $6,428,959.00$ & \\
\hline
\end{tabular}

S SUNAT 
CUENTA UNICA MENSUAL

El día 20 de cada mes aparecerá la siguiente ventana mostrando la Cuenta Única Mensual

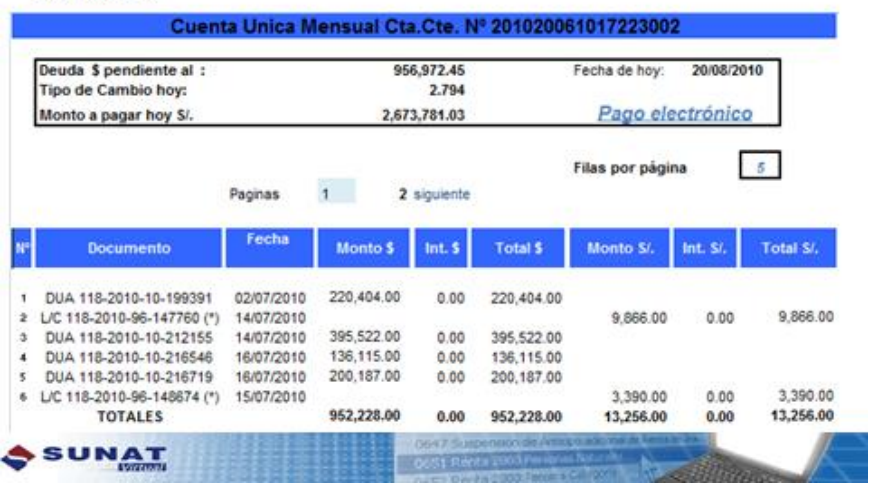

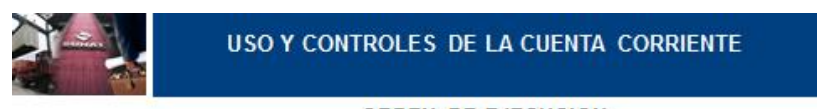

ORDEN DE EJECUCION

La orden de ejecución se genere automáticamente el día 21 si no se pagó la cuenta mensual

ORDEN DE EJECUCIÓN Cta.Cte. Nº 201020061017223002

\begin{tabular}{|c|c|c|}
\hline $\begin{array}{l}\text { Deuda } 5 \text { pendiente al : } \\
\text { Tipo de Cambio hoy: }\end{array}$ & $\begin{array}{r}957,193.54 \\
2.794\end{array}$ & Fecha de hoy: 210082010 \\
\hline Monto a pagar hoy s. & $2,674,398.75$ & Pago electrónico \\
\hline
\end{tabular}

$0.0243 \quad$ Filas por página 5

$0.0507 \quad$ Paghas 1,2 siguente

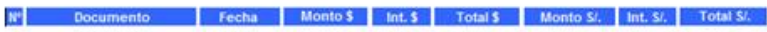

1. DUA $118-2010-10-199391 \quad 0207072010 \quad 220,404.00 \quad 53.56 \quad 220,457.56$

$9.86600 \quad 500 \quad 9.87100$

DUA 118-2010-10-212155 $14,072010 \quad 395,522.00 \quad 96.11 \quad 395,618.11$

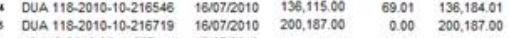

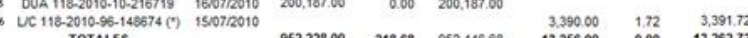

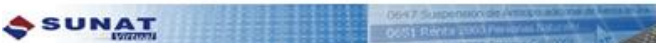

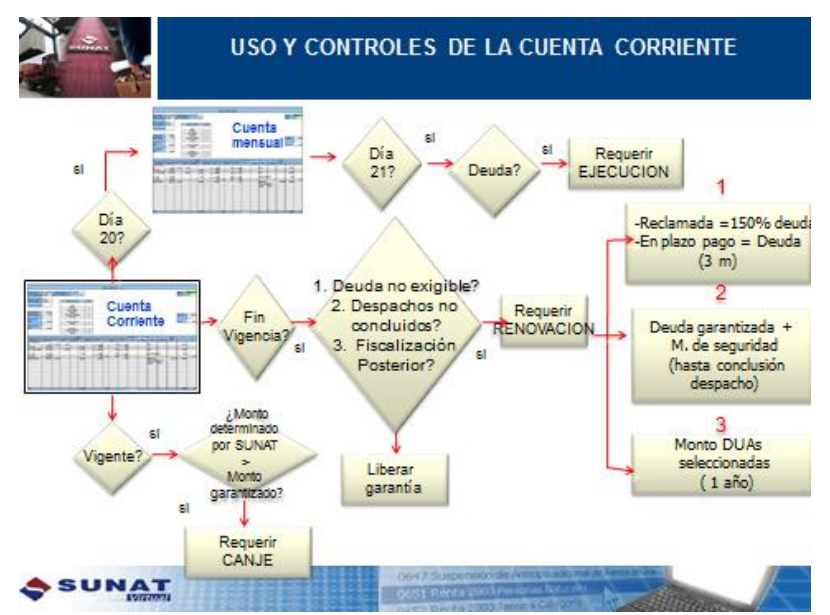



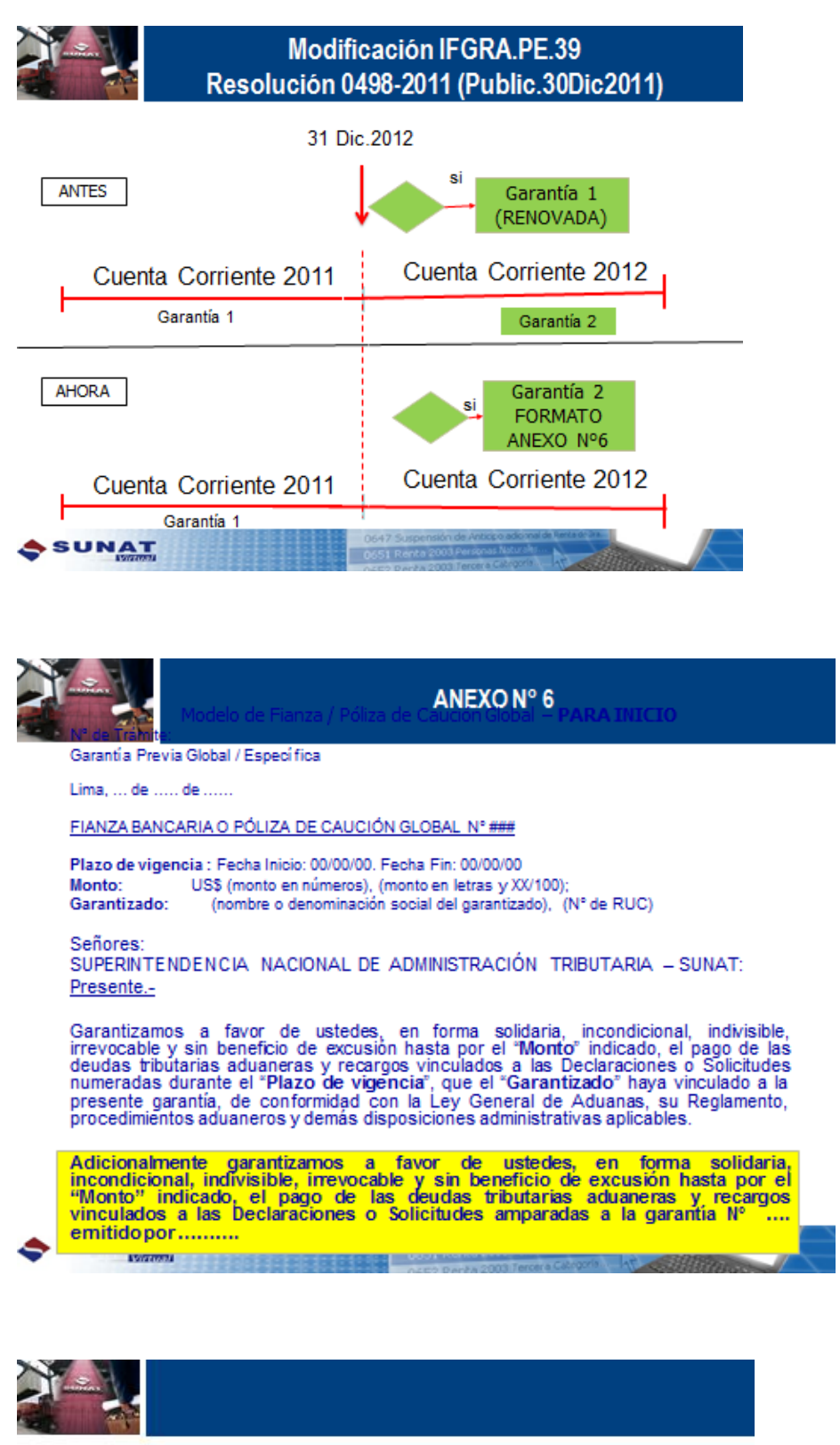

III. EVOLUCION Y SITUACION ACTUAL DEL SISTEMA DE GARANTIAS PREVIAS 


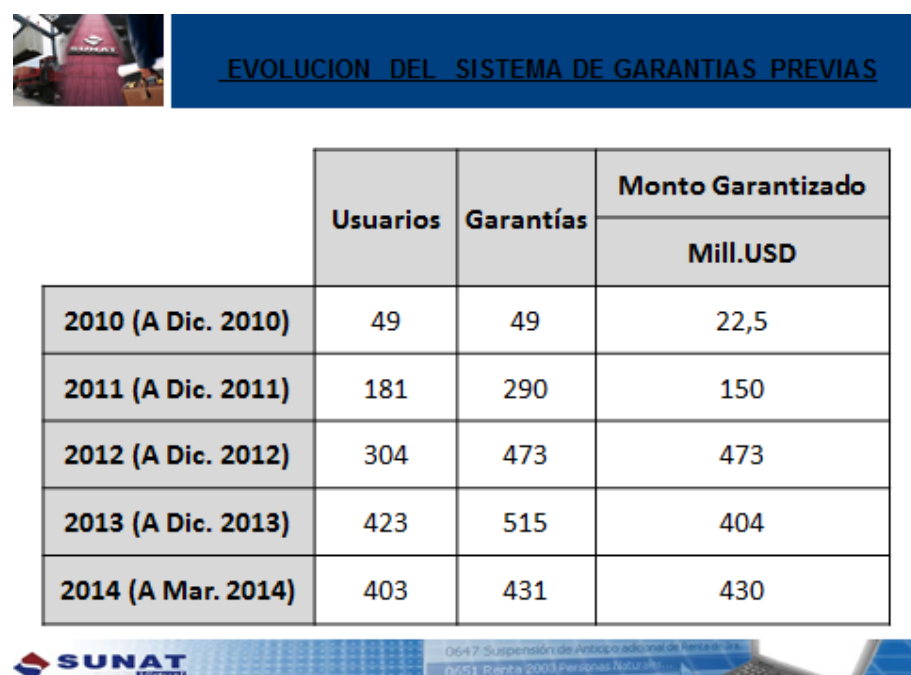

Lista de usuarios

\begin{tabular}{|c|c|c|c|}
\hline NRO. & RAZON SOCIAL & NRO. & RAZON SOCIAL \\
\hline 1 & PETRO PERU & 21 & QUIMTIA SA \\
\hline 2 & FERREYROS S.A & 22 & MINERA CHINALCO PERU S.A. \\
\hline 3 & SAMSUNG ELECTRONICS PERU S.A.C. & 23 & COMPAÑÍA GOODYEAR DEL PERU S.A \\
\hline 4 & DIVEIMPORT S.A. & 24 & HIPERMERCADOS TOTTUS SA \\
\hline 5 & ALICORP S.A.A. & 25 & GRUPO DELTRON \\
\hline 6 & KIMBERLY CLARK PERU SRL & 26 & MINERA YANACOCCHA S.R.L. \\
\hline 7 & BRITISH AMERICAN TOBACCO DEL PERU HOLDINGS SAA & 27 & SIEMENS SAC \\
\hline 8 & KOMATSU MITSUI MAQUINARIAS PERU S.A. & 28 & CORPORACION LINDLEY S.A. \\
\hline 9 & SAGA FALABELLA SA & 29 & HASBRO PERU S.R.L. \\
\hline 10 & XSTRATA LAS BAMBAS S.A. & 30 & VOLVO PERU S.A. \\
\hline 11 & AUTOMOTORES GILDEMEISTER PERU SA & 31 & ABB S.A. \\
\hline 12 & AMERICA MOVIL PERU S.A.C. & 32 & TRADING FASHION LINE S.A. \\
\hline 13 & DERCO PERU S.A. & 33 & AJEPER SA \\
\hline 14 & LG ELECTRONICS PERU SA & 34 & COMPAÑIA MINERA ANTAPACCAY S.A. \\
\hline 15 & OPP Film S.A & 35 & PHILIPS PERUANA S.A \\
\hline 16 & SOCIEDAD MINERA CERRO VERDE SAA & 36 & UNIQUE S.A. \\
\hline 17 & GLORIA S.A. & 37 & CELISTICS PERU S.A.C. \\
\hline 18 & UNIMAQ S.A. & 38 & COMPAÑÍA MINERA MISKI MAYO S.R.L. \\
\hline 19 & ABENGOA PERU S.A. & 39 & PERUPLAST SA \\
\hline 20 & CORPORACION ACEROS AREQUIPA S.A. & & \\
\hline
\end{tabular}




\begin{tabular}{|c|l|c|l|}
\hline NRO. & \multicolumn{1}{|c|}{ RAZON SOCIAL } & NRO. & \multicolumn{1}{|c|}{ RAZON SOCIAL } \\
\hline 40 & PANASONIC PERUANA S.A. & 59 & MAXIMA INTERNACIIONAL S.A. \\
\hline 41 & ATLAS COPCO PERUANA S.A. & 60 & PERUFARMA S.A. \\
\hline 42 & TRUPAL S.A & 61 & MAQUINARIA NACIONAL SA PERU \\
\hline & & 62 & $\begin{array}{l}\text { MOTORED SOCIEDAD ANONIMA- } \\
\text { MOTORED SA }\end{array}$ \\
\hline 43 & IASACORP INTERNATIONAL SA & 63 & MOTORES DIESEL ANDINOS S.A. \\
\hline 44 & A. W. FABER CASTELL PERUANA S.A. & 64 & HEWLETT PACKARD PERU S.R.L. \\
\hline 46 & PLUSPETROL PERU CORPORATION S.A. & 65 & PRODUCTOS AVON S.A. \\
\hline 47 & TIENDAS POR DEPARTAMENTOS RIPLEY S.A & 66 & PAPELERA NACIONAL SA \\
\hline 48 & YRICA CHEMICALS PERU S.A.C. & 67 & G.W. YICHANG \& CIA S.A. \\
\hline 49 & POLINPLAST S.A.C. & 68 & PRAXIS COMERCIAL S.A.C. \\
\hline 50 & TRACTO CAMIONES USA EIRL & 69 & G Y M S.A. \\
\hline 51 & NEXTEL PERU S.A. & 70 & INGRAM MICRO PERU S.A. \\
\hline & & & ADIDAS CHILE LTD SUCURSAL DEL \\
\hline 52 & VICCO S.A. & 71 & PERU \\
\hline 53 & COLGATE PALMOLIVE PERU SA & 72 & SODIMAC PERU SA \\
\hline 54 & QUIMICA SUIZA INDUSTRIAL DEL PERU S.A. & 73 & UNILEVER ANDINA PERU S.A. \\
\hline 55 & SUDAMERICANA DE FIBRAS & 74 & SUPERMERCADOS PERUANOS \\
\hline 56 & MONTANA S.A. & 75 & INTCOMEX PERU SAC \\
\hline 57 & MOTOR MUNDO SA & 76 & MAESTRO PERU SA \\
\hline 58 & DISTRIBUIDORA CUMMINS PERU S.A.C. & & \\
\hline
\end{tabular}

\begin{tabular}{|c|l|r|l|}
\hline NRO. & RAZON SOCIAL & NRO. & RAZON SOCIAL \\
\hline 77 & \multicolumn{1}{|c|}{ INDUSTRIAS TEAL S.A. } & 97 & \multicolumn{1}{|c|}{ LOREAL PERU S.A. } \\
\hline 78 & MOLINERA INCA S.A. & 98 & BRENNTAG PERU S.A.C \\
\hline 79 & CETCO S.A. & 99 & $\begin{array}{l}\text { INVERSIONES E IMPORTACIONES } \\
\text { PIEL S.A.C }\end{array}$ \\
\hline 80 & TIENDAS PERUANAS S.A. & 100 & $\begin{array}{l}\text { COMPAÑÍA MINERA ANTAMINA } \\
\text { S.A. }\end{array}$ \\
\hline 81 & AMCOR RIGID PLASTICS DEL PERU S.A. & 101 & LIMA CAUCHO S.A. \\
\hline 82 & PERUANA DE MOLDEADOS SA & 102 & EMUSA SAC \\
\hline 83 & YAMAHA MOTOR DEL PERU S.A. & 103 & TEVA PERU S.A. \\
\hline 84 & B. BRAUN MEDICAL PERU S.A. & 104 & NEXUS TECHNOLOGY SAC \\
\hline 85 & TRANSMERQUIM DEL PERU S.A. & 105 & FARMINDUSTRIA SA \\
\hline & & 106 & $\begin{array}{l}\text { HERRAMIENTAS Y ACCESORIOS } \\
\text { S.A.C }\end{array}$ \\
\hline 86 & VULCO PÉRU S.A. & 107 & MOTA ENGIL PERU S.A. \\
\hline 87 & PRECOR SA & 108 & DELL PERU SAC \\
\hline 88 & CENCOSUD RETAIL PERU S.A. & 109 & ASCENSORES SCHINDLER DEL PERU \\
\hline 89 & SCHENEIDER ELECTRIC PERU S.A. &
\end{tabular}




\begin{tabular}{|c|l|l|l|} 
& & & S.A. \\
\hline 90 & J.CH. COMERCIAL S.A. & 110 & $\begin{array}{l}\text { CORPORACION DE VIDRIOS Y } \\
\text { ALUMINIOS CORRALES SAC }\end{array}$ \\
\hline 91 & SANDVIK DEL PERU S.A. & 111 & IPESA SAC \\
\hline 92 & IBEROAMERICANA DE PLASTICOS S.A.C. & 112 & MERCK PERUANA S.A \\
\hline 93 & TRITON TRADING S.A & 113 & $\begin{array}{l}\text { OVERSEAS SUCURSAL DEL PERU } \\
\text { SECHTEL INC.- }\end{array}$ \\
\hline 94 & OSTER DEL PERU S.A.C. & 114 & CUBIX PERU SAC \\
\hline 95 & CEMENTO SUR SA & & \\
\hline 96 & PLUSPETROL NORTE S.A. & & \\
\hline
\end{tabular}

\begin{tabular}{|c|c|c|c|}
\hline NRO. & RAZON SOCIAL & NRO. & RAZON SOCIAL \\
\hline 115 & SAN BARTOLOME SA & 134 & FARMEX S.A. \\
\hline 116 & PTS S.A. & 135 & QUIMICA ANDERS S.A.C. \\
\hline 117 & ORVISA S.A. & 136 & $\begin{array}{l}\text { ROCWELL AUTOMATION DE PERU } \\
\text { S.A. }\end{array}$ \\
\hline 118 & TAI LOY S.A & 137 & $\begin{array}{l}\text { INVERSIONES DINAMICAS M\&W } \\
\text { S.A. }\end{array}$ \\
\hline 119 & SAVIA PERU S.A. & 138 & HOUSEMART PERU SAC \\
\hline 120 & TEXTILES OLINDA S.A.C. & 139 & $\begin{array}{l}\text { JOHNSON \& JOHNSON DEL PERU } \\
\text { S.A. }\end{array}$ \\
\hline 121 & COLCA DEL PERU SA & 140 & $\begin{array}{l}\text { PACKAGING PRODUCTS DEL PERU } \\
\text { SA }\end{array}$ \\
\hline 122 & CAMPOSOL S.A & 141 & IBEROTEX S.AC. \\
\hline 123 & COMERCIAL INDUSTRIAL DELTA S.A. & 142 & SOCIEDAD AGRICOLA DROKASA S.A \\
\hline 124 & LAIVE S.A. & 143 & OREGON FOODS S.A.C. \\
\hline 125 & LINEA PLASTICA PERU S.A. & 144 & $\begin{array}{l}\text { COMPAÑÍA } \\
\text { PROSEGUR S.A. }\end{array}$ \\
\hline 126 & NOVARTIS BIOSCIENCES PERU S.A. & 145 & ROCA SAC \\
\hline 127 & MERCANTIL COMMODITY S.A.C. & 146 & AJEPER DEL ORENTE S.A. \\
\hline 128 & DRUPREE VENTAS DIRECTAS S.A. & 147 & NOVOAUTOS S.A. \\
\hline 129 & MULTITOP S.A.C. & 148 & OPTICAS GMO PERU \\
\hline 130 & GLOBALPLAST SAC & 149 & KROTON SAC \\
\hline 131 & UNION YCHICAWA SA & 150 & TECHINT S.A.C. \\
\hline 132 & A. JAIME ROJAS REPRESENTACIONES GENERALES & 151 & REPRESENTACIONES \\
\hline
\end{tabular}




\begin{tabular}{|l|l|c|l|} 
& S.A. & & DISTRIBUICIONES IVER \\
\hline \multirow{2}{*}{133} & $\begin{array}{l}\text { HERSIL S.A LABORATORIOS INDUSTRIALES } \\
\text { FARMACEUTICO }\end{array}$ & 152 & SCHLUMBERGER DEL PERU S.A. \\
\hline
\end{tabular}

\begin{tabular}{|c|c|c|c|}
\hline NRO. & RAZON SOCIAL & NRO. & RAZON SOCIAL \\
\hline 153 & E \& M S.R.L. & 173 & MERCANTIL LABORATORIOS S.A.C. \\
\hline 154 & G. O. TRADERS S.A. & 174 & MATHIESEN PERU S.A.C. \\
\hline 155 & DIAMOND CORPORACION S.A. & 175 & 3M PERU S.A \\
\hline 156 & EDEGEL SAA & 176 & $\begin{array}{l}\text { ALCON PHARMACEUTICAL DEL } \\
\text { PERU S.A. }\end{array}$ \\
\hline 157 & MERCANTIL S.A. & 177 & HUANCATEX S.A.C. \\
\hline 158 & COMPAÑÍA REFINADORA DEL PACIFICO S.A.C. & 178 & TEXTILES OLINDA SAC \\
\hline 159 & STENICA S.A. & 179 & GRAINGER PERU SRL \\
\hline 160 & IMPORT \& EXPORT RODOTEX SAC & 180 & INCA SUGAR SAC \\
\hline 161 & GAS NATURAL DE LIMA Y CALLAO & 181 & LAFRANCOL PERU S.R.L. \\
\hline 162 & INDURA PERU S.A. & 182 & TRICORZO SA \\
\hline 163 & COMEXA COMERCIALIZADORA EXTRANJERA S.A & 183 & TEXCORP S.A.C. \\
\hline 164 & SCHUBERT COMPANY S.A.C. & 184 & TECNO FAST ATCO SAC \\
\hline 165 & RUMI IMPORT SA & 185 & $\begin{array}{l}\text { CORPORACION DE INVERSION Y } \\
\text { SERVICIOS S.A.C. }\end{array}$ \\
\hline 166 & REPRESENTACIONES MARTIN SAC & 186 & \begin{tabular}{|l} 
MANUFACTURAS INDUSTRIALES \\
MENDOZA S.A.
\end{tabular} \\
\hline 167 & GULDA \& CIA S.A.C. & 187 & VIPLASTIC PERU S.A. \\
\hline 168 & $\begin{array}{l}\text { EMPRESA DE DISTRIBUCION ELECTRICA DE LIMA } \\
\text { NORTE SAA }\end{array}$ & 188 & RENZO COSTA S.A.C \\
\hline 169 & ELECTRO FERRO CENTRO S.A.C. & 189 & EUROFHARMA EUFHA S.A.C. \\
\hline 170 & IMPULSO INFORMATICO S.A. & 190 & TOPSA PRODUCTOS OPTICOS S.A. \\
\hline 171 & PERU LYCRA SAC & 191 & POLINSUMOS SA \\
\hline 172 & C.A.M.E. CONTRATISTAS Y SERV. GENERALES S.A. & & \\
\hline
\end{tabular}

\begin{tabular}{|c|l|c|c|}
\hline NRO. & RAZON SOCIAL & NRO. & RAZON SOCIAL \\
\hline 192 & XYLEM WATER SOLUTIONS PERU S.A. & 212 & P.S.V. CONSTRUCTORES S.A. \\
\hline 193 & CONSTRUCTEK S.A. & 213 & OUTEC (PERU) S.A.C. \\
\hline
\end{tabular}




\begin{tabular}{|c|l|c|l|}
\hline 194 & COMERCIAL TEXTIL S.A. & 214 & SISTEMAS ANALITICOS S.R.L \\
\hline 195 & CHEMSUPPLY SA.C. & 215 & INDUSTRIAS GABUTEAU S.A. \\
\hline 196 & ELKA RETAIL DEL PERU SAC & 216 & NOVUS PERU S.R.L \\
\hline 197 & COVIDIEN PERU S.A. & 217 & COINREFRI AIR SAC \\
\hline 198 & E. WONG S.A. & 218 & $\begin{array}{l}\text { BOMBAS TECNOLOGICAS Y } \\
\text { SERVICIOS EIRL }\end{array}$ \\
\hline 199 & TEXTILES JACKELINE SAC & 219 & $\begin{array}{l}\text { CONSTRUCCIONES METALICAS } \\
\text { UNION S.A. }\end{array}$ \\
\hline 200 & LA LLAVE S.A. & 220 & $\begin{array}{l}\text { CANA DYNE EQUIPMENT AND } \\
\text { SERVICE S.A. }\end{array}$ \\
\hline 201 & CORPORACION DE INGENIERIA DE REFRIGERACION & 221 & SHURTAPE PERU S.A. \\
\hline 202 & HIDROSTAL S.A. & 222 & MAKRO SUPERMAYORISTA S.A. \\
\hline 203 & OSRAM DE PERU S.A.C. & 223 & CLARIANT PERU S.A. \\
\hline 204 & GYPLACPERU S.A.C. & 224 & INVERSIONES FLOTEX SAC \\
\hline 205 & TEDITEX SAC & 225 & IZA MOTORS PERU SAC \\
\hline 206 & INVERSIONES VETERINARIAS S.A. & 226 & RIVELSA S.R.L. \\
\hline 207 & CAMS SAC & 227 & GENOVA STAR E.I.R.L \\
\hline 208 & FABRICA PERUANA ETERNIT S.A. & $\begin{array}{l}\text { PRODUCTOS PARA TAPICERIA Y } \\
\text { COLCHONERIA SAC }\end{array}$ \\
\hline 209 & ALITECNO S.A. & 228 & $\begin{array}{l}\text { GRAFIMUNDO ETIQUETAS PAPELES } \\
\text { Y AUTOADHESIVOS SA. }\end{array}$ \\
\hline 210 & FIBRAS MARINAS S.A. & 230 & $\begin{array}{l}\text { Total GRAFIMUNDO ETIQUETAS } \\
\text { PAPELES Y AUTOADHESIVOS SA. }\end{array}$ \\
\hline 211 & INVERSIONES JOCEMA S.A.C & 231 & CAYMAN S.A.C. \\
\hline
\end{tabular}

\begin{tabular}{|c|l|c|l|}
\hline NRO. & RAZON SOCIAL & NRO. & RAZON SOCIAL \\
\hline 232 & \multicolumn{1}{|c|}{ LUCI TEXTIL S.A.C. } & 252 & \multicolumn{1}{|l|}{ GRUPO LIDER JRMBK S.A.C. } \\
\hline 233 & GLOBAL SOURCING S.A. & 253 & CONSORCIO UCAYALI \\
\hline 234 & SRK SOCIEDAD ANONIMA CERRADA SAC & 254 & TRACUSA E.I.R.L. \\
\hline 235 & $\begin{array}{l}\text { COMERCIO E INDUSTRIA DENTAL TARRILLO BARBA } \\
\text { S.A.C. }\end{array}$ & 255 & COSI COSAS S.R.L. \\
\hline 236 & COMERCIAL INDUSTRIAL SELVA S.A & 256 & $\begin{array}{l}\text { ALIMENTOS YG SERVICIOS } \\
\text { AGROPECUARIOS S.R.L. }\end{array}$ \\
\hline 237 & CIA. INDUSTRIAL CONTINENTAL S.R.L. & 257 & DISTRIBUIDORA MARYSABEL SAC \\
\hline 238 & GASEI PERU S.A.C. & 258 & HEADMARK CORPORATION S.A.C. \\
\hline 239 & TENMINSTE S.A.C. & 259 & UNLIMITED SYSTEMS SAC \\
\hline 240 & TOPSA RETAIL SA.C. & 260 & ENVASES INDUSTRIALES SA \\
\hline 241 & SANICENTER SAC & 261 & BROCATTI SAC \\
\hline
\end{tabular}




\begin{tabular}{|l|l|l|l|}
242 & CORPORACION CAYMAN SAC & 262 & PROFIANDINA PERU S.A. \\
\hline 243 & MONTACARGAS ZAPLER S.R.L & 263 & VITALIS PERU S.A.C. \\
\hline 244 & MERCANTIL LABORATORIO S.A.C. & 264 & CORPORACION CEMENTERA SAC \\
\hline 245 & SAMITEX S.A & 265 & GRUPO CAZA SAC \\
\hline 246 & ARUNTANI S.A.C. & 266 & INDUSTRIAL CONTROLS SAC \\
\hline 247 & EECOL ELECTRIC PERU S.A.C. & 267 & SOCIEDAD AGRICOLA VIRU S.A. \\
\hline 248 & DECORLUX SAC & 268 & CORPORACION JOCEMA S.A.C \\
\hline 249 & IBEROHOGAR SAC & 269 & ENERQUIMICA S.A.C \\
\hline \multirow{2}{*}{250} & AVERY DENNISON RETAIL INFORMATION SERVICES & \multirow{2}{*}{270} & MICHELLE BELAU S.A.C. \\
\hline \multirow{2}{*}{251} & PERU S.A.C. & & \\
\hline
\end{tabular}

\begin{tabular}{|c|c|c|c|}
\hline NRO. & RAZON SOCIAL & NRO. & RAZON SOCIAL \\
\hline 271 & VIBROREX E.I.R.L. & 291 & VETERQUIMICA PERU S.A.C. \\
\hline 272 & PROVEEDORES MINEROS S.A.C. & 292 & IMPORT EXPORT YOMICO S.A.C. \\
\hline 273 & CECOSAMI SA & 293 & PAPELERA LIZ SAC \\
\hline 274 & INDUBRAS S.A.C & 294 & ARES PERU SAC \\
\hline 275 & ENERQUIMICA SOCIEDAD ANONIMA CERRADA & 295 & VENTCORP PERU SAC \\
\hline 276 & MONTREAL IMPORTACIONES S.A.C. & 296 & EMPRESA ELECTRICA DE PIURA SA \\
\hline 277 & AGP PERU S.A.C. & 297 & SAN JORGE MODA S.A.C. \\
\hline 278 & SEGURINDUSTRIA S.A. & 298 & ICATOM S.A. \\
\hline 279 & ASYM INDUSTRIAL SAC & 299 & SATRA PERU SAC \\
\hline 280 & PROSEGUR ACTIVA PERU S.A. & 300 & ESTABLECIMIENTOS INCA S.A.C. \\
\hline 281 & PERUMOTOS EIRL & 301 & HALION INTERNATINAL S.A. \\
\hline 282 & CORPORACION MARA SA & 302 & IMPORT TEXTIL ROSSY CIELO SAC \\
\hline 283 & LABOCER S.A. & 303 & BEST INTERNATIONAL S.A.C. \\
\hline 284 & VIDEO BROADCAST S.A. & 304 & $\begin{array}{lll}\text { CORPORACION TEXTIL ICHIBAN } \\
\text { SAC }\end{array}$ \\
\hline 285 & VISTAMODA PERU S.A.C. & 305 & PIPING INDUSTRIAL S.A.C. \\
\hline 286 & CO. ESTRELLA DEL PERU SAC & 306 & $\begin{array}{lll}\text { TMC } & \text { TRIVEÑO } & \text { MERCURY } \\
\text { CORPORATION EIRL } & \\
\end{array}$ \\
\hline 287 & INVERSIONES FASHION HOUSE SAC & 307 & PAPELSA S.A. \\
\hline 288 & BORDEN SAC & 308 & $\begin{array}{l}\text { MULTIVAC CHILE SUCURSAL DEL } \\
\text { PERU }\end{array}$ \\
\hline 289 & IMPORTADORA Y DISTRIBUIDORA LA FERIA SRL & 309 & UNITRADE S.A.C. \\
\hline 290 & HSC TEX EIRL & 310 & KATALINA TEXTIL SAC \\
\hline
\end{tabular}




\begin{tabular}{|c|l|c|l|}
\hline NRO. & RAZON SOCIAL & NRO. & RAZON SOCIAL \\
\hline 311 & \multicolumn{1}{|c|}{ AMERICAN MOLDS S.A.C. } & 331 & \multicolumn{1}{c|}{$\begin{array}{l}\text { ANDINA DESARROLLO DE } \\
\text { COMERCIO SAC }\end{array}$} \\
\hline 312 & PROSEGUR TECNOLOGIA PERU S.A. & 332 & GRAFICA ASIA IMPORT S.A.C. \\
\hline 313 & CORPORACION VALPRASA SAC & 333 & J.S. INDUSTRIAL E.I.R.L. \\
\hline 314 & INTERNACIONAL DE MAQUINARIAS SAC & 334 & MODEPSA S.A.C. \\
\hline 315 & CONSULT TRADE S.A. & 335 & $\begin{array}{l}\text { MAQUI CORP } \\
\text { ANONIMA CERRADA }\end{array}$ \\
\hline 316 & INVERSIONES LIBER S.A. & & MAC POINT SAC \\
\hline 317 & PIAGGIO PROYECTA EIRL & 336 & PAD \\
\hline 318 & REPRESENTACIONES HEROV SAC & 337 & PANAPEX SA \\
\hline 319 & IMPORTACIONES CIELO SAC & 338 & $\begin{array}{l}\text { COMPAÑÍA LOGISTICA MAYORISTA } \\
\text { S.A.C. }\end{array}$ \\
\hline 320 & AK DRILLING INTERNATIONAL S.A. & 339 & CRODA PERU S.A.C. \\
\hline 321 & COPYFULL IMPORTACIONES EIRL & 340 & DONG HWA TEXTILE PERU E.I.R.L. \\
\hline 322 & METALES ANDINOS S.A. & 341 & UNION DE CONCRETERAS S.A. \\
\hline 323 & SOCIOS LOGISTICOS S.A.C. & 342 & FUKU E.I.R.L. \\
\hline 324 & PERUBATT S.A & 343 & COMTEL PERU S.R.L. \\
\hline 325 & LAFAYETTE DEL PERU SAC & 344 & SCHREDER PERU S.A. \\
\hline 326 & MUNDO TOY S.R.L. & 345 & $\begin{array}{l}\text { CORPORACION ANDES PRODUCTS } \\
\text { S.A.C }\end{array}$ \\
\hline 327 & DECORCLUB E.IIR.L & 346 & NIISA CORPORATION S.A. \\
\hline 328 & CRECER JUGANDO E.I.R.L. & 347 & PERU FOREIGN TRADE SAC \\
\hline 329 & PRODUCTOS DE SUJECION S.A.C. & 348 & FABRICA DE CUBIERTOS S.A.C. \\
\hline 330 & DISTRIBUCIONES OLANO S.A.C. & & \\
\hline & & \\
\hline
\end{tabular}

\begin{tabular}{|c|l|c|l|}
\hline NRO. & RAZON SOCIAL & NRO. & RAZON SOCIAL \\
\hline 349 & \multicolumn{1}{|c|}{ VIPRASA CORPORATION S.A.C. } & 369 & \multicolumn{1}{|c|}{ BIJOU PERU S.A.C. } \\
\hline 350 & CENTAURO COMUNICACIONES SRL & 370 & MUR-WY S.A.C. \\
\hline 351 & INVERSIONES M. TWIGG SAC & 371 & PROFIELD SAC \\
\hline 352 & FRANK TEXT EIRL & 372 & TECNITALIA S.A.C. \\
\hline 353 & UNILENE SAC & 373 & ASUSA TEXTIL SAC \\
\hline 354 & DISTRIBUIDORA GENERAL PUCALLPA S.A. & 374 & FER EXIMPORT EIRL. \\
\hline 355 & BIG SHOPPS SAC & 375 & REXEL PERU S.A.C. \\
\hline 356 & MULTY STORE S.A.C. & 376 & INVERSIONES TECNOLOGIA Y Y \\
\hline
\end{tabular}




\begin{tabular}{|l|l|l|l|} 
& & & SUMINISTROS \\
\hline 357 & LATINEX IMPORT EXPORT SAC & & \\
\hline 358 & CORPORACION ANDES PRODUCTS S.A. & 377 & PERUVIAN MEL S.A.C \\
\hline 359 & LUKOLL S.A.C. & 378 & COWDIN SAC \\
\hline 360 & CORPORACION TEXTIL SAN SALVADOR SAC & 380 & NOR ALIMENTOS SR LTDA \\
\hline 361 & IMPORT FORLTAL E.I.R.L. & 381 & ENSYS SAC \\
\hline 362 & IMPORTACIONES TAPYCUERO EIRL & 382 & CABANA IMPORT E.I.R.L. \\
\hline 363 & ADU SYSTEMS SRL & 383 & CLARIDECT PERU SAC \\
\hline 364 & LEXMARK INTERNATIONAL DE PERU S.R.L. & 384 & GRACIA \& COLOR S.A.C. \\
\hline 365 & DAWUS SAC & 385 & APUMAYO S.A.C. \\
\hline 366 & WING WA INC SOCIEDAD ANONIMA CERRADA & 386 & MICROS FIDELIO PERU S.A.C. \\
\hline 367 & VITRAL TEXTIL PERU S.A.C. & 387 & UMI FOODS SAC \\
\hline 368 & BAMUS S.A.C. & 388 & DROGUERIA FARMACARE S.A.C. \\
\hline
\end{tabular}

\begin{tabular}{|c|l|}
\hline NRO. & RAZON SOCIAL \\
\hline & \multicolumn{1}{|c|}{ DETALLES Y MODA PERU S.A.C. } \\
\hline 389 & \multicolumn{1}{|c|}{} \\
\hline 390 & TRIJET CORPORATION SUCURSAL DEL PERU \\
\hline 391 & IMPORTADORA GAMA TEXTIL \\
\hline 392 & TEXTIL RESO EILR \\
\hline 393 & CORPORACION NEMHER SAC \\
\hline 394 & MAGICA E.I.R.L. \\
\hline 395 & SWIT TRADING SAC \\
\hline 396 & BEN DA SAC \\
\hline 397 & JESUS ALIAGA FABIAN INDUSTRIAL BIKE SRL \\
\hline 398 & JVJ SERVICE ORIENTE SAC \\
\hline 399 & OUTEC (FILTERS) OY SUCURSAL PERU PERU \\
\hline 400 & MAYORISTAS DE PARTES Y OPCIONES S.A.C. \\
\hline 401 & IMERHA'S \\
\hline 402 & CHIQUI TOYS S.A.C. \\
\hline 403 & IMPORTACIONES BACHI SAC \\
\hline & \\
\hline & \\
\hline
\end{tabular}




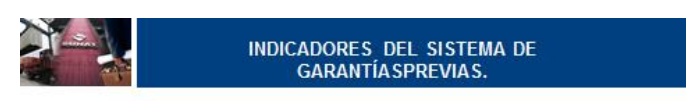

EL MECANISMO EN CIFRAS: Enero - Marzo 2014
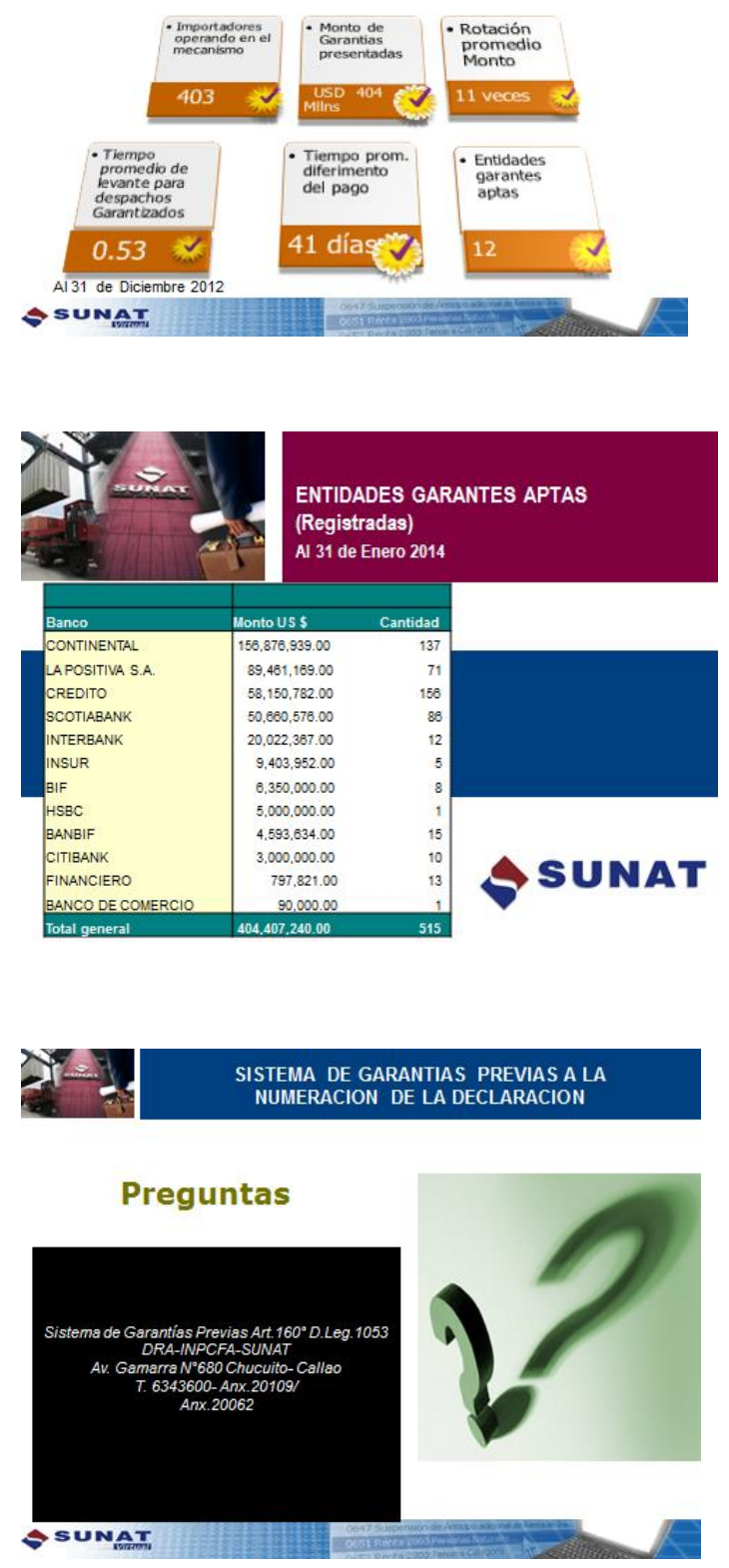
Anexo 2: Lista de empresas textiles que utilizan el sistema de garantías previas hasta el 2014

\begin{tabular}{|c|c|}
\hline 178 & TEXTILES OLINDA SAC \\
\hline 194 & COMERCIAL TEXTIL S.A. \\
\hline 199 & TEXTILES JACKELINE SAC \\
\hline 232 & LUCI TEXTIL S.A.C. \\
\hline 268 & TEXTIL DIAZ PONCE EIRL \\
\hline 342 & DONG HWA TEXTILE PERU E.I.R.L. \\
\hline 393 & IMPORTADORA GAMA TEXTIL \\
\hline 394 & TEXTIL RESO EILR \\
\hline 177 & HUANCATEX S.A.C. \\
\hline 141 & IBEROTEX S.AC. \\
\hline 160 & IMPORT \& EXPORT RODOTEX SAC \\
\hline 183 & TEXCORP S.A.C. \\
\hline 205 & TEDITEX SAC \\
\hline 224 & INVERSIONES FLOTEX SAC \\
\hline 285 & VISTAMODA PERU S.A.C. \\
\hline 287 & INVERSIONES FASHION HOUSE SAC \\
\hline 288 & BORDEN SAC \\
\hline 290 & HSC TEX EIRL \\
\hline 297 & SAN JORGE MODA S.A.C. \\
\hline 302 & IMPORT TEXTIL ROSSY CIELO SAC \\
\hline 304 & CORPORACION TEXTIL ICHIBAN SAC \\
\hline 310 & KATALINA TEXTIL SAC \\
\hline 360 & CORPORACION TEXTIL SAN SALVADOR SAC \\
\hline 361 & IMPORT FORLTAL E.I.R.L. \\
\hline 362 & IMPORTACIONES TAPYCUERO EIRL \\
\hline 367 & VITRAL TEXTIL PERU S.A.C. \\
\hline 373 & ASUSA TEXTIL SAC \\
\hline
\end{tabular}




\section{Anexo 3: Costo y Requisitos para emitir una Carta Fianza - Banco Financiero}

De: Arita Espinoza Vilchez

Enviado: jueves, 15 de marzo de 2018 23:33

Para: Maribel Yupan

Asunto: Fwd: Flujo de Carta Fianza con Deposito en Garantía

Maribel,

De acuerdo a la información solicitada, si un cliente requiere una carta fianza por $\$ 100,000$ dólar debe presentarse como empresa. (la información se encuentra en la página web del banco)

Solo atendemos empresas que facturen más de medio millón al año, para ello les aperturamos una cta. corriente y luego los evaluamos para asignarle una línea de crédito que respaldará la carta fianza.

Si factura menos de medio millón al año se les atendería como persona natural con negocio.

Tendría que aperturar una cta. a plazo fijo por el monto que solicitan en la carta fianza.

Te adjunto un ejemplo de costo de la comisión que pagaría un cliente que la carta fianza por S/. 50,000

Tasas de comisiones lo tramita el funcionario, según tarifario la tasa máxima es $4.5 \%$.

TASA: $4.5 \%$

PLAZO: 270 DIAS

IMPORTE: S/ 50,000

COMISION: $\mathrm{S} / 1,687.50$

PORTES: $\quad$ S/ 10.00

Saludos,

\section{Araminta Espinoza}

De: Maribel Yupan [mailto:maribel.yupan@newtransport.net]

Enviado el: jueves, 15 de marzo de 2018 13:17

Para: Arita Espinoza Vilchez

Asunto: CONSULTA - CARTA FIANZA

Estimada Araminta,

Favor tu apoyo con la sgte consulta; suponiendo que un cliente tiene una Importación de USD 100,000.00

Si es una empresa mediana y /o pequeña que sea cliente de uds?

Qué requisitos necesita para adquirir una carta fianza o garantía?

Cuál es el procedimiento para adquirir carta fianza o garantía?

Cual es costo para una carta fianza o garantía?

\section{Si es una empresa mediana y /o pequeña que NO sea cliente de uds?}


Qué requisitos necesita para adquirir una carta fianza o garantía?

Cuál es el procedimiento para adquirir carta fianza o garantía?

Cual es costo para una carta fianza o garantía?

\section{Si es una empresa grande que sea cliente de uds?}

Qué requisitos necesita para adquirir una carta fianza o garantía?

Cuál es el procedimiento para adquirir carta fianza o garantía?

Cual es costo para una carta fianza o garantía?

Quedo a la espera de tu ayuda

Gracias \& Saludos

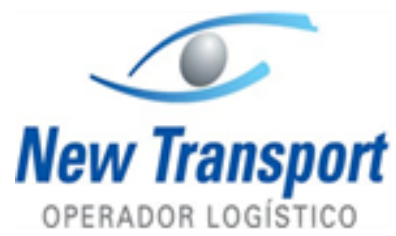

OPERADOR LOGISTICO
Maribel Yupan Ch.

Customer Service

New Transport S.A.

Phone: (+511) 613-9696 Anexo: 1813

Cell Phone: $(+511)$ 946-287-813

maribel.yupan @newtransport.net

www.newtransport.net

Nuestra nueva dirección es Av. Roosevelt $N^{\circ} 5790$ - Piso 5 - Miraflores (Edificio Corporativo Roosevelt)

\section{Anexo 4: Costo y Requisitos para emitir una Carta Fianza - Banco Interbank}

De: Lau Franco, Juan Carlos Tacjum [mailto:jlauf@intercorp.com.pe]

Enviado el: viernes, 16 de marzo de 2018 06:13 p.m.

Para: Felix Guillen

Asunto: CARTA FIANZA COLORTEX PERU

Felix,

Claro, envíanos la siguiente info.

EEFF cierre 2017 con detalle de las cuentas y/o anexos de las cuentas.

La comisión estaría alrededor de 5.00\%.

Tener en cuenta que dependerá lo que se vaya a garantizar para evaluar la carta fianza.

En el caso de cliente nuevo necesitamos lo siguiente:

Documentos para Líneas de crédito:

EEFF D J SUNAT 2015 , 2016 y 2017 SUNAT con detalle de las cuentas y/o anexos. Enviar detalles de los gastos e ingresos financieros. Información básica relevante (IBR - adjunto).

Manifestación de bienes patrimoniales (adjunto).

Cualquier duda nos avisas.

Juan Lau 
De: Felix Guillen [mailto:felix.guillen@colortexperu.com.pe]

Enviado el: jueves, 15 de marzo de 2018 06:02 p.m.

Para: Lau Franco, Juan Carlos Tacjum

Asunto: CARTA FIANZA COLORTEX PERU

Estimado:

Necesitamos tu apoyo con la siguiente información para una CARTA FIANZA;

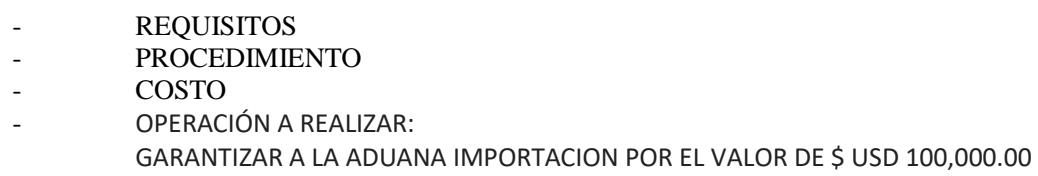

En caso de no ser cliente lo solicitado lineas arriba es igual?, coméntanos un poco ya que COLORTEX PERU quiere importar bajo una razón social aparte (NUEVA).

Gracias

Felix Guillén H.

International Purchasing Department

felix.quillen@colortexperu.com.pe

Phone: (511)-2640469 - 2640960 anex : 273

Fax: (511) - 2640034

web site: www.colortexperu.com.pe 
Anexo 5: Subpartidas arancelarias más utilizadas en el periodo

Tabla 8: $\quad$ Subpartidas arancelarias más utilizadas en el periodo

\begin{tabular}{|c|c|c|c|c|c|}
\hline & & $49.95 \%$ & $52.08 \%$ & $49.81 \%$ & $49.52 \%$ \\
\hline Código & Descripción del producto & 2013 & 2014 & 2015 & 2016 \\
\hline \multicolumn{2}{|r|}{ Total Importado todos los productos } & $\$ 43,321,710,000.00$ & $\$ 42,193,570,000.00$ & $\$ 38,104,614,000.00$ & $\$ 36,185,035,000.00$ \\
\hline \multicolumn{2}{|r|}{ Total Importado Sector Textil } & $\$ 1,850,810,000.00$ & $\$ 1,941,488,000.00$ & $\$ 1,799,007,000.00$ & $\$ 1,676,486,000.00$ \\
\hline 520100 & Algodón sin cardar ni peinar & $\$ 128,143.00$ & $\$ 139,435.00$ & $\$ 108,352.00$ & $\$ 67,847.00$ \\
\hline '600410 & $\begin{array}{l}\text { Tejidos de punto de anchura }>30 \mathrm{~cm} \text {, con un } \\
\text { contenido de hilados de elastómeros }>=5 \% \\
\text { en peso... }\end{array}$ & $\$ 49,676.00$ & $\$ 65,478.00$ & $\$ 63,315.00$ & $\$ 70,332.00$ \\
\hline '540233 & $\begin{array}{l}\text { Hilados texturados, de filamentos de } \\
\text { poliésteres (exc. hilos de coser e hilados } \\
\text { acondicionados... }\end{array}$ & $\$ 49,954.00$ & $\$ 54,419.00$ & $\$ 53,109.00$ & $\$ 48,206.00$ \\
\hline '611030 & $\begin{array}{l}\text { Suéteres "jerseys", "pullovers", cardiganes, } \\
\text { chalecos y artículos simil., de punto, de fibras } \\
\text {... }\end{array}$ & $\$ 48,144.00$ & $\$ 50,946.00$ & $\$ 44,380.00$ & $\$ 37,127.00$ \\
\hline '520523 & $\begin{array}{l}\text { Hilados de algodón, sencillos, de fibras } \\
\text { peinadas, con un contenido de algodón }>= \\
85 \% \text { en peso, ... }\end{array}$ & $\$ 48,521.00$ & $\$ 46,458.00$ & $\$ 31,214.00$ & $\$ 37,094.00$ \\
\hline '620342 & $\begin{array}{l}\text { Pantalones largos, pantalones con peto, } \\
\text { pantalones cortos "calzones" y "shorts", de } \\
\text { algodón, ... }\end{array}$ & $\$ 46,679.00$ & $\$ 41,777.00$ & $\$ 43,711.00$ & $\$ 42,311.00$ \\
\hline '550320 & $\begin{array}{l}\text { Fibras discontinuas de poliésteres, sin cardar, } \\
\text { peinar ni transformar de otra forma para la ... }\end{array}$ & $\$ 39,461.00$ & $\$ 40,730.00$ & $\$ 30,783.00$ & $\$ 27,986.00$ \\
\hline '621210 & $\begin{array}{l}\text { Sostenes "corpiños" de todo tipo de materia } \\
\text { textil, incl. elásticas y de punto }\end{array}$ & $\$ 32,483.00$ & $\$ 39,970.00$ & $\$ 29,914.00$ & $\$ 30,520.00$ \\
\hline '610910 & T-shirts y camisetas, de punto, de algodón & $\$ 35,057.00$ & $\$ 37,871.00$ & $\$ 40,288.00$ & $\$ 37,240.00$ \\
\hline '611020 & $\begin{array}{l}\text { Suéteres "jerseys", "pullovers", cardiganes, } \\
\text { chalecos y artículos simil., de punto, de } \\
\text { algodón ... }\end{array}$ & $\$ 28,901.00$ & $\$ 34,540.00$ & $\$ 32,192.00$ & $\$ 24,544.00$ \\
\hline
\end{tabular}




\begin{tabular}{|c|c|c|c|c|c|}
\hline '620520 & $\begin{array}{l}\text { Camisas de algodón, para hombres o niños } \\
\text { (exc. de punto, así como camisones y } \\
\text { camisetas) }\end{array}$ & $\$ 27,981.00$ & $\$ 31,114.00$ & $\$ 30,859.00$ & $\$ 30,810.00$ \\
\hline '600632 & $\begin{array}{l}\text { Tejidos de punto, de anchura }>30 \mathrm{~cm} \text {, de } \\
\text { fibras sintéticas, teñidos (exc. tejidos de punto } \\
\text {... }\end{array}$ & $\$ 27,385.00$ & $\$ 30,883.00$ & $\$ 20,122.00$ & $\$ 20,227.00$ \\
\hline '620462 & $\begin{array}{l}\text { Pantalones largos, pantalones con peto, } \\
\text { pantalones cortos "calzones" y "shorts", de } \\
\text { algodón, ... }\end{array}$ & $\$ 31,377.00$ & $\$ 29,246.00$ & $\$ 26,685.00$ & $\$ 28,013.00$ \\
\hline '520942 & $\begin{array}{l}\text { Tejidos de mezclilla "denim", con un } \\
\text { contenido de algodón }>=85 \% \text { en peso, de } \\
\text { peso }>200 \mathrm{~g} / \mathrm{m}^{2}, \ldots\end{array}$ & $\$ 38,011.00$ & $\$ 27,923.00$ & $\$ 23,861.00$ & $\$ 18,147.00$ \\
\hline '630140 & $\begin{array}{l}\text { Mantas de fibras sintéticas (exc. mantas } \\
\text { eléctricas, manteles y colchas, así como } \\
\text { artículos... }\end{array}$ & $\$ 27,183.00$ & $\$ 27,454.00$ & $\$ 21,810.00$ & $\$ 25,260.00$ \\
\hline '560392 & $\begin{array}{l}\text { Tela sin tejer, incl. impregnada, recubierta, } \\
\text { revestida o estratificada, n.c.o.p., de peso ... }\end{array}$ & $\$ 28,766.00$ & $\$ 25,813.00$ & $\$ 15,904.00$ & $\$ 9,454.00$ \\
\hline '520513 & $\begin{array}{l}\text { Hilados de algodón, sencillos, de fibras } \sin \\
\text { peinar, con un contenido de algodón }>=85 \% \\
\text { en ... }\end{array}$ & $\$ 13,113.00$ & $\$ 24,412.00$ & $\$ 20,898.00$ & $\$ 26,928.00$ \\
\hline '520522 & $\begin{array}{l}\text { Hilados de algodón, sencillos, de fibras } \\
\text { peinadas, con un contenido de algodón }>= \\
85 \% \text { en peso, ... }\end{array}$ & $\$ 20,519.00$ & $\$ 23,716.00$ & $\$ 22,780.00$ & $\$ 25,037.00$ \\
\hline '610990 & $\begin{array}{l}\text { T-shirts y camisetas, de punto, de materia } \\
\text { textil (exc. de algodón) }\end{array}$ & $\$ 23,924.00$ & $\$ 23,692.00$ & $\$ 26,536.00$ & $\$ 26,711.00$ \\
\hline '620193 & $\begin{array}{l}\text { Anoraks, cazadoras y artículos simil., de fibras } \\
\text { sintéticas o artificiales, para hombres o ... }\end{array}$ & $\$ 18,263.00$ & $\$ 23,593.00$ & $\$ 19,241.00$ & $\$ 16,197.00$ \\
\hline 590320 & $\begin{array}{l}\text { Telas impregnadas, recubiertas, revestidas o } \\
\text { estratificadas con poliuretano (exc. } \\
\text { revestimientas ... }\end{array}$ & $\$ 18,715.00$ & $\$ 22,556.00$ & $\$ 14,727.00$ & $\$ 14,603.00$ \\
\hline '520526 & $\begin{array}{l}\text { Hilados de algodón, sencillos, de fibras } \\
\text { peinadas, con un contenido de algodón }>= \\
85 \% \text { en peso, ... }\end{array}$ & $\$ 17,755.00$ & $\$ 22,284.00$ & $\$ 20,637.00$ & $\$ 16,644.00$ \\
\hline '540769 & $\begin{array}{l}\text { Tejidos de hilados con un contenido }>=85 \% \\
\text { en peso de filamentos de poliésteres sin } \\
\text { texturar ... }\end{array}$ & $\$ 19,820.00$ & $\$ 22,111.00$ & $\$ 23,900.00$ & $\$ 23,701.00$ \\
\hline
\end{tabular}




\begin{tabular}{|c|c|c|c|c|c|}
\hline '630790 & $\begin{array}{l}\text { Artículos de materia textil, confeccionados, } \\
\text { incl. los patrones para prendas de vestir, } \\
\text { n.c.o.p. }\end{array}$ & $\$ 21,387.00$ & $\$ 20,620.00$ & $\$ 22,079.00$ & $\$ 17,760.00$ \\
\hline '510529 & Lana peinada (exc. "a granel" ["open tops"]) & $\$ 20,161.00$ & $\$ 19,006.00$ & $\$ 18,559.00$ & $\$ 20,544.00$ \\
\hline '620640 & $\begin{array}{l}\text { Camisas, blusas y blusas camiseras, de fibras } \\
\text { sintéticas o artificiales, para mujeres o niñas } \\
\text {... }\end{array}$ & $\$ 13,969.00$ & $\$ 17,690.00$ & $\$ 20,387.00$ & $\$ 22,552.00$ \\
\hline '540752 & $\begin{array}{l}\text { Tejidos de hilados con un contenido de } \\
\text { filamentos de poliésteres texturados }>=85 \% \\
\text { en peso, ... }\end{array}$ & $\$ 13,901.00$ & $\$ 17,559.00$ & $\$ 15,269.00$ & $\$ 18,417.00$ \\
\hline '520512 & $\begin{array}{l}\text { Hilados de algodón, sencillos, de fibras sin } \\
\text { peinar, con un contenido de algodón }>=85 \% \\
\text { en ... }\end{array}$ & $\$ 10,652.00$ & $\$ 17,072.00$ & $\$ 20,355.00$ & $\$ 15,669.00$ \\
\hline '630260 & $\begin{array}{l}\text { Ropa de tocador o cocina, de tejido con } \\
\text { bucles, del tipo toalla, de algodón (exc. } \\
\text { bayetas, ... }\end{array}$ & $\$ 11,315.00$ & $\$ 16,419.00$ & $\$ 16,426.00$ & $\$ 14,748.00$ \\
\hline '620293 & $\begin{array}{l}\text { Anoraks, cazadoras y artículos simil., de fibras } \\
\text { sintéticas o artificiales, para mujeres o ... }\end{array}$ & $\$ 13,195.00$ & $\$ 16,329.00$ & $\$ 17,806.00$ & $\$ 15,582.00$ \\
\hline
\end{tabular}


Anexo 6: Análisis de las subpartidas arancelarias y empresas que las utilizan

Tabla 9: Empresas que utilizaron las subpartidas arancelarias en el periodo

\begin{tabular}{|l|c|}
\hline AÑO & TOTAL DE EMPRESAS \\
\hline 2014 & 3820 \\
\hline 2015 & 3476 \\
\hline 2016 & 3316 \\
\hline
\end{tabular}

Tabla 10: Empresas acorde a lo importado y al UIT/AÑO

\begin{tabular}{|l|c|c|c|}
\hline TIPO DE EMPRESA/AÑO & $\mathbf{2 0 1 4}$ & $\mathbf{2 0 1 5}$ & $\mathbf{2 0 1 6}$ \\
\hline MEDIANA & 14 & 21 & 19 \\
\hline PEQUEÑA & 473 & 436 & 402 \\
\hline TOTAL & 487 & 457 & 421 \\
\hline
\end{tabular}

Fuente: Veritrade

Elaboración propia

Tabla 11: Contraste de las Mype por Monto Importado vs Directorio de Produce

\begin{tabular}{|c|c|}
\hline AÑO & EMPRESAS MYPE \\
\hline 2014 & 60 \\
\hline 2015 & 53 \\
\hline 2016 & 39 \\
\hline
\end{tabular}

Fuente: Produce, Veritrade

Elaboración propia

Tabla 12: $\quad$ Empresas Mype que importaron textiles en el 2014

2014

IMPORTADORES TOTALES

A Y B TEXTIL SOCIEDAD COMERCIAL DE RESPONSABILIDAD LIMITADA - A Y B TEXTIL S.R.L.

ANDINA COTTON S.A.

BASAURI LESCANO YSABEL

BOLPERTEX S.A.C

CONFECCIONES PULLI'S CASUALS E.I.R.L.

CORPORACION RAVE SUOMI SOCIEDAD ANONIMA

CORPORACION RIIF S A C - CORPORISAC 
CORTITEX S.A.C.

CREACIONES MEL-LIZ E.I.R.L

CRUZ TAPIA FRANCISCO

DANNIEL KNITTING SAC

DESING TO EXPORT E.I.R.L. - DEXPORT E.I.R.L.

FABRICA DE TEJIDOS SANTA RITA E.I.R.L.

FABRICA DE TEJIDOS Y ELASTICOS P Y S A

FABRICA DE TEJIDOS Y SERVICIOS S.A.C

FABRITEX S.A.C.

FUTURE TRENZ S.A.C

GALVER S.A.C.

HARTEX RELY SOCIEDAD ANONIMA CERRADA

INVERSIONES NATY \& GABY SAC

ISSAPERU SOCIEDAD ANONIMA CERRADA - ISSAPERU S.A.C.

LLUVISOL TEXTIL SAC

$M$ \& F TEXTILES SOCIEDAD ANONIMA CERRADA

M C TEJIDOS Y CONFECCIONES S.R.L.

MANUFACTURA TEXTIL SAN PEDRO S.A.C

MANUFACTURAS LA REAL S.A.

NIKOTELAS S.A.C.

NOVEDADES BERROSPI S R L

ROCKY TEXTIL S.A.C.

RODITEX SOCIEDAD ANONIMA CERRADA

SPORTEX PERU S.A.C.

TEJIDOS GLOBAL S.A.C.

TEXTIL ARLEY S.A.C.

TEXTIL DIAZ PONCE E.I.R.L

TEXTIL GIANMAR SOCIEDAD ANONIMA CERRADA

TEXTIL MELA SAC - TEME SAC

TEXTIL MERCURIO E.I.R.L.

TEXTIL SAN LUIS E.I.R.L.

TEXTILES BURGA SOCIEDAD ANONIMA CERRADA

TEXTILES EL PAISA SOCIEDAD ANONIMA CERRADA

TEXTILES GARCIA EIRL

TEXTILES JOSE ABEL S.A.C.

TEXTILES RELY S.A.C.

TEXTILES TEXSANPE EMPRESA INDIVIDUAL DE RESPONSABILIDAD LIMITADA

CREACIONES DE EXPORTACION SA

ASUSA TEXTIL S.A.C. - ASUSA TEXTIL

BORDEN S.A.C. 
IMPORT TEXTIL ROSSY CIELO S.A.C.

IMPORTACIONES TAPYCUERO EIRL

INVERSIONES FASHION HOUSE S.A.C.

INVERSIONES HUANCATEX E.I.R.L.

KATALINA TEXTIL S.A.C

LUCI TEXTIL S.A.C.

SAN JORGE MODA S.A.C.

TEXCORP S.A.C.

TEXTIL RESO E.I.R.L.

VISTAMODA PERU S.A.C.

IMPORT \& EXPORT RODOTEX S.A.C.

TEXTILES JACKELINE S.A.C.

INVERSIONES FLOTEX S.A.C.

Fuente: Produce, Veritrade

Elaboración propia

Tabla 13: Empresas Mype que importaron textiles en el 2015

2015

\section{IMPORTADORES TOTALES}

ANDINA COTTON S.A.

BASAURI LESCANO YSABEL

BOLPERTEX S.A.C

CORTITEX S.A.C.

CREACIONES MEL-LIZ E.I.R.L

CRUZ TAPIA FRANCISCO

DANNIEL KNITTING SAC

EXPORT \& IMPORT VANIST S.A.C.

FABRICA DE TEJIDOS SANTA RITA E.I.R.L.

FABRICA DE TEJIDOS Y ELASTICOS P Y S A

FABRICA DE TEJIDOS Y SERVICIOS S.A.C

FABRITEX S.A.C.

FUTURE TRENZ S.A.C

GALVER S.A.C.

HARTEX RELY SOCIEDAD ANONIMA CERRADA

INVERSIONES NATY \& GABY SAC

ISSAPERU SOCIEDAD ANONIMA CERRADA - ISSAPERU S.A.C.

LLUVISOL TEXTIL SAC

$M$ \& F TEXTILES SOCIEDAD ANONIMA CERRADA

M C TEJIDOS Y CONFECCIONES S.R.L.

MACO GEESS S.A.C 
MANUFACTURAS LA REAL S.A.

R.H. COTTON SOCIEDAD ANONIMA CERRADA

ROCKY TEXTIL S.A.C.

RODITEX SOCIEDAD ANONIMA CERRADA

SAFITEX S.A.C.

SOHO BRANDS S.A.C.

TEJIDOS CELESTE SOCIEDAD ANONIMA CERRADA

TEJIDOS GLOBAL S.A.C.

TEJIDOS PUNTO COTTON SAC

TEXTIL ARLEY S.A.C.

TEXTIL DIAZ PONCE E.I.R.L

TEXTIL GIANMAR SOCIEDAD ANONIMA CERRADA

TEXTIL MELA SAC - TEME SAC

TEXTIL MERCURIO E.I.R.L.

TEXTIL SAMHY'S E.I.R.L.

TEXTIL SOTELO S.A.

TEXTILES BURGA SOCIEDAD ANONIMA CERRADA

TEXTILES GARCIA EIRL

TEXTILES JOSE ABEL S.A.C.

TEXTILES RELY S.A.C.

TEXTILES TEXSANPE EMPRESA INDIVIDUAL DE RESPONSABILIDAD LIMITADA

CREACIONES DE EXPORTACION SA

BORDEN S.A.C.

IMPORT \& EXPORT RODOTEX S.A.C.

IMPORT TEXTIL ROSSY CIELO S.A.C.

SAN JORGE MODA S.A.C.

TEXCORP S.A.C.

TEXTIL RESO E.I.R.L.

TEXTILES EL PAISA SOCIEDAD ANONIMA CERRADA

TEXTILES HUANCATEX II SOCIEDAD ANONIMA CERRADA-TEXTILES HUANCATEX II S.A.C.

VISTAMODA PERU S.A.C.

HSC TEX E.I.R.L.

Fuente: Produce, Veritrade

Elaboración propia

Tabla 14: Empresas Mype que importaron textiles en el 2016

2016

\section{IMPORTADORES TOTALES}

ANDINA COTTON S.A.

BASAURI LESCANO YSABEL

BOLPERTEX S.A.C 
CORTITEX S.A.C.

CRUZ TAPIA FRANCISCO

DANNIEL KNITTING SAC

FABRICA DE TEJIDOS SANTA RITA E.I.R.L.

FABRICA DE TEJIDOS Y ELASTICOS P Y S A

FABRICA DE TEJIDOS Y SERVICIOS S.A.C

FUTURE TRENZ S.A.C

GALVER S.A.C.

HARTEX RELY SOCIEDAD ANONIMA CERRADA

INVERSIONES NATY \& GABY SAC

ISSAPERU SOCIEDAD ANONIMA CERRADA - ISSAPERU S.A.C.

LLUVISOL TEXTIL SAC

M \& F TEXTILES SOCIEDAD ANONIMA CERRADA

MANUFACTURAS LA REAL S.A.

MEGAHILOS SOCIEDAD ANONIMA CERRADA

R.H. COTTON SOCIEDAD ANONIMA CERRADA

RAMI TEXTILES S.A.C.

ROCKY TEXTIL S.A.C.

RODITEX SOCIEDAD ANONIMA CERRADA

TEJIDOS CELESTE SOCIEDAD ANONIMA CERRADA

TEJIDOS GLOBAL S.A.C.

TEXTIL DIAZ PONCE E.I.R.L

TEXTIL GIANMAR SOCIEDAD ANONIMA CERRADA

TEXTIL MERCURIO E.I.R.L.

TEXTIL SAMHY'S E.I.R.L.

TEXTIL SOTELO S.A.

TEXTILES BOZA EIRL

TEXTILES BURGA SOCIEDAD ANONIMA CERRADA

TEXTILES JOSE ABEL S.A.C.

BORDEN S.A.C.

HSC TEX E.I.R.L.

IMPORT \& EXPORT RODOTEX S.A.C.

IMPORT TEXTIL ROSSY CIELO S.A.C.

TEXCORP S.A.C.

TEXTILES EL PAISA SOCIEDAD ANONIMA CERRADA

VISTAMODA PERU S.A.C.

Fuente: Produce, Veritrade

Elaboración propia 
Tabla 15: $\quad$ Unificado de empresas que importaron textiles del 2014-2016

\begin{tabular}{|c|}
\hline IMPORTADORES TOTALES \\
\hline A Y B TEXTIL SOCIEDAD COMERCIAL DE RESPONSABILIDAD LIMITADA - A Y B TEXTIL S.R.L. \\
\hline ANDINA COTTON S.A. \\
\hline ASUSA TEXTIL S.A.C. - ASUSA TEXTIL \\
\hline BASAURI LESCANO YSABEL \\
\hline BOLPERTEX S.A.C \\
\hline BORDEN S.A.C. \\
\hline CONFECCIONES PULLI'S CASUALS E.I.R.L. \\
\hline CORPORACION RAVE SUOMI SOCIEDAD ANONIMA \\
\hline CORPORACION RIIF S A C - CORPORISAC \\
\hline CORTITEX S.A.C. \\
\hline CREACIONES DE EXPORTACION SA \\
\hline CREACIONES MEL-LIZ E.I.R.L \\
\hline CRUZ TAPIA FRANCISCO \\
\hline DANNIEL KNITTING SAC \\
\hline DESING TO EXPORT E.I.R.L. - DEXPORT E.I.R.L. \\
\hline EXPORT \& IMPORT VANIST S.A.C. \\
\hline FABRICA DE TEJIDOS SANTA RITA E.I.R.L. \\
\hline FABRICA DE TEJIDOS Y ELASTICOS P Y S A \\
\hline FABRICA DE TEJIDOS Y SERVICIOS S.A.C \\
\hline FABRITEX S.A.C. \\
\hline FUTURE TRENZ S.A.C \\
\hline GALVER S.A.C. \\
\hline HARTEX RELY SOCIEDAD ANONIMA CERRADA \\
\hline HSC TEX E.I.R.L. \\
\hline IMPORT \& EXPORT RODOTEX S.A.C. \\
\hline IMPORT TEXTIL ROSSY CIELO S.A.C. \\
\hline IMPORTACIONES TAPYCUERO EIRL \\
\hline INVERSIONES FASHION HOUSE S.A.C. \\
\hline INVERSIONES FLOTEX S.A.C. \\
\hline INVERSIONES HUANCATEX E.I.R.L. \\
\hline INVERSIONES NATY \& GABY SAC \\
\hline ISSAPERU SOCIEDAD ANONIMA CERRADA - ISSAPERU S.A.C. \\
\hline KATALINA TEXTIL S.A.C \\
\hline LLUVISOL TEXTIL SAC \\
\hline LUCI TEXTIL S.A.C. \\
\hline
\end{tabular}


$M$ \& F TEXTILES SOCIEDAD ANONIMA CERRADA

M C TEJIDOS Y CONFECCIONES S.R.L.

MACO GEESS S.A.C

MANUFACTURA TEXTIL SAN PEDRO S.A.C

MANUFACTURAS LA REAL S.A.

MEGAHILOS SOCIEDAD ANONIMA CERRADA

NIKOTELAS S.A.C.

NOVEDADES BERROSPI S R L

R.H. COTTON SOCIEDAD ANONIMA CERRADA

RAMI TEXTILES S.A.C.

ROCKY TEXTIL S.A.C.

RODITEX SOCIEDAD ANONIMA CERRADA

SAFITEX S.A.C.

SAN JORGE MODA S.A.C.

SPORTEX PERU S.A.C.

TEJIDOS CELESTE SOCIEDAD ANONIMA CERRADA

TEJIDOS GLOBAL S.A.C.

TEJIDOS PUNTO COTTON SAC

TEXCORP S.A.C.

TEXTIL ARLEY S.A.C.

TEXTIL DIAZ PONCE E.I.R.L

TEXTIL GIANMAR SOCIEDAD ANONIMA CERRADA

TEXTIL MELA SAC - TEME SAC

TEXTIL MERCURIO E.I.R.L.

TEXTIL RESO E.I.R.L.

TEXTIL SAMHY'S E.I.R.L.

TEXTIL SAN LUIS E.I.R.L.

TEXTIL SOTELO S.A.

TEXTILES BOZA EIRL

TEXTILES BURGA SOCIEDAD ANONIMA CERRADA

TEXTILES EL PAISA SOCIEDAD ANONIMA CERRADA

TEXTILES GARCIA EIRL

TEXTILES HUANCATEX II SOCIEDAD ANONIMA CERRADA-TEXTILES HUANCATEX II S.A.C.

TEXTILES JACKELINE S.A.C.

TEXTILES JOSE ABEL S.A.C.

TEXTILES RELY S.A.C.

TEXTILES TEXSANPE EMPRESA INDIVIDUAL DE RESPONSABILIDAD LIMITADA

VISTAMODA PERU S.A.C.

Fuente: Produce, Veritrade

Elaboración propia 
Tabla 16: Muestra de empresas medianas y pequeñas que utilizan el sistema de garantías previas durante el 2014-2016.

\begin{tabular}{|l|}
\hline \multicolumn{1}{|c|}{ IMPORTADORES TOTALES } \\
\hline BORDEN S.A.C. \\
\hline HSC TEX E.I.R.L. \\
\hline INVERSIONES FASHION HOUSE S.A.C. \\
\hline INVERSIONES HUANCATEX E.I.R.L. \\
\hline LUCI TEXTIL S.A.C. \\
\hline TEXTIL DIAZ PONCE E.I.R.L \\
\hline TEXTILES JACKELINE S.A.C. \\
\hline
\end{tabular}

Fuente: Produce, Veritrade

Elaboración propia

Tabla 17: Muestra de empresas medianas y pequeñas que no utilizan el sistema de garantías previas durante el 2014-2016.

\section{IMPORTADORES TOTALES}

IMPORT \& EXPORT RODOTEX S.A.C.

INVERSIONES FLOTEX S.A.C.

ROCKY TEXTIL S.A.C.

TEXCORP S.A.C.

TEXTIL RESO E.I.R.L.

TEXTILES EL PAISA SOCIEDAD ANONIMA CERRADA

Fuente: Produce, Veritrade

Elaboración propia 
Anexo 7: Cuestionarios por segmento - Entrevistas de profundidad

\section{Entrevista Segmento 1: Importadores Textiles (Empresas medianas y pequeñas).}

- Nombre de la empresa:

- Contacto:

- Cargo:

Muchas gracias por brindarnos su tiempo en poder realizar la presente entrevista. $\mathrm{Su}$ información nos será de gran utilidad para nuestro proyecto de titulación de la UPC. Toda la información brindada será utilizada únicamente en el desarrollo de nuestro tema y será tratada de manera confidencial.

1. ¿Cuánto tiempo lleva la empresa en el rubro de importación de textiles y/o afines?

2. ¿Los embarques de importación los realiza en FCL o LCL?

3. Entrando en temas aduaneros, ¿Nos podría indicar si los despachos de importación los realiza bajo la modalidad excepcional o SADA?

4. ¿Nos podría comentar brevemente como realiza el pago de tributos para la nacionalización de la carga? ¿ha tenido en alguna oportunidad inconvenientes en dicho proceso?

5. ¿Nos gustaría saber si ustedes han escuchado sobre el uso de garantías previas a la numeración de la importación?

6. ¿Si su respuesta es afirmativa, nos podría comentar que información cuenta sobre este tema? ¿alguna vez lo ha aplicado en el trámite de desaduanaje?

Entrevista Segmento 2: Superintendencia Nacional de Administración Tributaria (Aduanas).

- Nombre de la empresa:

- Contacto:

- Cargo:

Muchas gracias por brindarnos su tiempo en poder realizar la presente entrevista. $\mathrm{Su}$ información nos será de gran utilidad para nuestro proyecto de titulación de la UPC. Toda 
la información brindada será utilizada únicamente en el desarrollo de nuestro tema y será tratada de manera confidencial.

1. ¿Cómo percibe el panorama de la importación de textiles en los últimos años, desde la perspectiva como entidad del estado que facilita el ingreso de mercancías al país?

2. De acuerdo a la experiencia que viene trabajando en los despachos, ¿qué modalidad considera que es la más utilizada por los importadores?

3. En el caso diga Desp. Excepcional, ¿Por qué considera que el SADA no es muy utilizado por los importadores de textiles?

4. En el caso diga Despacho SADA, ¿Por qué considera que el SADA es el más utilizado por los importadores de textiles?

5. ¿Cuál es el beneficio para la Aduana cuando un importador se acoge al despacho con modalidad SADA?

\section{Entrevista Segmento 3: Agentes de Aduanas}

- Nombre de la empresa:

- Contacto:

- Cargo:

Muchas gracias por brindarnos su tiempo en poder realizar la presente entrevista. Su información nos será de gran utilidad para nuestro proyecto de titulación de la UPC. Toda la información brindada será utilizada únicamente en el desarrollo de nuestro tema y será tratada de manera confidencial.

1. De acuerdo a la experiencia que viene trabajando en los despachos, ¿qué modalidad considera que es la más utilizada por los importadores de textiles?

2. ¿Es común que tus clientes textiles te soliciten SADA con garantía?

3. ¿Dentro de tu cartera de clientes cuantas empresas textiles utilizan las garantías previas antes de la numeración de la DAM?

4. ¿Consideras que este procedimiento ayuda mucho con el costo beneficio de tu cliente? ¿Por qué?

5. ¿Su contacto es el dueño de la empresa o el encargado de Comercio exterior

6. En caso es COMEX, ¿Tu contacto tiene autonomía sobre las operaciones y/o financiamiento de la empresa? 


\section{Entrevista Segmento 4: Entidades Garantes (Bancos y Aseguradoras).}

- Nombre de la empresa:

- Contacto:

- Cargo:

Muchas gracias por brindarnos su tiempo en poder realizar la presente entrevista. Su información nos será de gran utilidad para nuestro proyecto de titulación de la UPC. Toda la información brindada será utilizada únicamente en el desarrollo de nuestro tema y será tratada de manera confidencial.

1. ¿En su experiencia como entidad bancaria que tipo de producto financiero es el más utilizado por las empresas importadoras?

2. En caso la respuesta sea Carta Fianza, ¿Qué tan rentable es para tu entidad emitir una Carta Fianza?

3. En caso la respuesta sea otro producto, ¿Qué nos podría mencionar sobre la Carta Fianza?

4. ¿Qué característica debe cumplir tu cliente para que puedan brindarle este tipo de producto?

5. ¿Su contacto es el dueño de la empresa o el encargado de Comercio exterior?

6. En caso es COMEX, ¿Tu contacto tiene autonomía sobre las decisiones del financiamiento de la empresa? 
Anexo 8: Cuadro de Segmentos y Categorías

\begin{tabular}{|c|c|c|c|c|}
\hline $\begin{array}{l}\text { CATEGORIAS / } \\
\text { SEGMENTOS }\end{array}$ & $\begin{array}{c}\text { Importadores Textiles } \\
\text { (Empresas medianas y pequeñas) }\end{array}$ & Sunat (Sistema de Garantías) & Agentes de Aduanas & $\begin{array}{c}\text { Entidades Garantes } \\
\text { (Bancos y Aseguradoras) }\end{array}$ \\
\hline $\begin{array}{l}\text { Categoría } 1 \\
\text { Descocimiento del } \\
\text { Procedimiento a la } \\
\text { Garantía Previa }\end{array}$ & $\begin{array}{l}\text { 1.- ¿Cuánto tiempo tiene la empresa en el rubro de importación } \\
\text { de textiles? } \\
\text { 2. ¿Qué tipos de cargas suelen importar con mayor frecuencia } \\
\text { FCL O LCL? } \\
\text { 3. Los despachos de importación los realizas bajo la modalidad } \\
\text { excepcional o Sada? } \\
\text { 4. Ha escuchado sobre el procedimiento de las garantías } \\
\text { previas a la numeración de la DAM? }\end{array}$ & $\begin{array}{l}\text { 1.- De acuerdo a la experiencia que viene } \\
\text { trabajando en los despachos como modalidad } \\
\text { Sada, ¿que procedimiento considera que es el } \\
\text { más utilizado por los importadoes? } \\
\text { 2. Considera ud ¿que éste procedimiento Sada } \\
\text { con garantía es uno de los más usado } \\
\quad \text { actualmente? } \\
\text { 3. cuál es la modalidad más usada en rubro? }\end{array}$ & $\begin{array}{l}\text { 1. En tus operaciones diarias, ¿es } \\
\text { común que tus clientes te soliciten } \\
\text { Sada con garantía? }\end{array}$ & No aplica \\
\hline $\begin{array}{l}\text { Categoría } 2 \\
\text { Costo del } \\
\text { Financiamiento }\end{array}$ & $\begin{array}{l}\text { 1. Dentro de tu empresa, iqué tipos de cargas suelen importar } \\
\text { con mayor frecuencia FCL o LCL? } \\
\text { 2. ¿Los despachos de importación los realizas bajo la } \\
\text { modalidad excepcional o Sada? } \\
\text { 3. Nos podrías comentar, ¿cómo realizar el pago de tributos } \\
\text { para nacionalizar la carga? ¿Han tenido en alguna oportunidad } \\
\text { inconvenientes para el pago? }\end{array}$ & NO APLICA & $\begin{array}{l}\text { 1. Dentro de su cartera de clientes, } \\
\text { ¿cuantos utilizan la garantía previa } \\
\text { antes de la numeración de la DAM? } \\
\text { 2. ¿Consideras que éste } \\
\text { procedimiento ayuda mucho con el } \\
\text { costo beneficio de tu cliente? }\end{array}$ & $\begin{array}{l}\text { 1. ¿Qué tipos de productos financieros son los } \\
\text { más utilizados por las empresas importadoras? } \\
\text { 2. ¿Qué tan rentable es para su entidad emitir } \\
\text { una garantía nominal o póliza de Caución? } \\
\text { 3. ¿Qué características debe cumplir tu cliente } \\
\text { para que puedan brindarle este tipo de } \\
\text { producto?. }\end{array}$ \\
\hline $\begin{array}{c}\text { Categoría } 3 \\
\text { Cultura y/o Tradición } \\
\text { empresarial }\end{array}$ & NO APLICA & NO APLICA & $\begin{array}{l}\text { 1. Tu contacto, ¿Es el dueño de la } \\
\text { empresa o el encargado de comercio } \\
\text { exterior? } \\
\text { 2. En caso sea comercio exterior, } \\
\text { ¿tiene autonomía sobres las decisiones } \\
\text { operaciones y o financiamiento de la } \\
\quad \text { empresa? }\end{array}$ & $\begin{array}{l}\text { 1. Tu contacto, ¿Es el dueño de la empresa o el } \\
\text { encargado de comercio exterior? } \\
\text { 2. ¿En caso sea comercio exterior, tiene } \\
\text { autonomía sobres las decisiones de } \\
\text { financiamiento de la empresa? }\end{array}$ \\
\hline
\end{tabular}

Elaboración Propia 


\begin{tabular}{|c|c|c|c|c|}
\hline $\begin{array}{l}\text { CATEGORIAS / } \\
\text { SEGMENTOS }\end{array}$ & $\begin{array}{c}\text { Importadores Textiles } \\
\text { (Empresas medianas y pequeñas) }\end{array}$ & Sunat (Sistema de Garantías) & Agentes de Aduanas & $\begin{array}{l}\text { Entidades Garantes } \\
\text { (Bancos y Aseguradoras) }\end{array}$ \\
\hline $\begin{array}{c}\text { Categoria } 1 \\
\text { Descocimiento del } \\
\text { Procedimiento a la Garantía } \\
\text { Previa }\end{array}$ & $\begin{array}{l}\text { Los entrevistados indican que si han escuchado de } \\
\text { las garantías previas antes de numerar la DAM; sin } \\
\text { embargo cada uno de ellos tiene un concepto } \\
\text { diferente, por la necesidad de sus operaciones, y que } \\
\text { no necesariamente concuerdan con el procedimiento } \\
\text { establecido por el sistema de garantías previas. }\end{array}$ & $\begin{array}{l}\text { Con respecto a la modalidad mas utilizada por } \\
\text { los importadores textiles es el despacho } \\
\text { excepcional o diferido; no se ha logrado } \\
\text { convencer a los textiles a utilizar SADA } \\
\text { porque el sector textil no es muy dinamico es } \\
\text { decir no son muy periodicas. La Aduana va a } \\
\text { empezar una difusion masiva para que los } \\
\text { importadores sepan las ventajas y bondades } \\
\text { del sistema SADA con garantia previa; } \\
\text { ademas han sacado un producto que permitira } \\
\text { que los importadores frecuentes se conviertan } \\
\text { en OEA, de esa manera podran presentar solo } \\
\text { garantias nominales en vez de las fianzas o } \\
\text { polizas de caución. }\end{array}$ & \begin{tabular}{|c|} 
El 50\% de los entrevistados consideran que \\
el SADA es el despacho mas utilizado, entre \\
los comentarios resaltantes a mencionar, la \\
modalidad mas utilizada anteriormente fue \\
el excepcional y ahora es el SADA, al \\
utilizar el SADA los importadores \\
ahorrarian dinero en el procedimiento; sin \\
embargo para algunos importadores no es \\
tan atractivo debido a que tendrian que \\
desaduanarlo y llevarlo a su almacen cuando \\
en realidad ellos no tienen almacen y eso \\
obligaria a que tengan un costo fijo mas.
\end{tabular} & NO APLICA \\
\hline $\begin{array}{l}\text { Categoria } 2 \\
\text { Costo del Financiamiento }\end{array}$ & $\begin{array}{l}\text { Las empresas importadoras utilizan crédito y capital } \\
\text { propio para pagar sus derechos; en el caso del } \\
\text { crédito, se financian con los agentes de aduana } \\
\text { mediante letras y cuando mencionan del capital de } \\
\text { trabajo quiere decir que pagan los derechos al } \\
\text { Contado, entre los comentarios más resaltantes con } \\
\text { respecto a inconvenientes con el pago de los } \\
\text { derechos de aduana mencionaron que felizmente hay } \\
\text { liquidez y que eso les permitía poder pagar al } \\
\text { contado, en algunos casos podían tener la facilidad } \\
\text { de negociar crédito con los agentes de Aduana y que } \\
\text { eso les permitía optimizar la liquidez para otras } \\
\text { operaciones. }\end{array}$ & NO APLICA & $\begin{array}{l}\text { De acuerdo a las respuestas que los } \\
\text { entrevistados indican por lo menos el } 50 \% \\
\text { de los clientes textiles utilizan las G. previas } \\
\text { a la numeración de la DAM y si el } \\
\text { importador se acoge hay una minimización } \\
\text { de riesgo, gestión y el ahorro de personal, } \\
\text { debido que hay más control por parte del } \\
\text { importador en vez de otorgarle esa } \\
\text { responsabilidad a la agencia de aduana, por } \\
\text { ende, se minimiza el costo que hay que } \\
\text { invertir en ese personal de la agencia. }\end{array}$ & $\begin{array}{l}\text { La empresa aseguradora utiliza cartas fianzas y polizas } \\
\text { de caución; sin embargo menciona que la carta fianza es } \\
\text { las mas utilizada debido a que los clientes prefieren } \\
\text { utilizarlo por el nombre, la poliza de caución no les } \\
\text { brinda confianza a diferencia de la carta fianza, para la } \\
\text { empresa aseguradora este producto no es ofrecido sino } \\
\text { requerido ya que es una necesidad para los clientes; por } \\
\text { otro lado las entidades bancarias indican que la carta } \\
\text { fianza es un producto importante porque no hay un } \\
\text { desembolso de dinero, si bien existe un riesgo como } \\
\text { todo préstamo; la carta fianza es un riesgo indirecto } \\
\text { salvo ésta se ejecute por algún siniestro (Para el banco es } \\
\text { un producto con alto riesgo pero a la vez tiene alta } \\
\text { rentabilidad segun los entrevistados). }\end{array}$ \\
\hline $\begin{array}{c}\text { Categoria } 3 \\
\text { Cultura y/o Tradicion } \\
\text { empresarial }\end{array}$ & NO APLICA & NO APLICA & $\begin{array}{l}\text { El contacto para todos los entrevistados fue } \\
\text { el gerente de alto rango ya que es un } \\
\text { proceso que implica mas tema operativo; } \\
\text { esto implica que la autonomia sea menor } \\
\text { debido a que deben consultar para algun } \\
\text { cambio o decision con los dueños de la } \\
\text { empresa. }\end{array}$ & $\begin{array}{l}\text { Dos de los tres entrevistados concordaron que el } \\
\text { contacto principal para la empresa de seguros y los } \\
\text { bancos son los dueños de la empresa y esto hace que la } \\
\text { autonomia del cliente sea de manera directa. }\end{array}$ \\
\hline
\end{tabular}

Elaboración Propia 